\title{
Effects of Flaming Gorge Dam Hydropower Operations on Sediment Transport in the Browns Park Reach of the Green River, Utah and Colorado.
}

Environmental Assessment Division Argonne National Laboratory

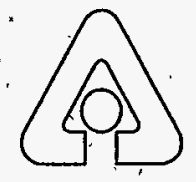

Operated by The University of Chicago, under Contract W-31-109-Eng-38, for the United States Department of Energy DISTRIBUTION OF. THIS DOCUMENT IS.UNLIMÍITED 


\section{Argonne National Laboratory}

Argonne National Laboratory, with facilities in the states of Illinois and Idaho, is owned by the United States Government, and operated by the University 'of Chicago under the provisions of a contract with the Departinent of Energy:

This technical memo is a product of Àrgonne's Environmental Assessment Division (EAD). For information on the division's scientific and engineering activities, contact:

Director, Environmental Assessment Division

Argonne National Laboratory

Argonne, Illinois 60439-4815

Telephone (708) 252-3107

Presented in this technical memo are preliminary results of ongoing work or work that is more limited in scope and depth than that describied in formal reports issued by the EAD.

\section{Publishing Support Services}

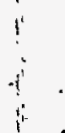

Publishing support senvices provided by Argonne's Information and Publishing Division.

\section{Disclaimer}

This report was prepared as an account of work sponsored by an agency of the United States Government. Neither the United States Government nor any agency thereof, nor any of their employees, makes any warranty, express or implied, or assumes any legal liability or responsibility for the accuracy, completeness, or usefulness of any information, apparatus; product, or process disclosed, or represents that its use would not infringe privately owned rights. Reference herein to any specific commercia! product, process, or service by trade name, trademark, manufiacturer, or otherwise, does not necessarily constitute or imply its endorsement, recommendation, or favoring by the United States. Government or any agency, thereof. The views and opinions of authors expressed herein do not necessarily state or reflect those of the United States Governinent or any agency thereof.

Reproduced directly from the best available copy.

Available to DOE and DOE contractors from the Office of Scientific and Technical Information, P.O. Box 62, Oak Ridge, TN 37831; prices available from (615) 576-8401.

Available to the public from the National Technical Information Service, U.S. Department of Commerce, \$285 Port Royal Road, Springfield, VA 22161. 


\section{DISCLAIMER}

Portions of this document may be illegible in electronic image products. Images are produced from the best available original document. 


\section{Effects of Flaming Gorge Dam Hydropower Operations on Sediment Transport in the Browns Park Reach of the Green River, Utah and Colorado}

by G.P. Williams, D. Tomasko, H.E. Cho, and S.C.L. Yin

Environmental Assessment Division,

Argonne National Laboratory, 9700 South Cass Avenue, Argonne, Illinois 60439

May 1995

Work sponsored by United States Department of Energy, Western Area Power Administration 
This report is printed on recycled paper. 


\section{FOREWORD}

This report is one of a series of technical memorandums prepared to support an environmental impact statement (EIS) on power marketing prepared by Argonne National Laboratory for the U.S. Department of Energy's Western Area Power Administration (Western). Western markets electricity produced at hydroelectric facilities operated by the Bureau of Reclamation. The facilities are known collectively as the Salt Lake City Area Integrated Projects (SLCA/IP) and include dams equipped for power generation on the Colorado, Green, Gunnison, and Rio Grande rivers and on Plateau Creek in the states of Arizona, Colorado, New Mexico, Utah, and Wyoming.

Western proposes to establish a level of commitment (sales) of long-term firm electrical capacity and energy from the SLCA/IP hydroelectric power plants; the impacts of this proposed action are evaluated in the EIS. Of the SLCA/IP facilities, only the Glen Canyon Dam, Flaming Gorge Dam, and Aspinall Unit (which includes Blue Mesa, Morrow Point, and Crystal dams) are influenced by Western's power scheduling and transmission decisions. For this reason, the impacts of hydropower operations at these three facilities were examined in the EIS.

The technical memorandums present detailed findings of studies conducted by Argonne National Laboratory specifically for the EIS. These studies are summarized in the EIS, and the results were used to assess environmental impacts related to alternative commitment levels. Technical memorandums were prepared on a number of socioeconomic and natural resource topics. Staff members of Argonne National Laboratory's Decision and Information Sciences Division and Environmental Assessment Division prepared these technical memorandums and the EIS as part of a joint effort managed by the Environmental Assessment Division. 


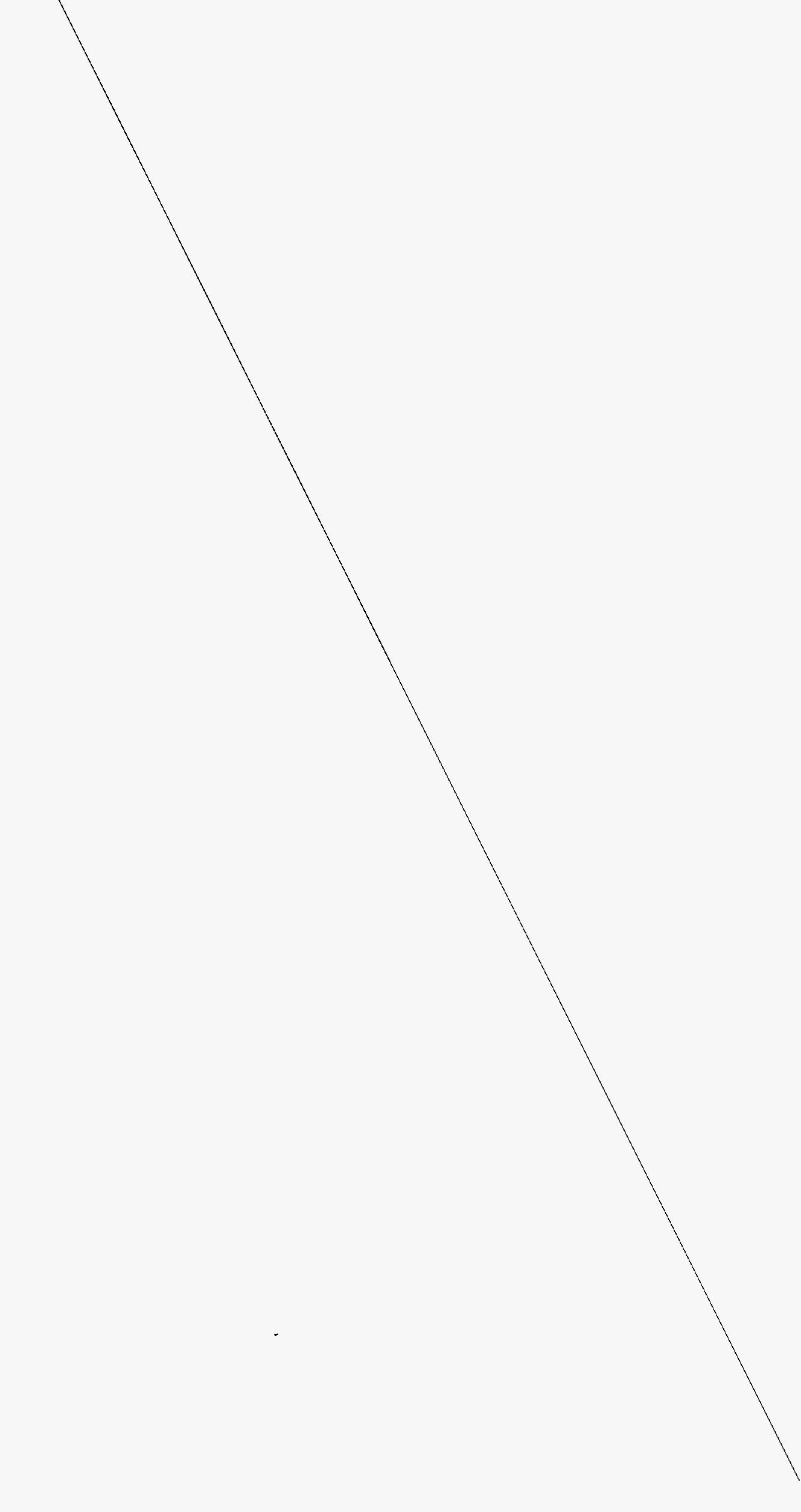




\section{CONTENTS}

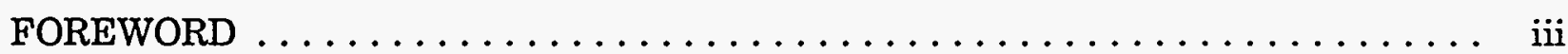

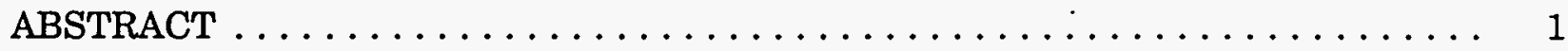

1 INTRODUCTION $\ldots \ldots \ldots \ldots \ldots \ldots \ldots \ldots \ldots \ldots \ldots \ldots \ldots \ldots \ldots \ldots \ldots \ldots$

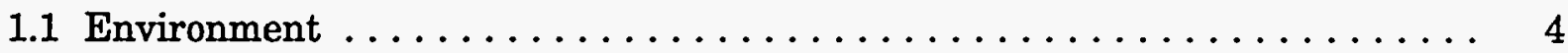

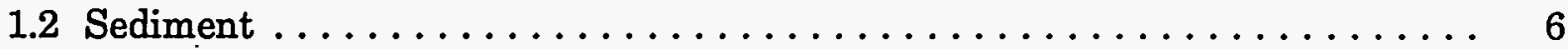

1.3 Hydropower Operational Scenarios $\ldots \ldots \ldots \ldots \ldots \ldots \ldots \ldots \ldots . \ldots . \ldots$

2 MATHEMATICAL MODELS $\ldots \ldots \ldots \ldots \ldots \ldots \ldots \ldots \ldots \ldots \ldots \ldots \ldots$

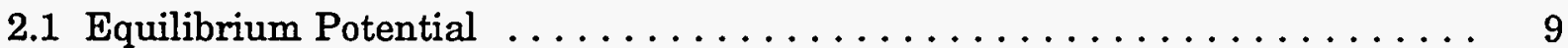

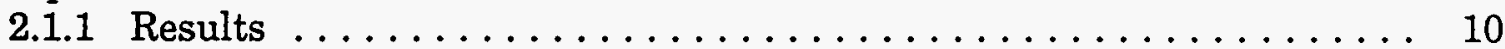

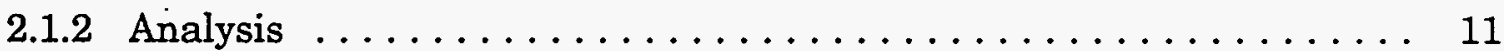

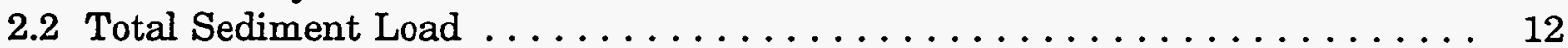

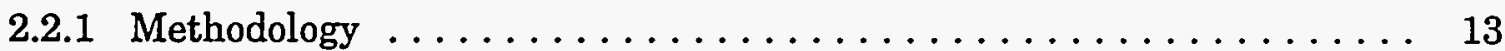

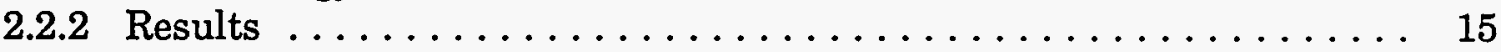

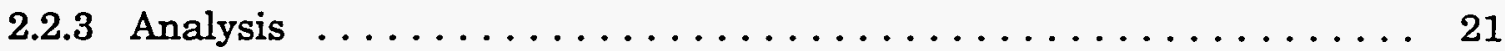

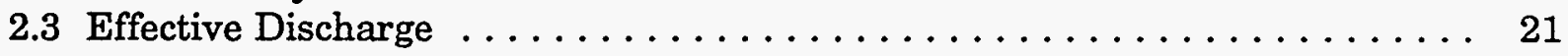

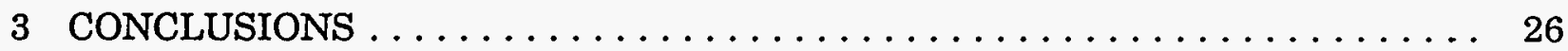

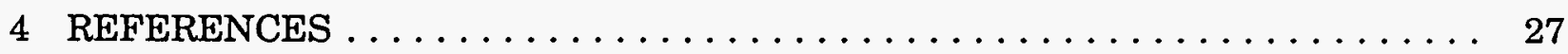

APPENDIX A: Historical Flows for Water Years 1987, 1989, and $1983 \ldots \ldots \ldots .29$

APPENDIX B: Hydropower Operational Scenarios $\ldots \ldots \ldots \ldots \ldots \ldots \ldots \ldots$

\section{FIGURES}

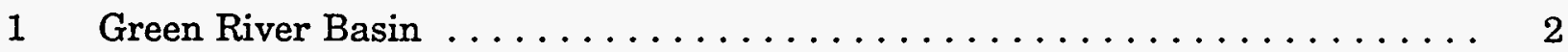

2 Green River from Flaming Gorge Dam to Jensen, Utah $\ldots \ldots \ldots \ldots$

3 Maximum and Minimum Daily Water Releases for Power

Generation at Flaming Gorge Dam for Moderate, Dry, and Wet Water Years

4 Flow-Exceedance Curves for Water Years 1987, 1989, and 1983 at Flaming Gorge Dam . . . . . . . . . . . . . . . . . . .

5 Block Structure for the Program Used to Integrate the EngelundHansen Sediment Transport Model over the Flow Time Series 


\section{FIGURES (Cont.)}

6 Total Annual Sediment Load for the Four Hydropower

Operational Scenarios for a Moderate Water Year ............... 16

$7 \quad$ Total Annual Sediment Load for the Four Hydropower

Operational Scenarios for a Dry Water Year . . . . . . . . . . . . 16

8 Total Annual Sediment Load for the Four Hydropower

Operational Scenarios for a Wet Water Year . . . . . . . . . . . . 17

9 Normalized Annual Sediment Load for the Four Hydropower

Operational Scenarios for a Moderate Water Year . . . . . . . . . . . . 17

10 Normalized Annual Sediment Load for the Four Hydropower

Operational Scenarios for a Dry Water Year ................. 18

11 Normalized Annual Sediment Load for the Four Hydropower

Operational Scenarios for a Wet Water Year ................. 18

12 Total Annual Sediment Load at Browns Park for the Historical

Water Years 1987, 1989, and $1983 \ldots \ldots \ldots \ldots \ldots \ldots \ldots \ldots$

13 Normalized Annual Sediment Load for the Historical Water

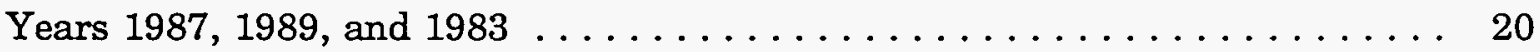

A.1 Mean Daily Flows for the Historical Moderate Water Year $1987 \ldots \ldots$

A.2 Mean Daily Flows for the Historical Dry Water Year $1989 \ldots \ldots \ldots \ldots$

A.3 Mean Daily Flows for the Historical Wet Water Year $1983 \ldots \ldots \ldots \ldots$. . . . 31

A.4 Hourly Flows for the First Quarter of Water Year $1987 \ldots \ldots \ldots \ldots$

A.5 Hourly Flows for the Second Quarter of Water Year $1987 \ldots \ldots \ldots 3$

A.6 Hourly Flows for the Third Quarter of Water Year $1987 \ldots \ldots \ldots$. . . . . . 34

A.7 Hourly Flows for the Fourth Quarter of Water Year $1987 \ldots \ldots \ldots$

B.1 Hourly Release Patterns under the Four Hydropower Operational

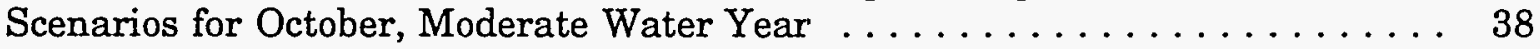

B.2 Hourly Release Patterns under the Four Hydropower Operational

Scenarios for November, Moderate Water Year . . . . . . . . . . . . . .

B.3 Hourly Release Patterns under the Four Hydropower Operational Scenarios for December, Moderate Water Year 


\section{FIGURES (Cont.)}

B.4 Hourly Release Patterns under the Four Hydropower Operational

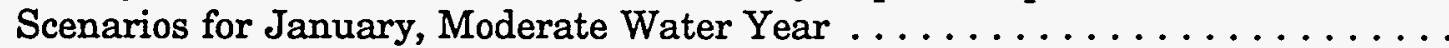

B.5 Hourly Release Patterns under the Four Hydropower Operational Scenarios for February, Moderate Water Year . . . . . . . . . . . . . 42

B.6 Hourly Release Patterns under the Four Hydropower Operational Scenarios for March, Moderate Water Year . . . . . . . . . . . . . .

B.7 Hourly Release Patterns under the Four Hydropower Operational Scenarios for April, Moderate Water Year . . . . . . . . . . . . . . 44

B.8 Hourly Release Patterns under the Four Hydropower Operational Scenarios for May, Moderate Water Year .....................

B.9 Hourly Release Patterns under the Four Hydropower Operational Scenarios for June 1 - June 21, Moderate Water Year ............. 46

B.10 Hourly Release Patterns under the Four Hydropower Operational Scenarios for June 22 - June 30, Moderate Water Year . . . . . . . . . . 47

B.11 Hourly Release Patterns under the Four Hydropower Operational Scenarios for July 1 - July 9, Moderate Water Year .............. 48

B.12 Hourly Release Patterns under the Four Hydropower Operational Scenarios for July 10 - July 31, Moderate Water Year ...............

B.13 Hourly Release Patterns under the Four Hydropower Operational Scenarios for August, Moderate Water Year

B.14 Hourly Release Patterns under the Four Hydropower Operational Scenarios for September, Moderate Water Year

B.15 Hourly Release Patterns under the Four Hydropower Operational Scenarios for October, Dry Water Year . . . . . . . . . . . . . . . .

B.16 Hourly Release Patterns under the Four Hydropower Operational Scenarios for November, Dry Water Year . . . . . . . . . . . . . . .

B.17 Hourly Release Patterns under the Four Hydropower Operational Scenarios for December, Dry Water Year . . . . . . . . . . . . . . . .

B.18 Hourly Release Patterns under the Four Hydropower Operational Scenarios for January, Dry Water Year . . . . . . . . . . . . . . .

B.19 Hourly Release Patterns under the Four Hydropower Operational Scenarios for February, Dry Water Year 


\section{FIGURES (Cont.)}

B.20 Hourly Release Patterns under the Four Hydropower Operational

Scenarios for March, Dry Water Year . . . . . . . . . . . . . . 57

B.21 Hourly Release Patterns under the Four Hydropower Operational

Scenarios for April, Dry Water Year ................... 58

B.22 Hourly Release Patterns under the Four Hydropower Operational

Scenarios for May, Dry Water Year ................... 59

B.23 Hourly Release Patterns under the Four Hydropower Operational

Scenarios for June 1 - June 21, Dry Water Year ................. 60

B.24 Hourly Release Patterns under the Four Hydropower Operational

Scenarios for June 22 - June 30, Dry Water Year ............... 61

B.25 Hourly Release Patterns under the Four Hydropower Operational

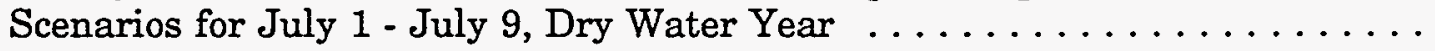

B.26 Hourly Release Patterns under the Four Hydropower Operational

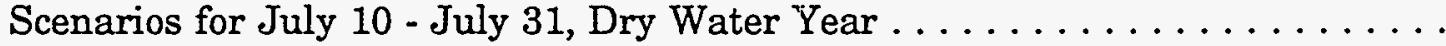

B.27 Hourly Release Patterns under the Four Hydropower Operational

Scenarios for August, Dry Water Year ...................... 64

B.28 Hourly Release Patterns under the Four Hydropower Operational

Scenarios for September, Dry Water Year . . . . . . . . . . . . . 65

B.29 Hourly Release Patterns under the Four Hydropower Operational

Scenarios for October, Wet Water Year $\ldots \ldots \ldots \ldots \ldots \ldots \ldots \ldots 66$

B.30 Hourly Release Patterns under the Four Hydropower Operational

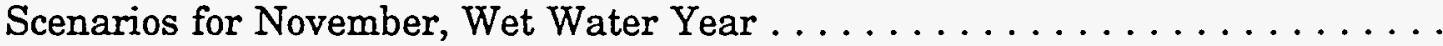

B.31 Hourly Release Patterns under the Four Hydropower Operational

Scenarios for December, Wet Water Year ................... 68

B.32 Hourly Release Patterns under the Four Hydropower Operational

Scenarios for January, Wet Water Year . . . . . . . . . . . . . . .

B.33 Hourly Release Patterns under the Four Hydropower Operational

Scenarios for February, Wet Water Year ................... 70

B.34 Hourly Release Patterns under the Four Hydropower Operational

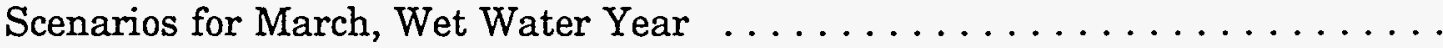

B.35 Hourly Release Patterns under the Four Hydropower Operational

Scenarios for April, Wet Water Year $\ldots \ldots \ldots \ldots \ldots \ldots \ldots \ldots$ 


\section{FIGURES (Cont.)}

B.36 Hourly Release Patterns under the Four Hydropower Operational Scenarios for May, Wet Water Year ....................... 73

B.37 Hourly Release Patterns under the Four Hydropower Operational Scenarios for June 1 - June 21, Wet Water Year ................ 74

B.38 Hourly Release Patterns under the Four Hydropower Operational Scenarios for June 22 - June 30 , Wet Water Year . . . . . . . . . . . 75

B.39 Hourly Release Patterns under the Four Hydropower Operational Scenarios for July 1 - July 9 , Wet Water Year ............... 76

B.40 Hourly Release Patterns under the Four Hydropower Operational Scenarios for July 10 - July 31 , Wet Water Year . . . . . . . . . . . 77

B.41 Hourly Release Patterns under the Four Hydropower Operational Scenarios for August, Wet Water Year . . . . . . . . . . . . . . 78

B.42 Hourly Release Patterns under the Four Hydropower Operational Scenarios for September, Wet Water Year

\section{TABLES}

1 Summary of the Coefficient of Variation and Index of Variability Values for the Operational Scenarios and Historical Flows at Flaming Gorge Dam $\ldots \ldots \ldots \ldots \ldots \ldots \ldots$

2 Summary of Sand Load in Browns Park for Different Hydropower Operational Scenarios and Water Years ............. 22

3 Effective Discharge and Percent of Total Sediment Load for Different Hydropower Operational Scenarios and Water Years 


\title{
EFFECTS OF FLAMING GORGE DAM HYDROPOWER OPERATIONS ON SEDIMENT TRANSPORT IN THE BROWNS PARK REACH OF THE GREEN RIVER, UTAH AND COLORADO
}

\author{
by \\ G.P. Williams, D. Tomasko, H.E. Cho, and S.C.L. Yin
}

\begin{abstract}
Three methods for comparing sediment transport were applied to four proposed hydropower operational scenarios under study for Flaming Gorge Dam on the Green River in Utah. These methods were effective discharge, equilibrium potential, and cumulative sediment load with flow exceedance plots. Sediment loads transported by the Green River in the Browns Park reach were calculated with the Engelund-Hansen equation for three historical water years and four hydropower operational scenarios. A model based on the Engelund-Hansen equation was developed using site-specific information and validated by comparing predictions for a moderate water year with measured historical values. The three methods were used to assess the impacts of hydropower operational scenarios on sediment resources. The cumulative sediment load method provided the most useful information for impact evaluation. Effective discharge was not a useful tool because of the limited number of discrete flows associated with synthetic hydrographs for the hydropower operational scenarios. The equilibrium potential method was relatively insensitive to the variations in operating conditions, rendering it comparatively ineffective for impact evaluation.
\end{abstract}

\section{INTRODUCTION}

Flaming Gorge Dam is located on the Green River, about 30 mi north of Vernal, Utah (Figure 1). Sediment transport calculations were performed to evaluate the impacts of four proposed hydropower operational scenarios and hydrologic conditions at Flaming Gorge Dam. The study area for these calculations extends from Flaming Gorge Dam downstream approximately $93 \mathrm{mi}$ to the U.S. Geological Survey (USGS) gage near Jensen, Utah. Field and literature studies have indicated that the part of the study area most susceptible to erosional impacts is Browns Park, located approximately $10 \mathrm{mi}$ below Flaming Gorge Dam on the Green River (Figure 2).

The report of Andrews (1986) presents approximately 20 years of suspended sediment records for gages located on the Green River in Utah and Colorado and the Yampa 


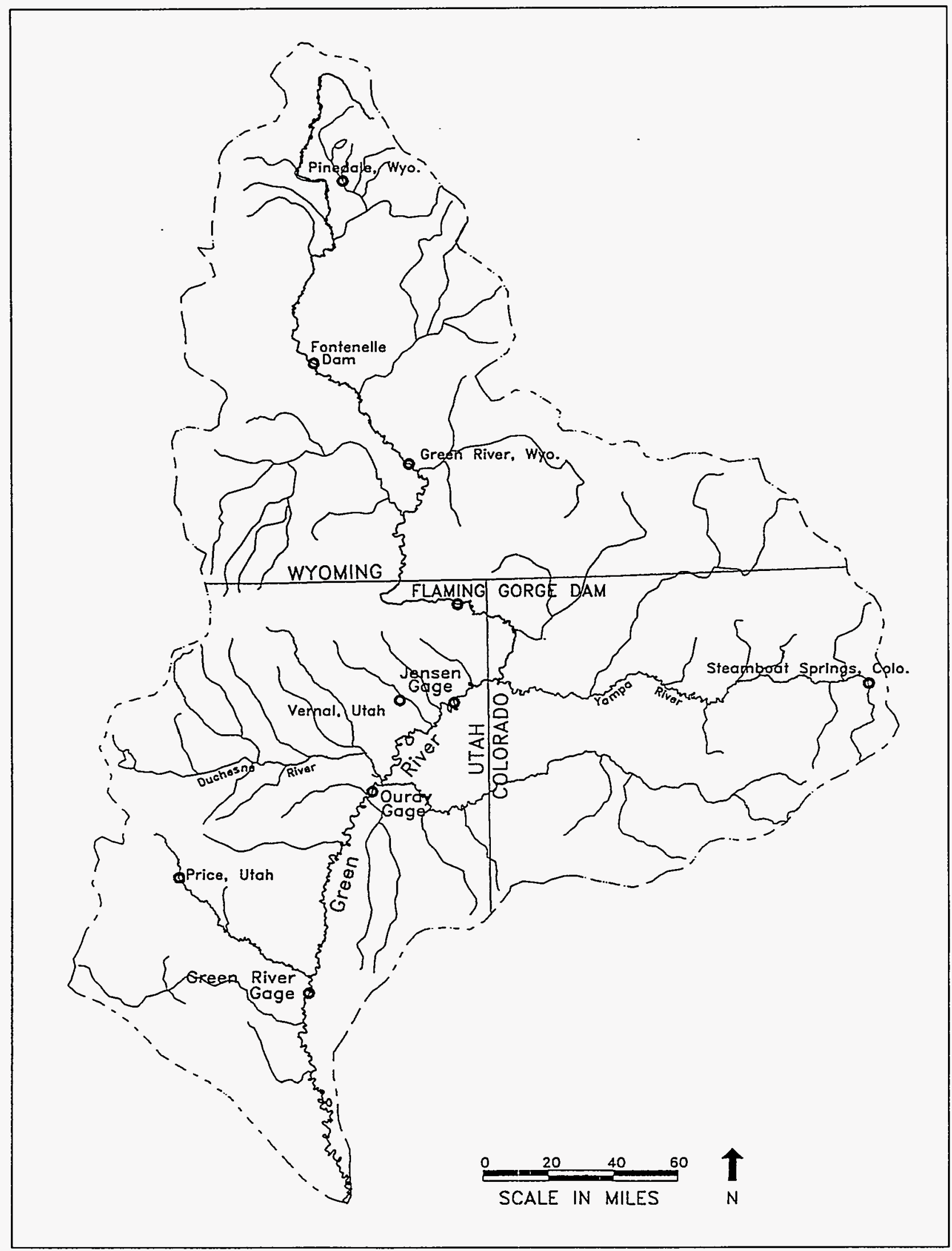

FIGURE 1 Green River Basin (Source: Adapted from USGS 1985) 


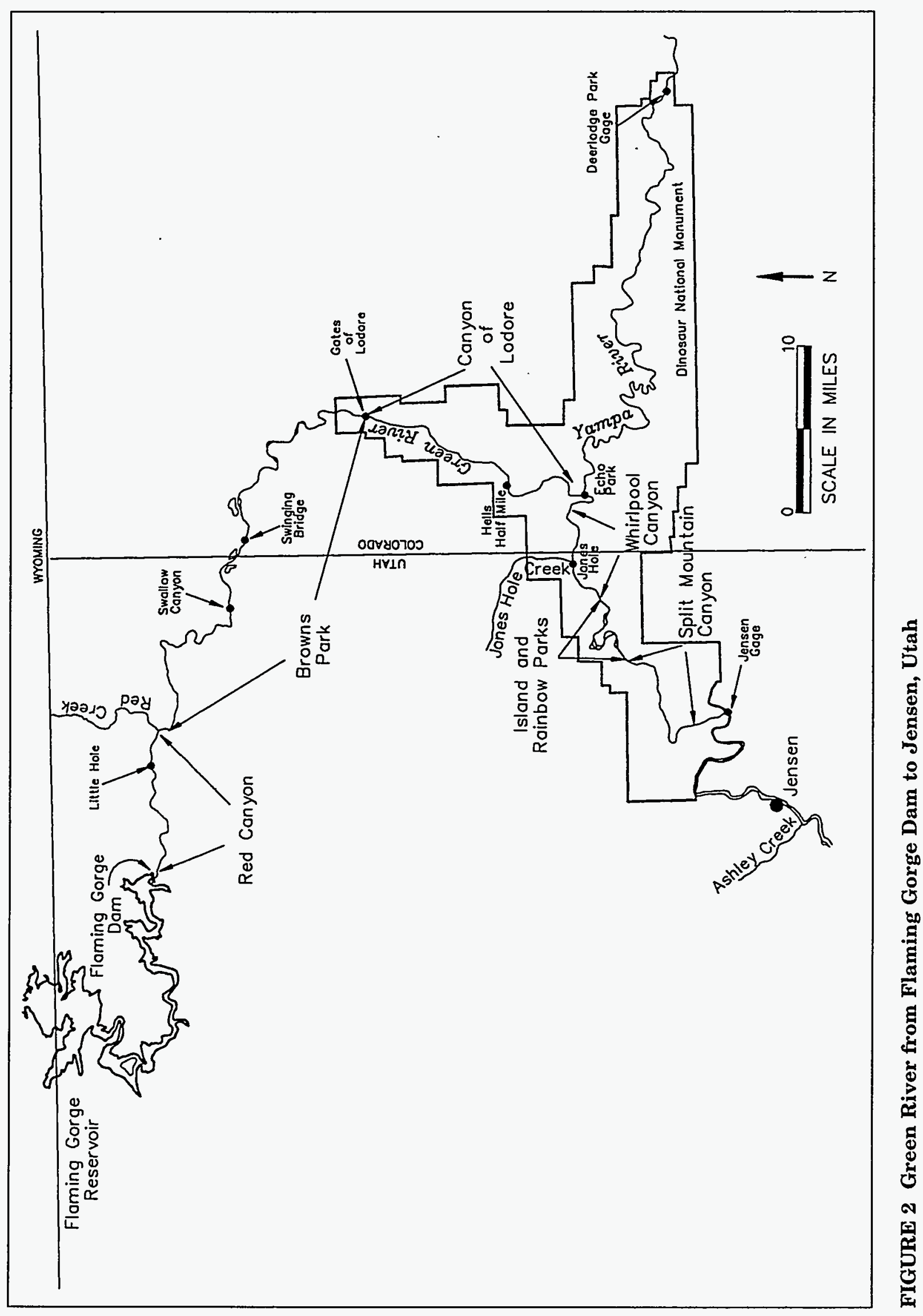


River in Colorado. These records indicate that the Green River picks up significant sediment load below the dam, upstream of the gage at Jensen, Utah. Lyons et al. (1992) indicate that approximately half of the sediment load at Jensen is carried by the flow of the Green River above the Yampa River, and the remainder of the sediment load comes from the Yampa River, a major tributary to the Green River, and its drainage.

Because there is no sediment gaging station within the alluvial reach of the Green River through Browns Park, mathematical models were developed to evaluate total sediment load, equilibrium potential, and effective discharge resulting from the three historical hydrological conditions under consideration - moderate, dry, and wet - and each of four hydropower operational scenarios - seasonally adjusted steady flows, seasonally adjusted moderate fluctuating flows, seasonally adjusted high fluctuating flows, and year-round high fluctuating flows. The historical water years 1987, 1989, and 1983 were chosen because of their representativeness of flow conditions (moderate, dry, and wet years, respectively) and because of the availability of hourly flow data. The results of the mathematical models were used to evaluate and compare the impacts of the various operational scenarios on sediment transport in the Green River below Flaming Gorge Dam.

\subsection{ENVIRONMENT}

Flaming Gorge Dam is part of the Colorado River Storage Project and serves the project through the storage and release of water from Flaming Gorge Reservoir (Weatherford and Brown 1983). The outflow from the dam is used for hydropower generation. The dam is located on the Green River about $32 \mathrm{mi}$ downstream of the Wyoming-Utah border and about $30 \mathrm{mi}$ north of Vernal, Utah (Figure 1). The Green River is $730 \mathrm{mi}$ long and has a drainage of about $44,700 \mathrm{mi}^{2}$ in Colorado, Utah, and Wyoming (Smith and Green 1991). The reach of river under study was chosen to be consistent with the Biological Opinion of the U.S. Fish and Wildlife Service (USFWS) for operation of the Flaming Gorge Dam, which dictates that Green River flows must achieve specified target values at the Jensen gage (USFWS 1992). From the dam to the Jensen gage, the main tributary of the Green River is the Yampa River, which contributes an estimated $40 \%$ of the measured sediment load at the Jensen gage. Although there are several other small tributaries, most of them are ephemeral and do not contribute a significant sediment load.

Prior to construction of Flaming Gorge Dam, flow in the Green River near Greendale, Utah, was unregulated and varied widely on a yearly basis (Andrews 1986). After the dam was completed in 1963, flow became more regular, but a number of releases in excess of $7,000 \mathrm{ft}^{3} / \mathrm{s}$ (cfs) have occurred.

Historically, water releases from the dam for power generation have ranged from 800 to $4,200 \mathrm{cfs}$ (Figure 3), although a turbine rewind currently allows power releases up to $4,950 \mathrm{cfs}$. The maximum power release is constrained by the size of the turbines, whereas the lower bound ( $800 \mathrm{cfs}$ ) is set by an agreement with the state of Utah to maintain a highquality cold-water fishery (Smith and Green 1991). An additional 4,000 cfs of water can be 

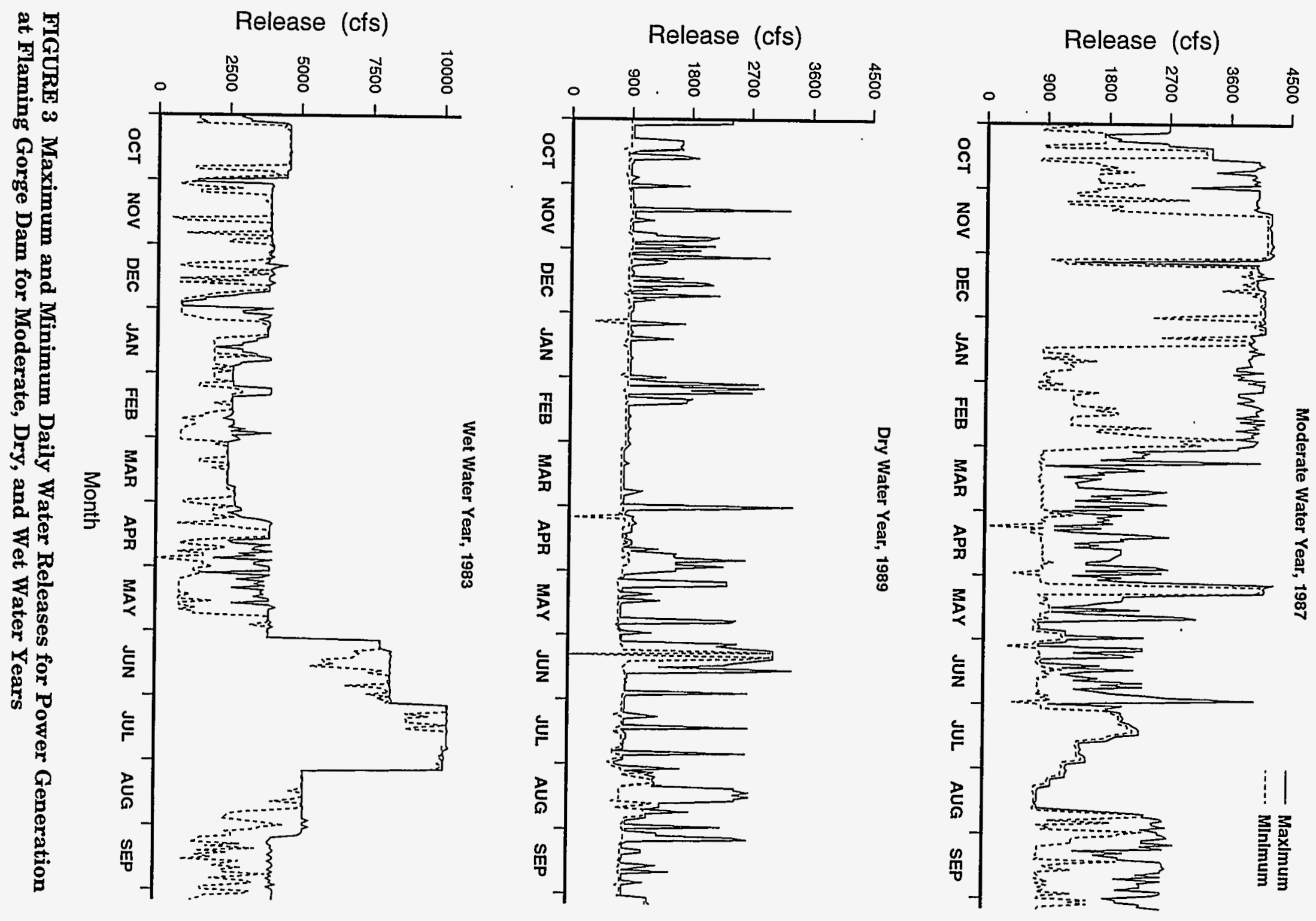
released through steel-lined jet tubes, and $28,800 \mathrm{cfs}$ can be discharged over the spillway. Flows greater than $4,950 \mathrm{cfs}$ are referred to as spills and produce no power. Ramping rates (up and down) for dam releases can be as high as $500 \mathrm{cfs} / \mathrm{min}(30,000 \mathrm{cfs} / \mathrm{h})$; however, historical rates have been limited to about $100 \mathrm{cfs} / \mathrm{min}(6,000 \mathrm{cfs} / \mathrm{h})$ to minimize the impacts of rapid changes in water elevation (Smith and Green 1991).

Flow-exceedance curves for historical water releases from Flaming Gorge Dam are shown in Figure 4 for water years 1987, 1989, and 1983 (October 1 through September 30 of the following year). For a dry year (1989), flow is maintained near $800 \mathrm{cfs}$ for approximately $75 \%$ of the time and only exceeds $2,000 \mathrm{cfs}$ approximately $10 \%$ of the time. For a wet year (1983), flow exceeds 4,000 cfs approximately $80 \%$ of the time and exceeds $8,000 \mathrm{cfs}$ approximately $30 \%$ of the time. Plots of the historical flows for the 1987, 1989, and 1983 water years are presented in Appendix A.

For the first 7 mi below Flaming Gorge Dam, the Green River flows through Red Canyon, a hard-rock canyon with fast currents and moderate rapids. Waters are clear and cold because the dam removes suspended sediment and delivers cold water from the lower levels of the reservoir to the downstream channel (Williams and Wolman 1984). Bed material in this reach consists mostly of coarse gravel, cobbles, and boulders (Andrews 1986). The river has a pool-and-riffle form and ranges in depth from about $3 \mathrm{ft}$ in the riffles to $25 \mathrm{ft}$ in the pools; the average slope of the river (change in elevation per distance) is about $8.5 \mathrm{ft} / \mathrm{mi}$ (Wheat 1989).

The river changes character abruptly about $2 \mathrm{mi}$ below Red Creek as the canyon opens into Browns Park, about $11 \mathrm{mi}$ downstream of the dam. Browns Park is a wide valley with deep alluvial deposits on the valley floor and river floodplain. The river meanders through Browns Park (about $36.5 \mathrm{mi}$ ), attaining widths of up to $500 \mathrm{ft}$. Under moderate flow conditions, the current is slow and the river is fairly shallow, with depths of about $3 \mathrm{ft}$; the slope is about $2.3 \mathrm{ft} / \mathrm{mi}$. Numerous sandbars occur in the reach, and the thalweg traces a circuitous route through the valley. The average sand particle size $\left(\mathrm{d}_{50}\right)$ in the riverbed is $0.4 \mathrm{~mm}$ (Andrews 1986). The banks of the river are composed of Holocene alluvium (Stephens and Shoemaker 1987), and cutbanks line the channel in the vicinity of channel meanders and valley plain terraces. In Browns Park, the river increases in turbidity as sediment is transported downstream from the bed and banks.

\subsection{SEDIMENT}

After completion of Flaming Gorge Dam in 1963, the mean annual sediment load at Jensen, Utah, decreased from $6.92 \times 10^{6}$ tons to $3.21 \times 10^{6}$ tons (Andrews 1986). From the dam to Red Creek, near the beginning of Browms Park (Figure 2), the Green River has been armored by previous flows; fine riverbed and bank sediment have been removed by highvelocity water, leaving only sediment too heavy or coarse to be moved (Andrews 1986), and 


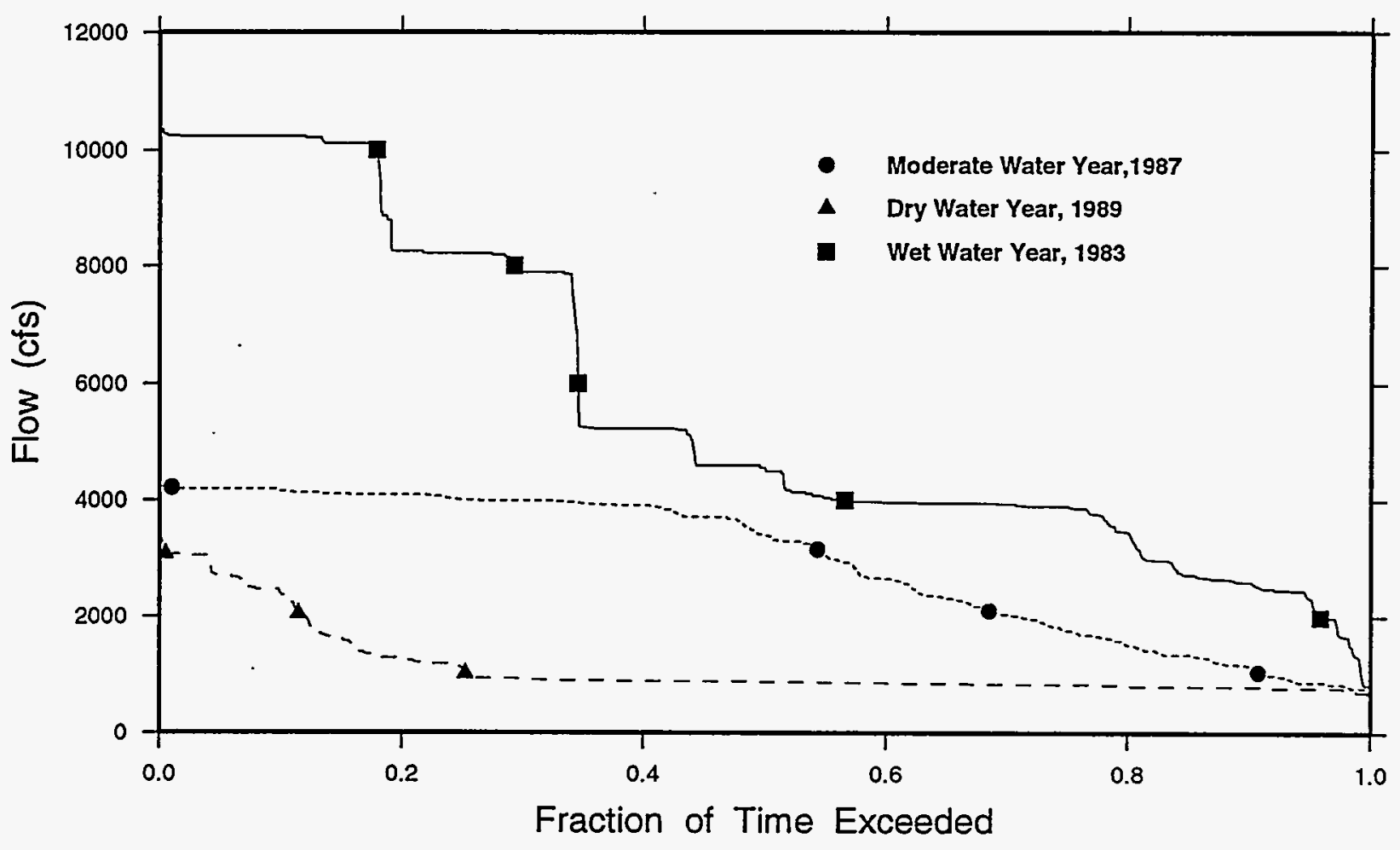

FIGURE 4 Flow-Exceedance Curves for Water Years 1987, 1989, and 1983 at Flaming Gorge Dam

few upstream tributaries contribute suspended sediment loads or debris flows to the main stem of the river. In this reach, the main stem of the river itself has little suspended sediment because of the effects of the dam and reservoir.

Beginning at Browns Park (Figure 2), the river erodes large quantities of sand and silt from the extensive alluvial banks and bed. In Lodore Canyon, additional erosion occurs; however, because of the influx of sediment from Browns Park, the rate of erosion is lower. In addition, the channel is geologically confined by steep and hard rock walls. At the confluence of the Yampa River, an additional large quantity of sand (approximately $2 \times 10^{6}$ tons annually) is delivered to the system (Elliott et al. 1984), further reducing downstream erosion. By the time the river reaches Jensen, Utah, a near equilibrium condition has been established, with no net erosion or aggradation taking place (Andrews 1986).

Browns Park is the most sensitive area for erosional impacts within the 93-mi study area considered for sediment transport modeling. The riverbed above this point is armored, and little sediment load is contributed by tributaries. The Green River is sediment-starved when it reaches the alluvial banks and bed of Browns Park, causing increased rates of erosion. Below Browns Park, sediment loads reach near equilibrium, and the probability of large impacts from erosion is lower. 


\subsection{HYDROPOWER OPERATIONAL SCENARIOS}

The purpose of this modeling study was to quantify the effects of four proposed hydropower operational scenarios on sediment transport and compare the results obtained for the different operational scenarios and similar historical flows. Erosional impacts were calculated for the three historical water years and four operational scenarios. Flow records for the historical water years - moderate (1987), dry (1989), and wet (1983) - were derived from Western Area Power Administration (Western) power generation records for Flaming Gorge Dam. These records consist of hourly values of net power generation in megawatts and spill at the dam. Hourly net power generation data were converted to hourly flow data through the use of auxiliary computer programs. These programs used a monthly conversion factor (based on reservoir elevation) supplied by Western and produced hourly flow values in cubic feet per second (cfs), as well as monthly and yearly flow summaries and files.

The four scenarios evaluated were seasonally adjusted steady flows, seasonally adjusted moderate fluctuating flows, seasonally adjusted high fluctuating flows, and yearround high fluctuating flows. Hourly release patterns under these scenarios are presented in Appendix B and described by Yin et al. (1995). The magnitude of daily fluctuation for the year-round high fluctuating flow scenario was constrained by the physical limits of the power generating structures and the USFWS Biological Opinion (USFWS 1992), and this scenario provided the upper limit for flow variability during a 24-hour period. For all scenarios, the minimum release from the dam was at least $800 \mathrm{cfs}$. The four hydropower operational scenarios would have releases ranging from high fluctuations ( 800 to $4,700 \mathrm{cfs}$ daily) to constant values (steady flows) on a daily basis.

The reservoir release patterns summarized in Appendix B for each scenario were developed for the three representative water years (1987, 1989, and 1983), as described by Yin et al. (1995). Each release pattern has a minimum release beginning at midnight, a ramp up to a maximum release in one hour, a hold at the maximum for the on-peak duration, and then a ramp down to the minimum release. The on-peak period is assumed to center around 4:00 p.m.

For a moderate year (1987), the year-round high fluctuating flow scenario would have a maximum daily variation of $3,900 \mathrm{cfs}$. The seasonally adjusted high fluctuating flow scenario would exhibit daily maximum variations of between 2,010 and $3,900 \mathrm{cfs}$. However, no fluctuations would be allowed in February and March (assumed ice-cover periods). October would have a steady release of $800 \mathrm{cfs}$ (the required minimum release), and June 1 through June 21 would have steady releases of $4,700 \mathrm{cfs}$, as required by the Biological Opinion (USFWS 1992). The seasonally adjusted moderate fluctuating flow scenario would have maximum daily variations ranging from 1,000 to $1,950 \mathrm{cfs}$ - with no fluctuations in February or March, a steady flow of $800 \mathrm{cfs}$ in October, and a steady flow of 4,700 cfs from June 1 to June 21. The seasonally adjusted steady flow scenario would exhibit no daily flow variations as a result of hydropower generation. The flows would be steady over each day, as dictated by reservoir storage concerns and the constraints of the Biological Opinion. 


\section{MATHEMATICAL MODELS}

Browns Park is the most sensitive location for assessing sediment transport impacts. However, because no sediment gaging station is available for Browns Park, mathematical approaches were used to develop time-integrated models for calculating total sediment loads, equilibrium potential, and effective discharges for the four hydropower operational scenarios under moderate, dry, and wet conditions (historical water years 1987, 1989, and 1983, respectively). The models were developed to evaluate potential impacts of the hydropower operational scenarios on sediment transport in the Browns Park reach of the Green River.

\subsection{EQUILIBRIUM POTENTIAL}

To predict whether a river is likely to develop an equilibrium condition between average discharge and sediment load, two coefficients can be calculated from flow records: the coefficient of variation, $C_{v}$, and the index of variability, $I_{v}$ (Gordon et al. 1992). Large values of these coefficients indicate that the river is likely to be out of equilibrium and will either aggrade or erode its bed and banks.

To calculate the $C_{v}$ and $I_{v}$ values, hourly dam release data for the three historical water years and the four hydropower operational scenarios were used. The equations for $C_{v}$ and $I_{v}$ are as follows (Gordon et al. 1992):

$$
C_{v}=\frac{s}{\bar{x}}
$$

and

$$
I_{v}=\sqrt[\left[\frac{\sum_{i}\left(\log x_{i}-\overline{\log x}\right)^{2}}{n-1}\right]]{[}
$$

where

$$
\begin{aligned}
\bar{x} & =\text { the mean dam release, } \\
x_{i} & =\text { the } i^{\text {th }} \text { dam release, } \\
n & =\text { the total number of dam releases, } \\
\overline{\log x} & =\text { the mean value of the logarithm of the dam releases, and }
\end{aligned}
$$


$s=$ the standard deviation of the dam releases, given by:

$$
s=\sqrt{\frac{\sum\left(x_{i}-\bar{x}\right)^{2}}{n-1}} .
$$

These coefficients are indexes to the general variability of the flow. The coefficient of variation is more sensitive to flow variations than the index of variation. $C_{v}$ reflects the effects of variations that occur over approximately one order of magnitude; $I_{v}$ is more suited for data that spans several orders of magnitude. In the case of flow for the Green River, flow data range from about 300 to almost $10,000 \mathrm{cfs}$, spanning the range for both $C_{v}$ and $I_{v}$. A small value for these coefficients indicates a data set that does not have great variability. However, these indexes are more useful for relative comparisons than absolute quantitative statements.

\subsubsection{Results}

Table 1 shows the tabulation of the $C_{v}$ and $I_{v}$ calculations. The largest coefficients of variation would occur under year-round high fluctuating flows for a moderate or wet year. For a dry year, seasonally adjusted high fluctuating flows would produce the highest value of $C_{v}$ (26\% greater than year-round high fluctuating flows). The smallest value of $C_{v}$ would be produced by seasonally adjusted steady flows $(26,48$, and $18 \%$ less than year-round high fluctuating flows for a moderate, wet, and dry year, respectively). In addition, seasonally adjusted steady flows would also produce the smallest index of variability, 44 and $24 \%$ less than year-round high fluctuating flows for a moderate and wet year, respectively (Table 1). For a dry year, the seasonally adjusted steady flows would produce an $I_{v}$ value $9 \%$ greater than that for year-round high fluctuating flows. However, because the values would be about the same and the flows would be substantially less during a dry year, this anomaly is not important.

Values of $C_{v}$ and $I_{v}$ for the historical water years fall within the range of values calculated for the operational scenarios. For the moderate water year 1987, the historical values of $C_{v}$ and $I_{v}$ fall between the values calculated for the seasonally adjusted high fluctuating flows and the seasonally adjusted moderate fluctuating flows. The $C_{v}$ value of 0.5666 for 1987 lies almost in the middle of the value for the seasonally adjusted high fluctuating flows (0.7343) and that for the seasonally adjusted moderate fluctuating flows (0.4411). For both the dry year, 1989, and the wet year, 1983, $I_{v}$ calculated for the historical flows is larger than that calculated for any of the operational scenarios. This result is most obvious in 1989, when the largest value of about 0.47 for an operational scenario (seasonally adjusted high fluctuating flows) is only $47 \%$ of the value calculated from the historical data. In the wet year $1983, I_{v}$ for the year-round high fluctuating flow scenario (about 0.92 ) is $92 \%$ of that calculated for the historical data. The coefficient of variation calculated for historical flows in both wet and dry water years fall within the range of values calculated for the various operational scenarios. 
TABLE 1 Summary of the Coefficient of Variation and Index of Variability Values for the Operational Scenarios and Historical Flows at Flaming Gorge Dam ${ }^{a}$

\begin{tabular}{|c|c|c|c|c|c|c|}
\hline \multirow[b]{3}{*}{ Operational Scenario } & \multicolumn{6}{|c|}{ Coefficient of Variation $\left(C_{v}\right)$} \\
\hline & \multicolumn{2}{|c|}{ Moderate Year } & \multicolumn{2}{|c|}{ Dry Year } & \multicolumn{2}{|c|}{ Wet Year } \\
\hline & Value & $\%$ Diff. & Value & $\%$ Diff. & Value & \% Diff. \\
\hline Year-round high fluctuating flows & 0.8414 & 0 & 0.6481 & 0 & 0.6563 & 0 \\
\hline $\begin{array}{l}\text { Seasonally adjusted high } \\
\text { fluctuating flows }\end{array}$ & 0.7343 & -13 & 0.8640 & 26 & 0.5118 & -22 \\
\hline $\begin{array}{l}\text { Seasonally adjusted moderate } \\
\text { fluctuating flows }\end{array}$ & 0.4875 & -42 & 0.6057 & -11 & 0.4918 & -25 \\
\hline Seasonally adjusted steady flows & 0.4411 & -48 & 0.5609 & -18 & 0.4860 & -26 \\
\hline \multirow[t]{3}{*}{ Historical flows } & 0.5666 & -32 & 0.5773 & -16 & 0.5783 & -12 \\
\hline & \multicolumn{6}{|c|}{ Index of Variability $\left(I_{v}\right)$} \\
\hline & \multicolumn{2}{|c|}{ Moderate Year } & \multicolumn{2}{|c|}{ Dry Year } & \multicolumn{2}{|c|}{ Wet Year } \\
\hline Operational Scenario & Value & $\%$ Diff. & Value & $\%$ Diff. & Value & $\%$ Diff. \\
\hline Year-round high fluctuating flows & 0.8540 & 0 & 0.3632 & 0 & 0.9215 & 0 \\
\hline $\begin{array}{l}\text { Seasonally adjusted high } \\
\text { fluctuating flows }\end{array}$ & 0.7507 & -12 & 0.4695 & 29 & 0.7920 & -14 \\
\hline $\begin{array}{l}\text { Seasonally adjusted moderate } \\
\text { fluctuating flows }\end{array}$ & 0.5058 & -41 & 0.4112 & 13 & 0.7136 & -23 \\
\hline Seasonally adjusted steady flows & 0.4811 & -44 & 0.3954 & 9 & 0.6982 & -24 \\
\hline Historical flows & 0.5682 & -33 & 0.9973 & 174 & 0.9979 & 8 \\
\hline
\end{tabular}

a \% Diff. is the percent difference from year-round high fluctuating flows.

\subsubsection{Analysis}

From a comparison of $C_{v}$ and $I_{v}$ values for the different operational scenarios, the seasonally adjusted steady flows would produce conditions most favorable for channel equilibrium between sediment load and discharge. The least favorable equilibrium conditions would be produced by year-round high fluctuating flows. Although the maximum difference between the operational scenarios is $48 \%$, the calculated coefficients are still small. The implied differences in impacts to the river channel would therefore be slight. When the various operational scenarios are compared with historical data, it is difficult to determine relative impacts. The calculated values for both the historical data and the various operational scenarios have low values of $C_{v}$ and $I_{v}$. These results indicate that the riverbed would be in relative equilibrium once the suspended sediment deficit caused by the dam was replenished. The hydropower operational scenarios are not distinguishable from the historical record when this method is used. 


\subsection{TOTAL SEDIMENT LOAD}

Total sediment load for a reach can be calculated with the Engelund-Hansen method (Engelund and Hansen 1972). This model was selected for the calculations performed in this study because the model requires a minimum amount of site-specific information and has been demonstrated to give satisfactory results for similar flow systems (Simons and Sentürk 1992) and for the Green River (Andrews 1986).

The functional form for the total sediment load, $Q_{s}$, is given by the following expression:

$$
Q_{s}=0.05 \gamma_{s} U^{2} \sqrt{\frac{d_{50}}{g\left(\frac{\gamma_{s}}{\gamma}-1\right)}}\left(\frac{\tau_{0}}{\left(\gamma_{s}-\gamma\right) d_{50}}\right)^{3 / 2}
$$

where

$$
\begin{aligned}
d_{50} & =\text { mean size of the sediment, } \\
g & =\text { gravitational constant, } \\
U & =\text { water velocity, } \\
\gamma_{s} & =\text { specific weight of sediment }=\rho_{\mathrm{s}} g, \\
\rho_{\mathrm{s}} & =\text { density of the sediment, } \\
\gamma & =\text { specific weight of water }=\rho g, \\
\rho & =\text { density of water, and } \\
\tau_{0} & =\text { bed shear stress given by the following: }
\end{aligned}
$$

where

$D=$ depth of the water and

$$
S=\text { bed slope of the reach. }
$$

In the relationship expressed in Equation 4, the wide-channel approximation is made, i.e., the hydraulic radius of the channel (area of channel divided by the wetted perimeter) is set approximately equal to the depth of the water (Garde and Ranga Raju 1985). 


\subsubsection{Methodology}

A computer program was developed to compute the total sediment load for the different hydropower operational scenarios under consideration. Input to the program consisted of hourly flow data for the scenarios and site-specific parameters. The program computed the sediment load transported during each one-hour time step. The data were analyzed with three types of plots: frequency exceedance plots to characterize the flow regime; percent exceedance and cumulative load versus flow plots to characterize sediment transport; and effective discharge plots to characterize sediment transport.

A pseudo-code structure representing the sediment transport model is shown in Figure 5. The program reads data from a sequential hourly flow data file. The program calls subroutine Channel for each flow record read. This subroutine accepts flow as input and returns the channel width, depth, and average flow velocity at a point near Swinging Bridge in Browns Park (Figure 2). This point was chosen because it is considered to be

\section{Main Program}

Begin Loop, I (from l=1 to end of data)

Read Data

Call Channel(Flow, Wdth, Vel, Dpth)

Call Sediment(Flow, Wdth, Vel, Dpth, Sed)

Call Round(Flow, Iflow, Max)

SedCurve (lflow) $=$ SedCurve $($ Iflow $)+$ Sed

FlowCurve $($ Iflow $)=$ FlowCurve $($ Iflow $)+1$

End Loop, I

Begin Loop, J

Write SedCurve(j), FlowCurve(j)

End Loop, J

End Program

\section{SubRoutine Channel}

Given flow in cfs, use linear models to return channel width, depth, and water velocity.

\section{SubRoutine Sediment}

Given channel and flow data, calculate sediment load for that flow assuming a one-hour time period.

\section{SubRoutine Round}

Given a flow, round it to the nearest whole number. Also determine maximum flow.

FIGURE 5 Block Structure for the Program Used to Integrate the Engelund-Hansen Sediment Transport Model over the Flow Time Series 
representative of the Browns Park reach. These values are calculated with the following equations:

$$
\left(\begin{array}{lr}
W=0.0569(Q)+1.822, & \text { if } 0 \leq Q<1000 \\
W=0.00748(Q)+237.64, & \text { if } 1000 \leq Q<2000 \\
W=0.00237(Q)+247.86, & \text { if } 2000 \leq Q<3000 \\
W=0.00206(Q)+248.79, & \text { if } 3000 \leq Q<4000 \\
W=0.001886(Q)+249.49, & \text { if } Q \geq 4000
\end{array}\right)
$$

and

$$
\left(\begin{array}{lrr}
D=0.0017(Q)+1.15, & \text { if } 0 \leq Q<1000 \\
D=0.0013(Q)+1.55, & \text { if } 1000 \leq Q<2000 \\
D=0.00106(Q)+2.03, & \text { if } 2000 \leq Q<3000 \\
D=0.00092(Q)+2.45, & \text { if } 3000 \leq Q<4000 \\
D=0.0008286(Q)+2.82, & \text { if } Q \geq 4000
\end{array}\right)
$$

and

$$
\left(\begin{array}{rrrr}
U=0.00055(Q)+1.22, & \text { if } 0 \leq Q<1000 \\
U=0.00048(Q)+1.29, & \text { if } 1000 \leq Q<2000 \\
U=0.00035(Q)+1.55, & \text { if } 2000 \leq Q<3000 \\
U=0.00029(Q)+1.73, & \text { if } 3000 \leq Q<4000 \\
U=0.000257(Q)+1.86, & \text { if } Q \geq 4000
\end{array}\right)
$$

where

$$
\begin{aligned}
& W=\text { channel width }(\mathrm{ft}) \\
& D=\text { average channel depth (ft, assuming a rectangular cross section), } \\
& U=\text { average flow velocity }(\mathrm{ft} / \mathrm{s}), \text { and } \\
& Q=\text { flow (cfs). }
\end{aligned}
$$

Equations 6 to 8 were developed with stage-discharge relationships obtained from the HEC-2 model for the Green River (Yin et al. 1995). The channel characteristics for this model were taken from USGS quadrangle maps of the Browns Park area. Channel roughness estimates used in the HEC-2 model were made from field observations and values in the literature. 
Subroutine Sediment uses the channel and flow values as parameters for the Engelund-Hansen sediment transport equation. In addition to the channel characteristics and flow parameters, Equation 4 requires the following values:

$$
\begin{aligned}
d_{50}= & 0.4 \mathrm{~mm} \text { (Andrews 1986), } \\
\gamma_{\mathrm{s}}= & 2.65 \times \gamma(\text { specific weight of sand), } \\
\gamma= & 62.4 \mathrm{lb} / \mathrm{ft}^{3} \text { (specific weight of water), and } \\
\mathrm{S}= & 0.0004356 \text { (slope of channel obtained from USGS } 7-1 / 2 \text { minute } \\
& \text { quadrangle). }
\end{aligned}
$$

After the sediment load for each hour of flow is calculated, the program calls subroutine Round to round the flow value to the nearest whole number. The values for flow and sediment are then stored in 1-cfs flow bins for analysis. This process of integrating the Engelund-Hansen sediment transport equation over the time history of river flow produces a histogram for the flow scenario and two integrated histograms, with 1-cfs bins that span the entire flow scenario from $0 \mathrm{cfs}$ to the maximum flow for the period of study. The integrated histograms, one for flow volume and one for sediment volume, differ from standard histograms by the method used for summing the total for each bin. In a standard histogram, the numbers of occurrences are summed to determine the value of each bin; for the integrated histograms, the total sediment volume or flow volume is summed to determine the bin value.

The cumulative sediment and cumulative flow curves are derived by integrating these three computed histograms. Normalized percent exceedance curves for both sediment transport and flow are also computed by dividing each data point by the total cumulative flow or sediment load. These curves show that the majority of the sediment transport occurs at high flows, which occur only a small fraction of the time.

\subsubsection{Results}

The results of sediment transport calculations for the various hydropower operational scenarios are shown in Figures 6 through 11. Each typical hydrologic condition (moderate, dry, or wet) is presented on two plot types. The first type plots cumulative sediment load versus flow (Figures 6,7 , and 8 ); the second plots the fractional sediment load versus flow (Figures 9,10, and 11). These plots are difficult to interpret because of the nature of the flows being studied, which attempt to maximize power generation and stay within the constraints of the USFWS Biological Opinion (USFWS 1992). In general, the dam releases under consideration are discrete and are not evenly spread over a wide range of values. These individual flow events form step-function plots because of the discrete nature of the flow distribution. The maximum number of discrete flow values for a given operational scenario is 28; however, most scenarios have fewer values. Because of the limited number of discrete flows, the plots take the form of a series of right angle lines, often with different hydropower operational scenarios overlying each other. 


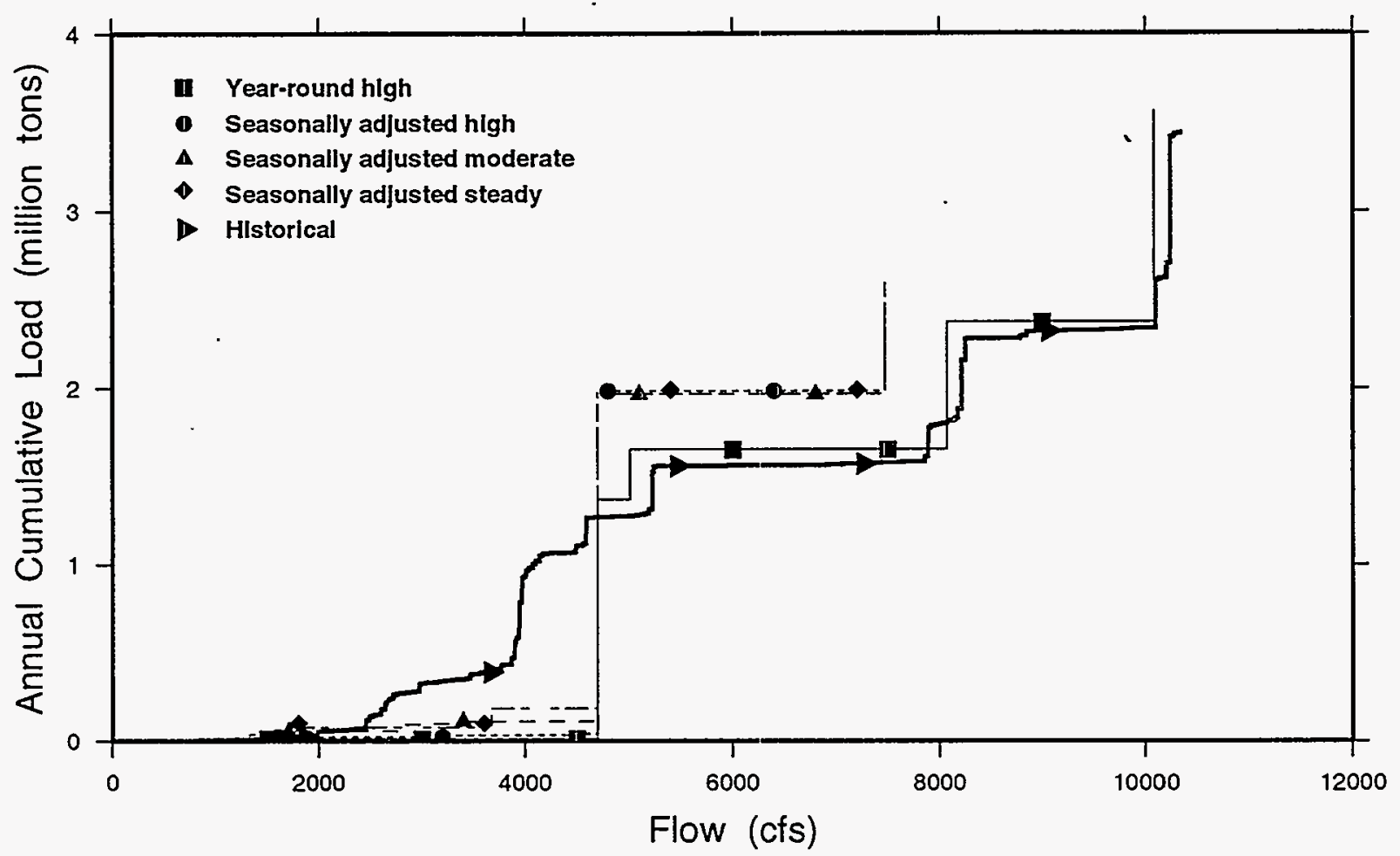

FIGURE 6 Total Annual Sediment Load for the Four Hydropower Operational Scenarios for a Moderate Water Year

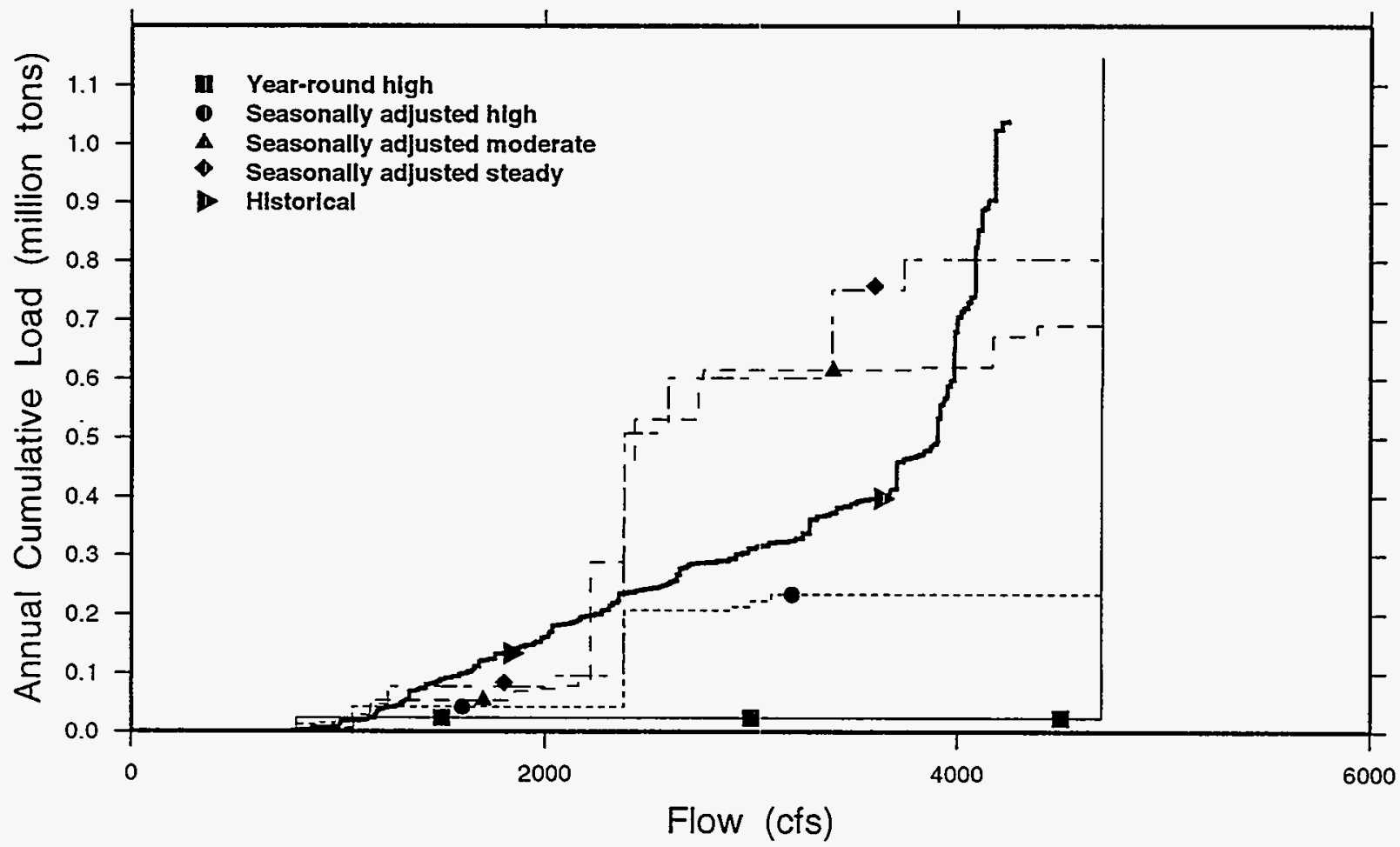

FIGURE 7 Total Annual Sediment Load for the Frour Hydropower Operational Scenarios for a Dry Water Year 


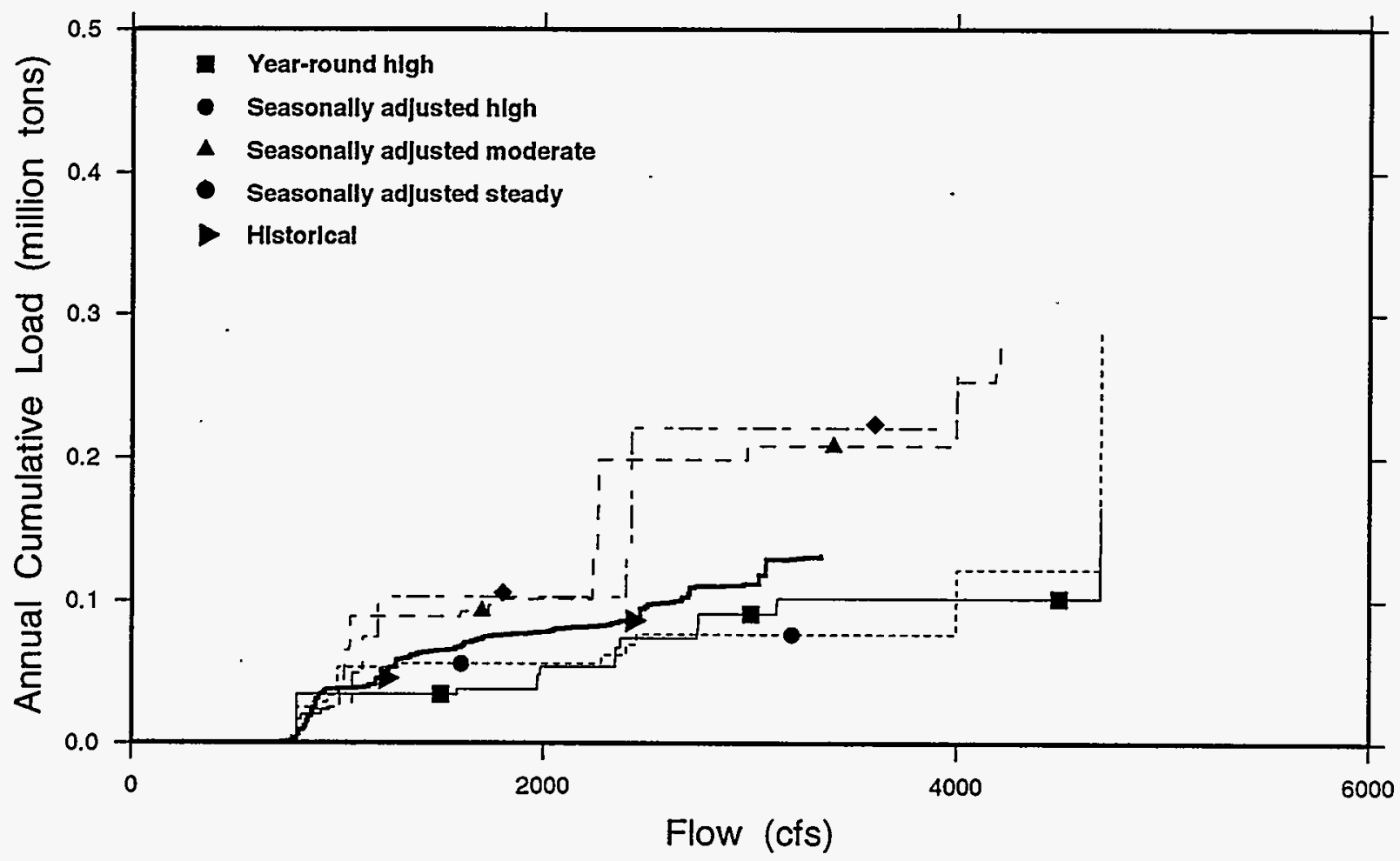

FIGURE 8 Total Annual Sediment Load for the Four Hydropower Operational Scenarios for a Wet Water Year

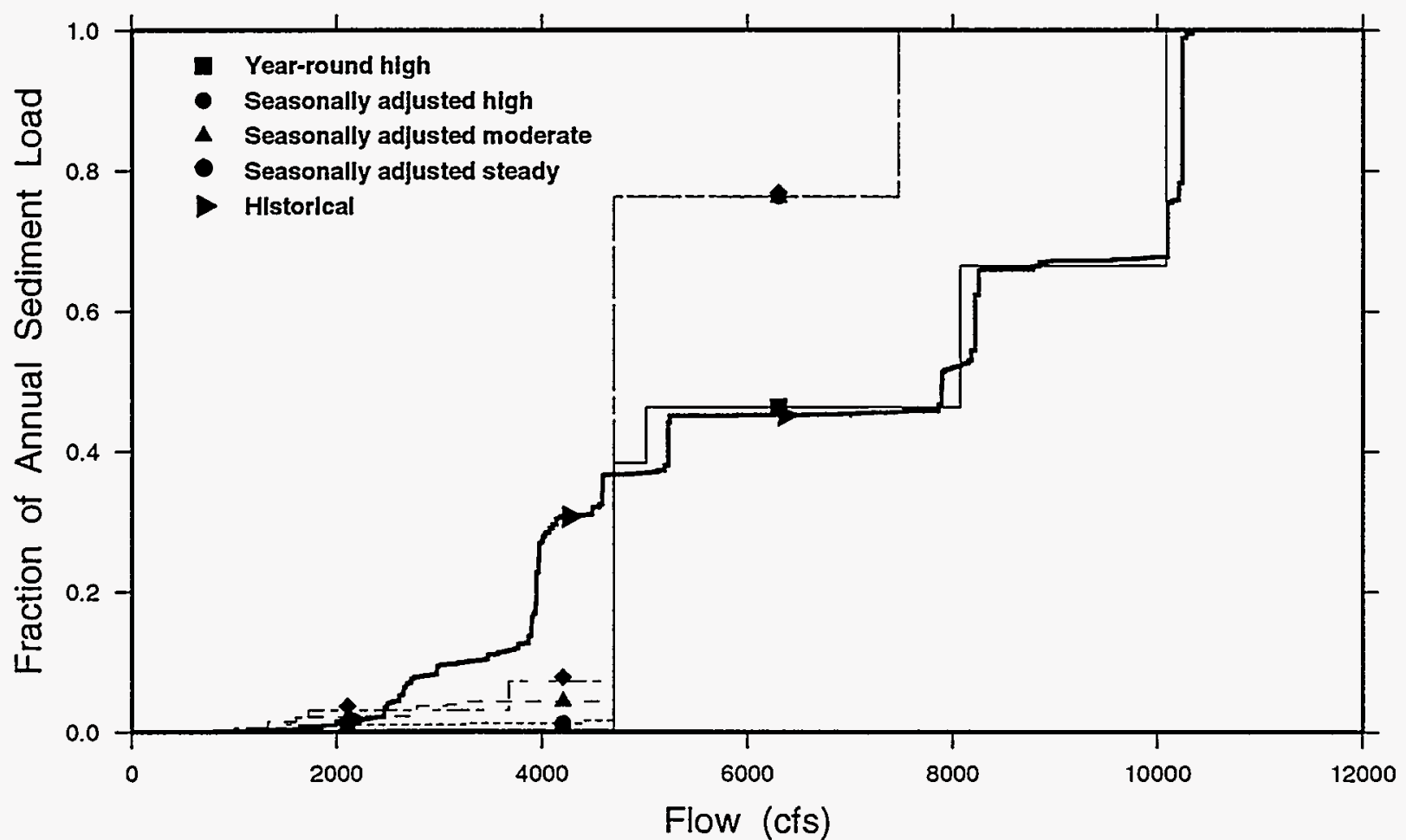

FIGURE 9 Normalized Annual Sediment Load for the Four Hydropower Operational Scenarios for a Moderate Water Year 


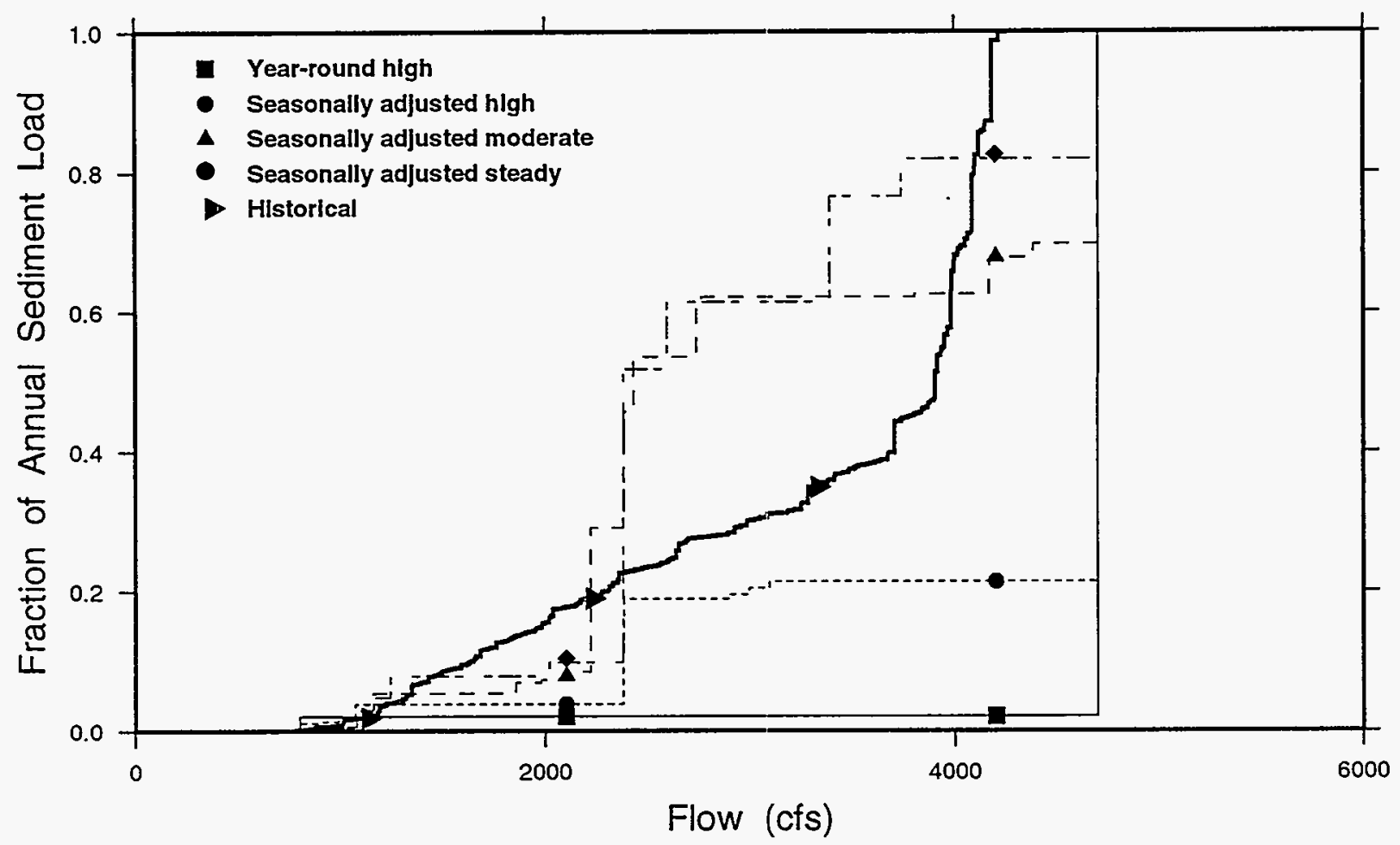

FIGURE 10 Normalized Annual Sediment Load for the Four Hydropower Operational Scenarios for a Dry Water Year

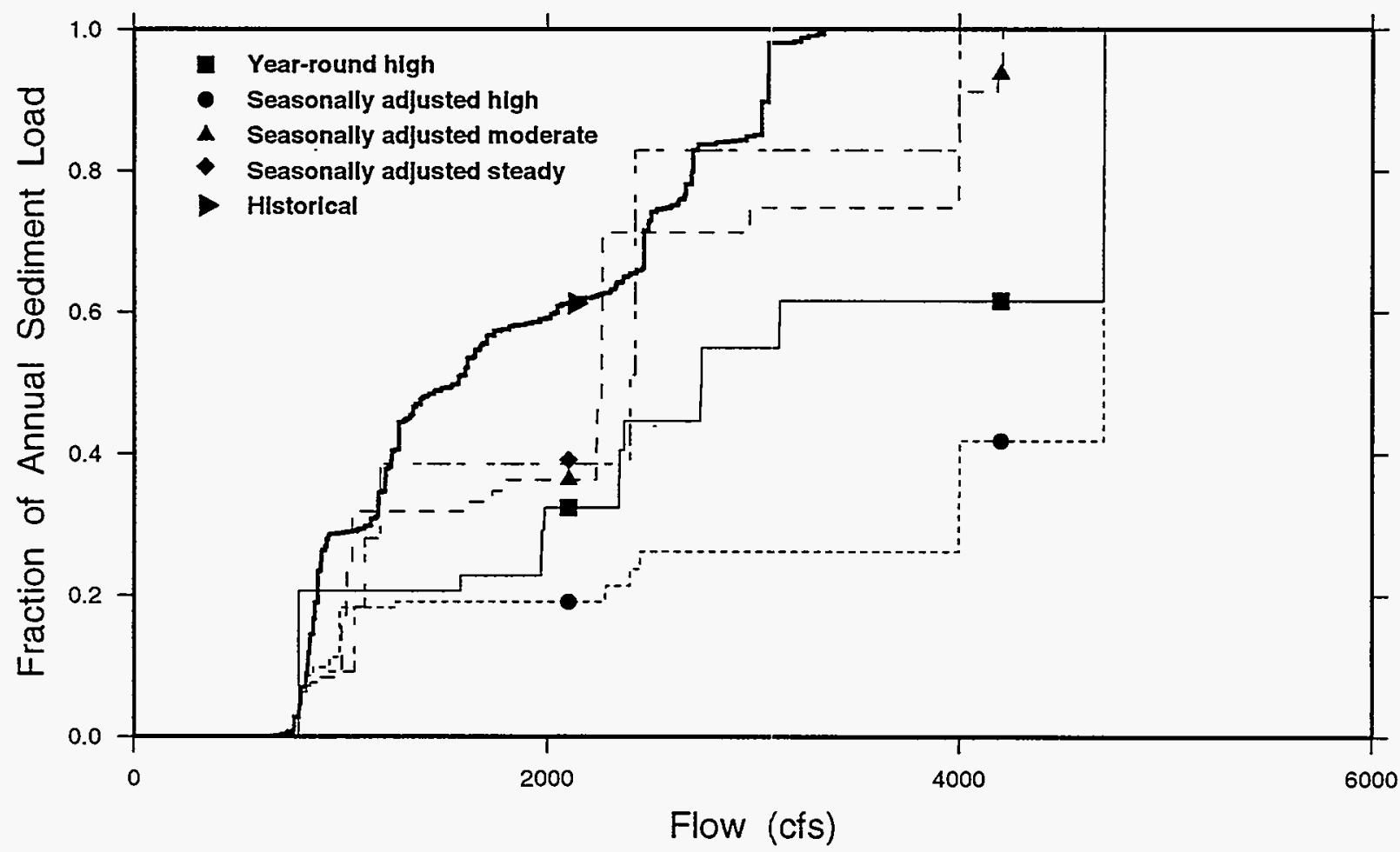

FIGURE 11 Normalized Annual Sediment Load for the Four Hydropower Operational Scenarios for a Wet Water Year 
The historical sediment loads for the three water years also were calculated with the Engelund-Hansen method. The results of these calculations are shown in Figure 12. For the wet year (1983), about $50 \%$ of the sediment load is transported by flows in excess of $8,000 \mathrm{cfs}$. For a dry year (1989), 100\% of the load is transported by flows of less than 4,000 cfs. Total loads for Browns Park were calculated to be 1,037,500; 131,600; and 3,454,200 tons for 1987, 1989 , and 1983, respectively.

In comparison with Andrews (1986), Lyons et al. (1992), and Smith and Green (1991), the computed total annual sediment load for Browns Park for a moderate year (1987) is reasonable. Andrews gives a value of $3.21 \times 10^{6}$ tons/yr for the mean annual sediment load for the dam post-closure period measured at Jensen, Utah. Andrews also gives a value of $1.9 \times 10^{6}$ tons/yr for the Yampa River contribution to the mean annual sediment load measured at Jensen. If the Yampa River contribution is subtracted from the mean annual sediment load measured at Jensen, the Green River below Flaming Gorge Dam and its other tributaries contribute about $1.31 \times 10^{6}$ tons/yr of sediment to the mean annual sediment load at Jensen. This value is about $26 \%$ higher than the value calculated in this study for the total annual sediment load for Browns Park. This discrepancy can be attributed to the inclusion of other tributaries and other alluvial reaches of the Green River between the dam and the Jensen gage.

Lyons et al. (1992) reported that the mean annual bed load at the Jensen gage over the 22-year period from 1965 to 1987 was $1.48 \times 10^{6}$ tons/yr and that this value was about

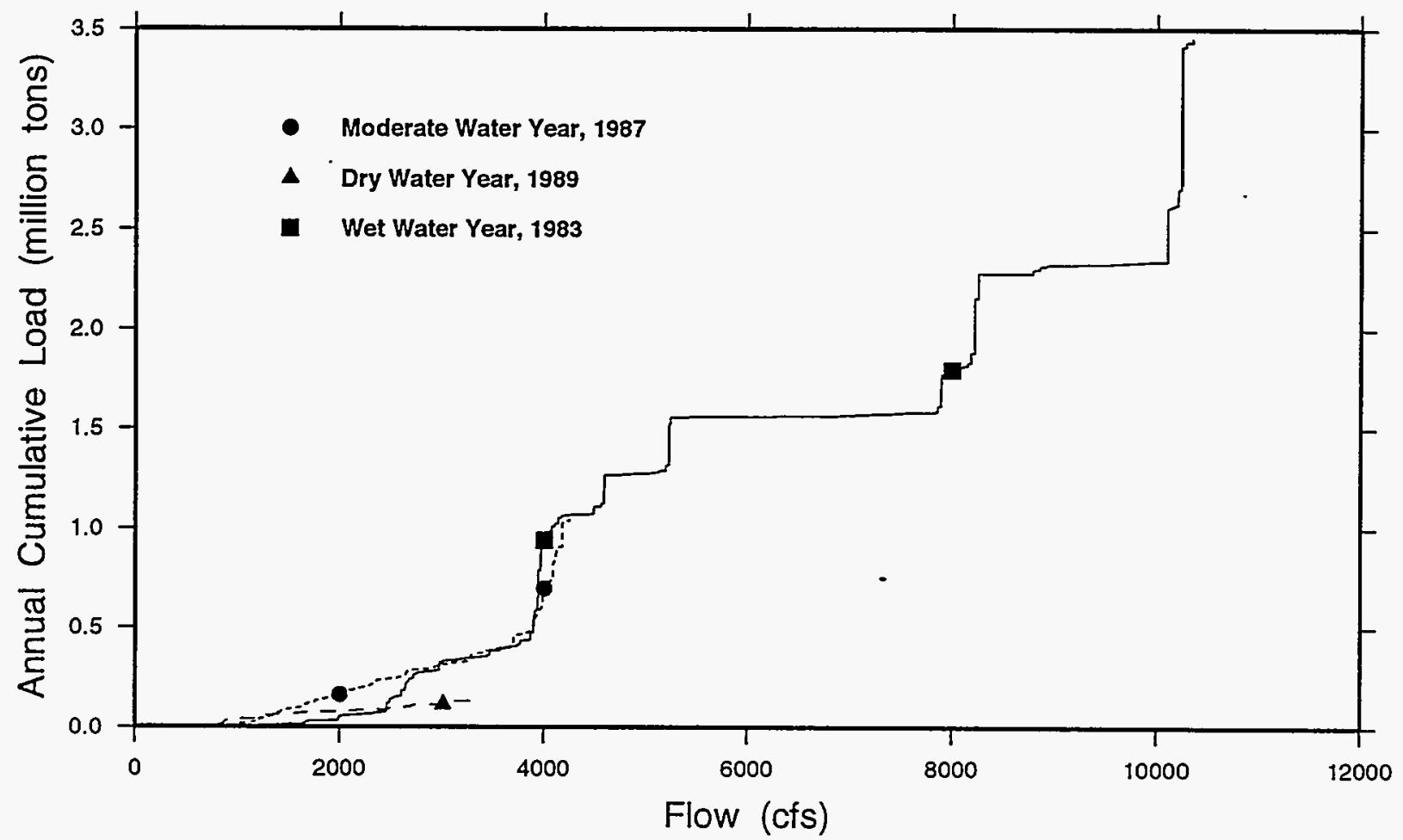

FIGURE 12 Total Annual Sediment Load at Browns Park for the Historical Water Years 1987, 1989, and 1983 
$50 \%$ of the total mean annual sediment load. By doubling this value and subtracting the Andrews value for the Yampa River contribution, the total sediment load calculated from the mean annual bed load is approximately $1.06 \times 10^{6}$ tons/yr. This value is within $2 \%$ of the value calculated for'Browns Park in this study.

Smith and Green (1991) stated that the mean annual sand load for the 22-year period from 1965 to 1987 at Jensen was $1.48 \times 10^{6}$ tons/yr. Similar to Lyons et al. (1992), Smith and Green stated that the mean annual sand load was approximately $50 \%$ of the total mean annual sediment load. Again, by repeating the procedures outlined above, the contribution to the total mean annual sediment load by the Green River and the other tributaries in this stretch is $1.06 \times 10^{6}$ tons/yr, which is also only about $2 \%$ higher than the value calculated for Browns Park in this study.

Figure 4 presents the historical flow regirnes for water years 1987, 1989, and 1983 in the form of fractional flow exceedance curves. Figure 12 presents the annual cumulative sediment load for the same three water years, and Figure 13 presents the cumulative sediment load data in a fractional context. Figure 11 shows that in a dry year (1989), flow is at or below approximately $1,000 \mathrm{cfs} 75 \%$ of the time. However, less than $1 \%$ of the sediment load is carried by these low flows (Figures 12 and 13). Figure 13 shows that nearly $100 \%$ of the sediment load is transported at flows above $1,500 \mathrm{cfs}$ in 1987 , but flows in this range occur only about 12 to $15 \%$ of the time. Similar observations can be made for the other water years. A disproportionate percentage of sediment volume is transported at lowfrequency high flows. This result occurs because the transported sediment volume is

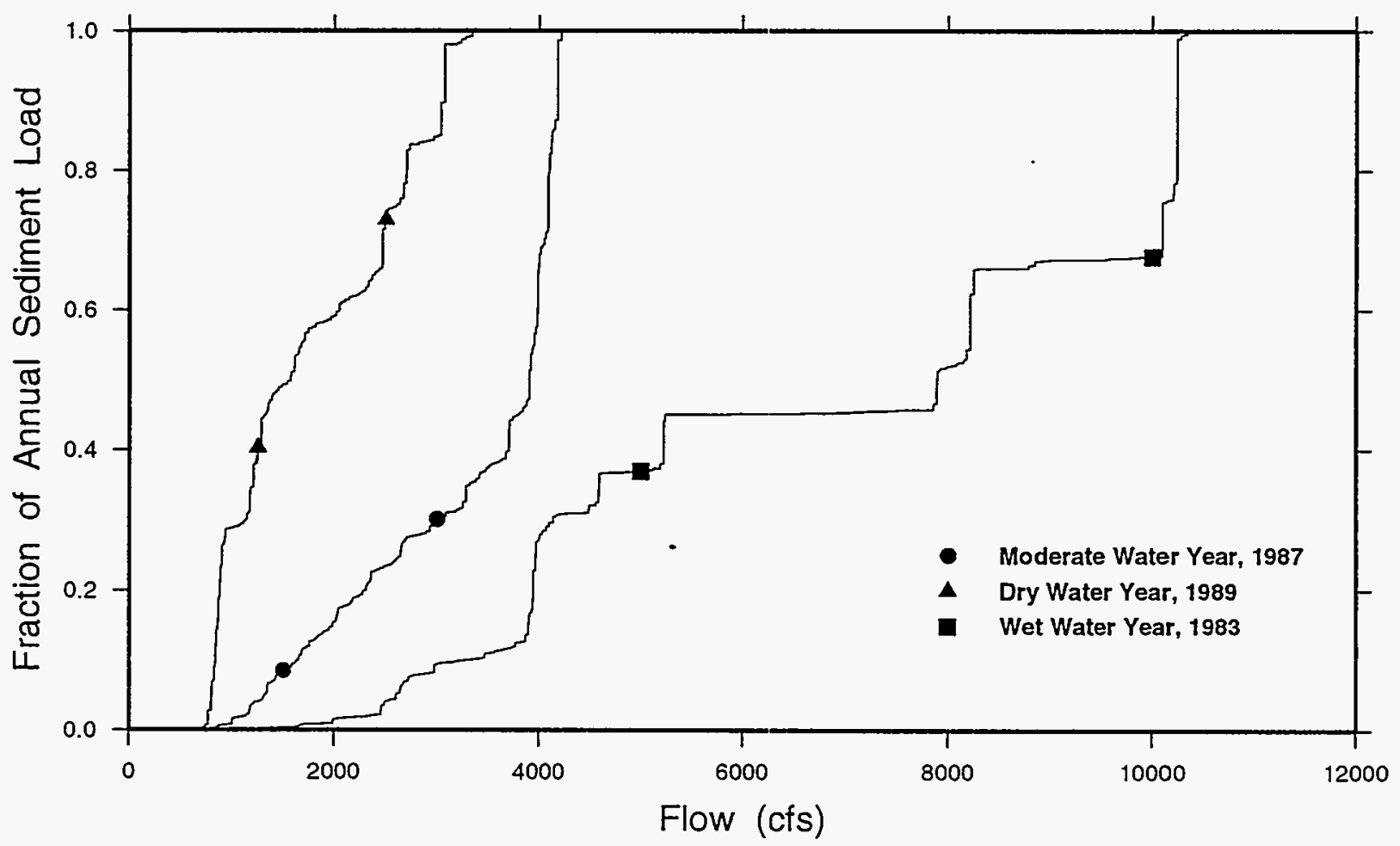

FIGURE 13 Normalized Annual Sediment Load for the Historical Water Years 1987, 1989 , and 1983 
proportional to the square of the average flow velocity. In the Green River at Browns Park, velocity varies more or less linearly with the flow in the river (Equations 6, 7, and 8).

\subsubsection{Analysis}

Leopold et al. (1984) showed that the rate of erosion and river meandering in an alluvial stream is proportional to the sediment removed. Total sediment loads can therefore be used to determine the rate at which the stream banks would erode under the different hydropower operational scenarios. However, because the relationship is linear, the largest variation (15\%) is within the uncertainty associated with the calculations and available data used for this study, so it is not possible to differentiate between the different hydropower operational scenarios on the basis of erosion rate.

Table 2 summarizes the total cumulative sediment loads for each of three hydrologic conditions (water years) and each of the hydropower operational scenarios. The data in this table are compared to the year-round high fluctuating flow operational scenario. The other scenarios are presented as total sediment load in millions $\left(10^{6}\right)$ of tons and as a percentage of those under the year-round high fluctuating flow scenario. In both the moderate and wet years, the year-round high fluctuating flow scenario contributes the largest sediment load. In a dry year, the year-round high fluctuating scenario produces the lowest cumulative sediment load.

The calculated cumulative sediment loads for the historical water years used to define the different hydrologic conditions are 90,77 , and $97 \%$ of the year-round high fluctuating flow scenario for the moderate, dry, and wet years, respectively (Table 2). Measured values presented by different investigators vary by as much as $26 \%$ from the calculated value, a discrepancy that makes it difficult to differentiate between the different scenarios for the moderate (1987) water year. The highest variation, $15 \%$, for the seasonally adjusted steady flows is within the margin of error of the calculations. The wet year (1983) shows a greater variation, up to $28 \%$; however, this difference is almost entirely attributable to flows over $8,000 \mathrm{cfs}$ (Figure 12). These flows occur only under emergency conditions, they are difficult to predict, and they might occur even under a steady flow operational scenario. For the dry year 1989, the seasonally adjusted flow scenarios have large percent differences compared with the year-round high fluctuating flow scenario, but the total sediment load difference is only 0.12 million tons (approximately $10 \%$ of the total load during a moderate water year). Again, this difference is relatively small and unimportant for impact evaluation.

\subsection{EFFECTIVE DISCHARGE}

Effective discharge is defined as the modal value of the sediment load-duration function (flow that carries the maximum sediment load for the specified time period) at a given location (Lyons et al. 1992). Traditionally, effective discharge has been a useful parameter for analyzing riverine systems. Changes in effective discharge indicate that a 
TABLE 2 Summary of Sand Load in Browns Park for Different Hydropower Operational Scenarios and Water Years ${ }^{\mathrm{a}}$

\begin{tabular}{|c|c|c|c|}
\hline \multirow[b]{2}{*}{$\begin{array}{c}\text { Water Year/ } \\
\text { Operational Scenario }\end{array}$} & \multicolumn{3}{|c|}{ Sand Load ( $10^{6}$ tons) } \\
\hline & Total & \% Diff. & $\begin{array}{l}\text { Erosion } \\
\text { Rate }\end{array}$ \\
\hline \multicolumn{4}{|l|}{ Moderate Water Year (1987) } \\
\hline Year-round high fluctuating flows & 1.15 & 0 & 1.0 \\
\hline $\begin{array}{l}\text { Seasonally adjusted high fluctuating } \\
\text { flows }\end{array}$ & 1.10 & -4 & 0.96 \\
\hline $\begin{array}{l}\text { Seasonally adjusted moderate } \\
\text { fluctuating flows }\end{array}$ & 0.99 & -14 & 0.86 \\
\hline Seasonally adjusted steady flows & 0.98 & -15 & 0.85 \\
\hline Historical flows & 1.03 & -10 & 0.90 \\
\hline \multicolumn{4}{|l|}{ Dry Water Year (1989) } \\
\hline Year-round high fluctuating flows & 0.17 & 0 & 1.0 \\
\hline $\begin{array}{l}\text { Seasonally adjusted high fluctuating } \\
\text { flows }\end{array}$ & 0.29 & 71 & 1.71 \\
\hline $\begin{array}{l}\text { Seasonally adjusted moderate } \\
\text { fluctuating flows }\end{array}$ & 0.28 & 65 & 1.65 \\
\hline Seasonally adjusted steady flows & 0.27 & 59 & 1.59 \\
\hline Historical flows & 0.13 & -24 & 0.76 \\
\hline \multicolumn{4}{|l|}{ Wet Water Year (1983) } \\
\hline Year-round high fluctuating flows & 3.57 & 0 & 1.0 \\
\hline $\begin{array}{l}\text { Seasonally adjusted high fluctuating } \\
\text { flows }\end{array}$ & 2.60 & -27 & 0.73 \\
\hline $\begin{array}{l}\text { Seasonally adjusted moderate } \\
\text { fluctuating flows }\end{array}$ & 2.58 & -28 & 0.72 \\
\hline Seasonally adjusted steady flows & 2.58 & -28 & 0.72 \\
\hline Historical flows & 3.45 & -3 & 0.97 \\
\hline
\end{tabular}

a \% Diff. is the percent difference from year-round high fluctuating flows; Erosion Rate is the rate of erosion or meandering relative to year-round high fluctuating flows. 
river is likely to either aggrade or erode its bed and banks (Andrews 1986; Lyons et al. 1992). However, effective discharge proved to be of little value in analyzing the four hydropower operational scenarios considered in this study. In the three hydrologic conditions used for this analysis, the distribution of flows is not continuous but consists of several discrete flow levels.

Effective discharge is computed by developing an integrated histogram of sediment load versus flow. There is no set procedure for determining the histogram bin size, although it is usually based on either a round number (e.g., 100-cfs bins) or an even division over the flow range (e.g., 10 bins from 0 to 4,700 cfs for a 470-cfs bin size). For any given hydropower operational scenario, the maximum number of discrete discharge values is 28 for one year. In most cases, the number is much less than this value. For example, only two discrete flows, 800 and 4,700 cfs, occur in a wet year for the year-round high fluctuating flow scenario.

Effective discharge plots were developed in a manner similar to the cumulative flow plots discussed in Section 2.2.2. A sediment volume carried by each flow event was computed for the hour over which the flow was assumed to have occurred. This computation produced an integrated histogram with 1-cfs bins, as discussed in Section 2.2.1. To compute an effective discharge, these 1 -cfs bins were summed to create 100-cfs bins.

The bin size chosen for the effective discharge plot is arbitrary. Generally, the bin size is chosen by dividing the range of flow values into an even number of compartments or by picking a flow interval to give a chosen resolution. This arbitrary choice can change the final result, especially in this case where the hydropower operational scenarios have a limited number of discrete flow values grouped at the extremes of the flow range. For example, the seasonally adjusted high fluctuating flow scenario in 1989 would have an effective discharge of 4,000 cfs if 100-cfs bins were used (Table 3). If the bin size were changed to $300 \mathrm{cfs}$, the effective discharge would be $800 \mathrm{cfs}$. This sensitivity to bin size is due, in part, to the large number of flow events that occur at low flows $(5,772,660$, and 1,320 events for the $701-$ to 800-, 801- to 900-, and 901- to 1,000-cfs bins, respectively) versus the low number of flow events that occur at the high flow range (168 flow events for the 3,900- to 4,000-cfs bin). No flow events occur between 2,500 and $3,900 \mathrm{cfs}$.

Effective discharge is also difficult to use for comparing the hydropower operational scenarios for reasons other than arbitrary bin size. For example, in the year-round high fluctuating flow scenario for 1987, only two discrete flows would occur during the year: $800 \mathrm{cfs}(5,460$ flow occurrences and 23,600 tons of sediment) and 4,700 cfs (3,180 flow occurrences and 1,122,300 tons of sediment). The effective discharge would therefore be $4,700 \mathrm{cfs}$, with $1.12 \times 10^{6}$ tons of sediment transported during the water year. The seasonally adjusted moderate fluctuating flow scenario for 1987 would also have an effective discharge of $4,700 \mathrm{cfs}$ ( 852 occurrences), with a total sediment load of 300,000 tons of annual sediment, if a 100-cfs bin size were used. However, if 300-cfs bins were used, the effective discharge would be 2,200 to $2,500 \mathrm{cfs}(1,980,1,440$, and 660 occurrences for the 2,300-, 2,400-, and 2,500-cfs bins, respectively), carrying a total annual volume of 456,000 tons of sediment $(208,000,168,000$, and 80,000 tons, respectively, for the 2,300-, 2,400-, and 2,500-cfs bins). 
TABLE 3 Effective Discharge and Percent of Total Sediment Load for Different Hydropower Operational Scenarios and Water Years

\begin{tabular}{|c|c|c|c|c|}
\hline \multirow[b]{2}{*}{$\begin{array}{c}\text { Water Year/ } \\
\text { Operational Scenario }\end{array}$} & \multirow[b]{2}{*}{$\begin{array}{l}\text { Total } \\
\text { Sediment } \\
\text { (tons) }\end{array}$} & \multirow[b]{2}{*}{$\begin{array}{c}\text { Effective } \\
\text { Discharge } \\
\text { (cfs) }\end{array}$} & \multicolumn{2}{|c|}{ Sediment } \\
\hline & & & $\begin{array}{l}\text { Value } \\
\text { (tons) }\end{array}$ & $\begin{array}{l}\text { Percent } \\
\text { of Total }\end{array}$ \\
\hline \multicolumn{5}{|l|}{ Moderate Water Year (1987) } \\
\hline Year-round high fluctuating flows & $1,145,947$ & 4,700 & $1,122,319$ & 98 \\
\hline $\begin{array}{l}\text { Seasonally adjusted high fluctuating } \\
\text { flows }\end{array}$ & $1,094,698$ & 4,700 & 860,805 & 79 \\
\hline $\begin{array}{l}\text { Seasonally adjusted moderate } \\
\text { fluctuating flows }\end{array}$ & 990,873 & 4,700 & 300,693 & 30 \\
\hline Seasonally adjusted steady flows & 980,540 & 2,400 & 420,783 & 43 \\
\hline Historical flows & $1,037,460$ & 3,900 & 208,102 & 20 \\
\hline \multicolumn{5}{|l|}{ Dry Water Year (1989) } \\
\hline Year-round high fluctuating flows & 165,307 & 4,700 & 63,526 & 38 \\
\hline $\begin{array}{l}\text { Seasonally adjusted high fluctuating } \\
\text { flows }\end{array}$ & 291,198 & 4,000 & 45,648 & 16 \\
\hline $\begin{array}{l}\text { Seasonally adjusted moderate } \\
\text { fluctuating flows }\end{array}$ & 278,449 & 2,300 & 99,265 & 36 \\
\hline Seasonally adjusted steady flows & 265,982 & 2,500 & 86,429 & 32 \\
\hline Historical flows & 131,611 & 800 & 27,209 & 20 \\
\hline \multicolumn{5}{|l|}{ Wet Water Year (1983) } \\
\hline Year-round high fluctuating flows & $3,566,564$ & 4,700 & $1,355,216$ & 38 \\
\hline $\begin{array}{l}\text { Seasonally adjusted high fluctuating } \\
\text { flows }\end{array}$ & $2,595,519$ & 4,700 & $1,941,695$ & 75 \\
\hline $\begin{array}{l}\text { Seasonally adjusted moderate } \\
\text { fluctuating flows }\end{array}$ & $2,576,761$ & 4,700 & $1,852,417$ & 72 \\
\hline Seasonally adjusted steady flows & $2,576,761$ & 4,700 & $1,778,666$ & 69 \\
\hline Historical flows & $3,454,189$ & 10,300 & 811,943 & 24 \\
\hline
\end{tabular}


The effective discharge for the year-round high fluctuating flow and year-round moderate fluctuating flow scenarios would be the same (4,700 cfs); however, the year-round moderate fluctuating flow scenario would carry only $26 \%$ of the sediment of the year-round high fluctuating flow scenario (301,000 versus $1.12 \times 10^{6}$ tons, respectively). For this case, the effective discharge would be the same, but the load carried by the effective discharge would differ dramatically, implying a difference in sediment transport. Although the loads carried by the effective discharge would be different, total loads for the year would be about the same $\left(1.15 \times 10^{6}\right.$ tons/yr for year-round high fluctuating flows and 991,000 tons/yr for year-round moderate fluctuating flows), showing that this difference is not as large as indicated by the effective discharge values. The seasonally adjusted high fluctuating flows show an even more dramatic result. Again, the effective discharge for this scenario would be the same $(4,700 \mathrm{cfs})$, but only 861,000 tons/yr of sediment would be carried by this flow (only $76 \%$ of that carried at the same effective discharge in the year-round high fluctuating flow scenario). But, the total annual sediment load carried by this scenario would be $1.09 \times 10^{6}$ tons, $96 \%$ of the total load carried by the year-round high fluctuating flow scenario.

These cases show that for some operational scenarios, calculated effective discharge values are significantly different in the amount of sediment carried, implying different erosional impacts. However, the total sediment load carried by a given flow scenario is approximately the same, implying that there is very little difference in the erosional characteristics of the different operational scenarios. These results indicate that when the number of discrete flows is small, effective discharge is not a reliable methodology for evaluation.

Most of the hydropower operational scenarios involve a large gap between the highest flow (generally $4,700 \mathrm{cfs}$ ) and the next lowest flow. In most cases, the flows in the middle range would be more spread out and would not have the high number of occurrences in the extremes of the range 800 to $4,700 \mathrm{cfs}$. This distribution hampers the use of effective discharge as a comparison tool between the hydropower operational scenarios.

The effective discharge values calculated for the historical water years 1987, 1989, and 1983 are presented in Table 3, along with the values calculated for the various hydropower operational scenarios. The most important difference between the historical values and those for the four hydropower operational scenarios is the percent of total sediment load carried by the effective discharge. The hydropower scenarios have percentages that vary considerably from 16 to $98 \%$ of the total sediment load being carried by the effective discharge. In comparison, the 1987, 1989, and 1983 percentages occur within a narrow range of 20 to 25\%. This result indicates that if effective discharge is to be used as a comparison tool for different sediment transport flow regimes, the percentage of total sediment load carried by the effective discharge should be relatively consistent between the various flow regimes. 


\section{CONCLUSIONS}

- Total sediment loads calculated with the Engelund-Hansen equation agree well with previously published values for the Green River. The use of a mathematical model to calculate sediment load for the 93-mi reach below Flaming Gorge Dam was validated by comparing the computed results for a moderate water year (1987) with published results from several sources. These comparisons showed that the computed results agreed with measured historical averages. Some variation was expected because the measured results were determined over various time periods whereas the calculated results were for a specific water year (1987). In addition, variation was introduced by the use of a relatively simple transport model and uncertain input variables.

Equilibrium potentials for the various hydropower operational scenarios could not be differentiated from the computed values for $C_{v}$ and $I_{v}$. Although these coefficients vary somewhat, the variation is relatively small and these small variations indicate that the various hydropower operational scenarios would have approximately the same equilibrium potential.

The total sediment load carried by the different hydropower operational scenarios, as calculated by the Engelund-Hanson equation, would be approximately the same. Some large percent variations occur in a dry water year, but these variations are not important because of the small percentage (10\%) of sediment carried in a dry versus moderate year.

Effective discharge is not an effective method for comparing the proposed hydropower operational scenarios under consideration in this study. The various scenarios would have only a small number of discrete flows. Because of the nature of the flow distributions, the percentage of total sediment load carried by the effective discharge for the various scenarios would vary greatly. The percentage of total sediment load carried by the effective discharge for the historical flows was approximately constant. Such results preclude using these values for comparison between the operational scenarios and the historical flows, although comparison between the historical flows is valid.

The best analytical method for the hydropower operational scenarios is sediment curves and normalized sediment curves used in conjunction with flow exceedance curves. These plots clearly show the range of flows where significant sediment transport is taking place. It was determined that even though sediment transport occurred differently under the various flow scenarios, the total sediment loads and impacts would be approximately the

same. No particular hydropower operational scenario could be identified as numerically different from the others in terms of sediment transport. 


\section{REFERENCES}

Andrews, E.E., 1986, "Downstream Effects of Flaming Gorge Reservoir on the Green River, Colorado and Utah," Geological Society of America Bulletin 97:1012-1023.

Elliott, et al., 1984, Sediment Transport in the Lower Yampa River, Northwest Colorado, U.S. Geological Survey Water Resources Investigation Report 84-4141.

Engelund, F., and E. Hansen, 1972, A Monograph of Sediment Transport in Alluvial Streams, 3rd ed. rev., Teknisk Forlag, Copenhagen, Denmark.

Garde, R.J., and K.G. Ranga Raju, 1985, Mechanics of Sediment Transportation and Alluvial Stream Problems, John Wiley and Sons, New York, N.Y.

Gordon, N.D., et.al., 1992, Stream Hydrology: An Introduction for Ecologists, John Wiley and Sons, New York, N.Y.

Leopold, B.L., et al., 1984, Fluvial Processes in Geomorphology, W.H. Freeman and Co., San Francisco, Calif.

Lyons, J.K., et al., 1992, "Sediment Transport and Channel Characteristics of a Sand-Bed Portion of the Green River below Flaming Gorge Dam, Utah, U.S.A.," Regulated Rivers: Research and Management 7:219-232.

Simons, D.B., and F. Sentürk, 1992, Sediment Transport Technology Water and Sediment Dynamics, Water Resources Publications, Littleton, Colo.

Smith, G., and R.G. Green, 1991, Flaming Gorge Consolidated Hydrology Report, U.S. Fish and Wildlife Service, Division of Water Resources, Region 6, Denver, Colo., Jan.

Stephens, H.G., and E.M. Shoemaker, 1987, In the Footsteps of John Wesley Powell: An Album of Comparative Photographs of the Green and Colorado Rivers, 1871-72 and 1968, Johnson Books, Boulder Colo.

U.S. Fish and Wildlife Service, 1992, Final Biological Opinion on the Operation of Flaming Gorge Dam, Mountain-Prairie Region, Denver, Colo., Nov. 25.

USFWS: see U.S. Fish and Wildlife Service.

U.S. Geological Survey, 1985, 1:2,000,000 Hydrologic Unit Map of the Conterminous United States, revision 1.1, Reston, Va. (accessed Dec. 20, 1991).

USGS: see U.S. Geological Survey. 
Weatherford, G.D., and F.L. Brown, 1983, New Courses for the Colorado River, University of New Mexico Press, Albuquerque, N.M.

Wheat, D., 1989, The Floaters Guide to Colorado, The Falcon Press, Billings, Mont.

Williams, G.P., and M.G. Wolman, 1984, Downstream Effects of Dams on Alluvial Rivers, U.S. Geological Survey Professional Paper 1286.

Yin, S.C.L., et al., 1995, Effects of Flaming Gorge Dam Hydropower Operations on Flow and Stage in the Green River, Utah and Colorado, ANL/EAD/TM-4, Argonne National Laboratory, Argonne, Ill. 


\section{APPENDIX A:}

HISTORICAL FLOWS FOR WATER YEARS 1987, 1989, AND 1983

Figures A.1 through A.3 show the historical flow regimes for the historical water years 1987, 1989, and 1983. These plots only show daily flow averages, rather than hourly values. Figures A.4 through A.7 show the historical hourly flows for the moderate water year 1987. These values are presented in quarters, with three monthly plots on each page. 


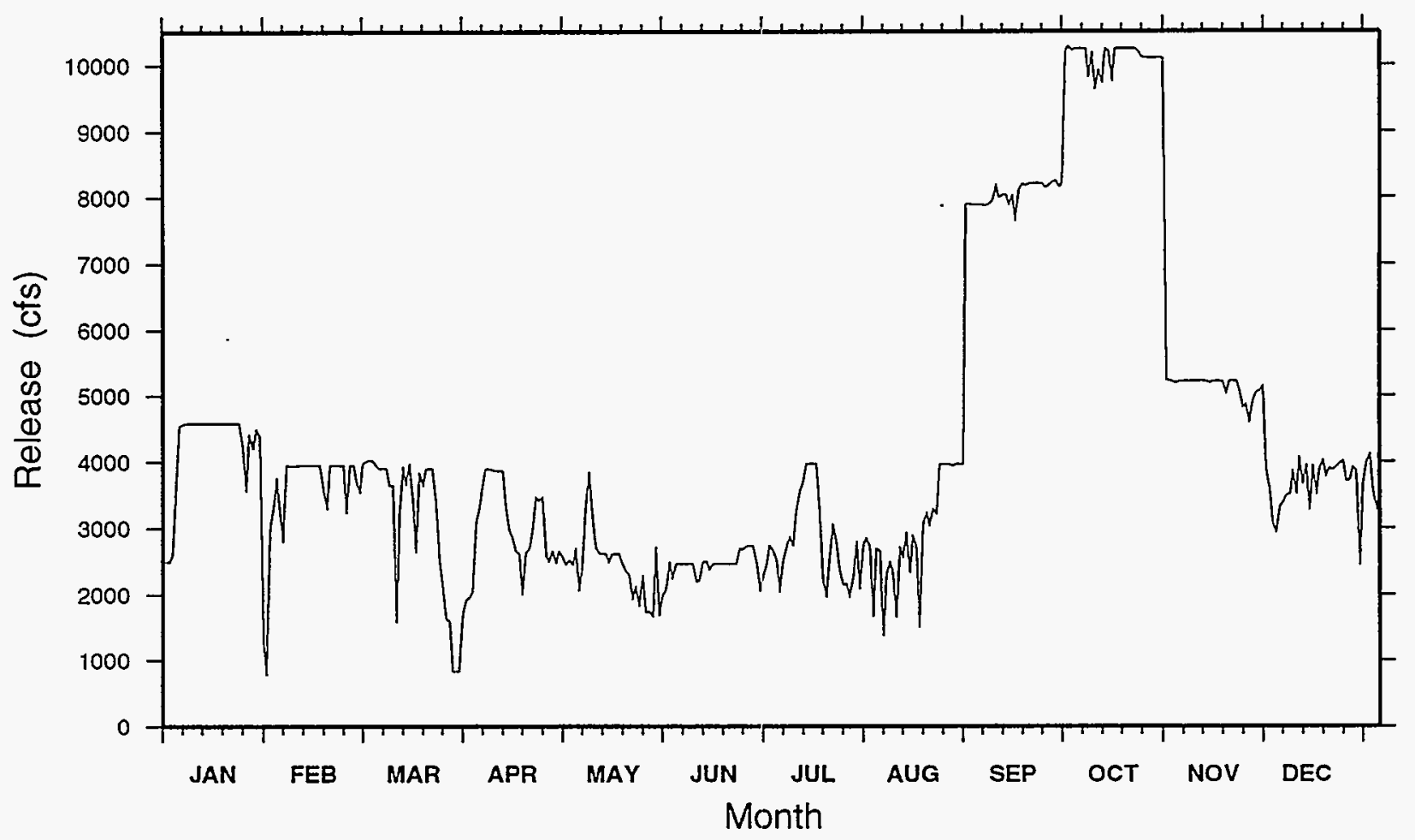

FIGURE A.1 Mean Daily Flows for the Historical Moderate Water Year 1987

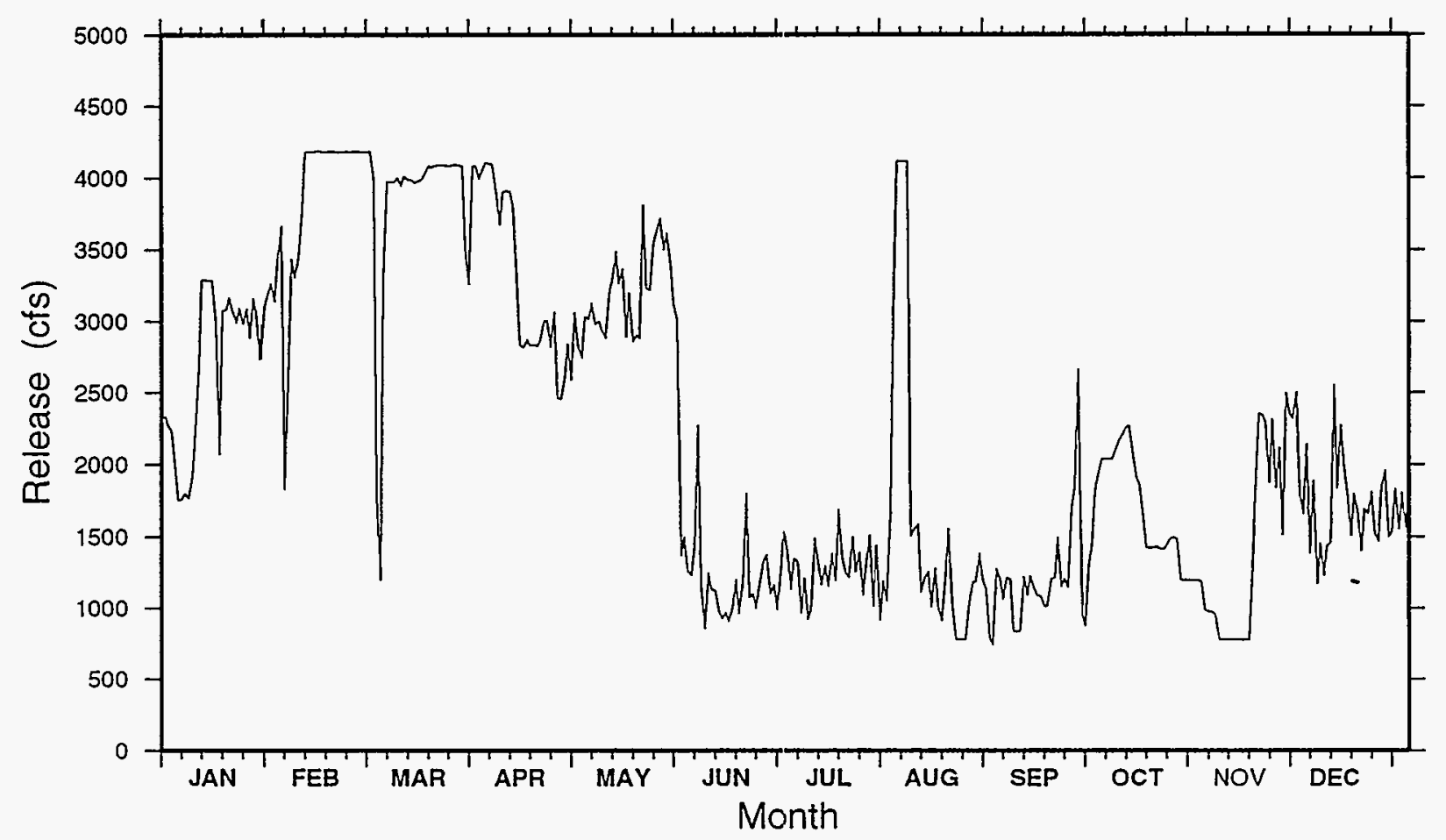

FIGURE A.2 Mean Daily Flows for the Historical Dry Water Year 1989 


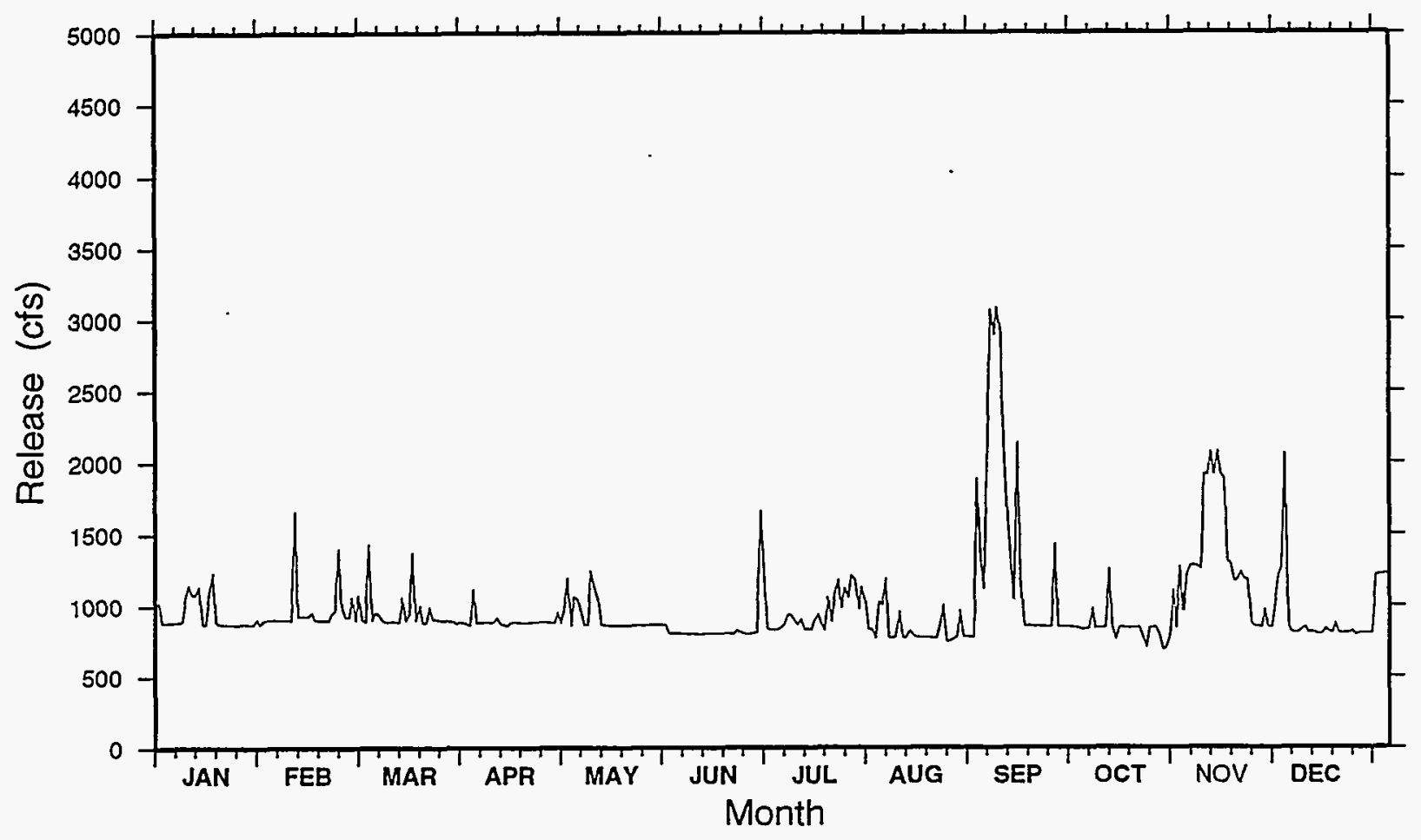

FIGURE A.3 Mean Daily Flows for the Historical Wet Water Year 1983 

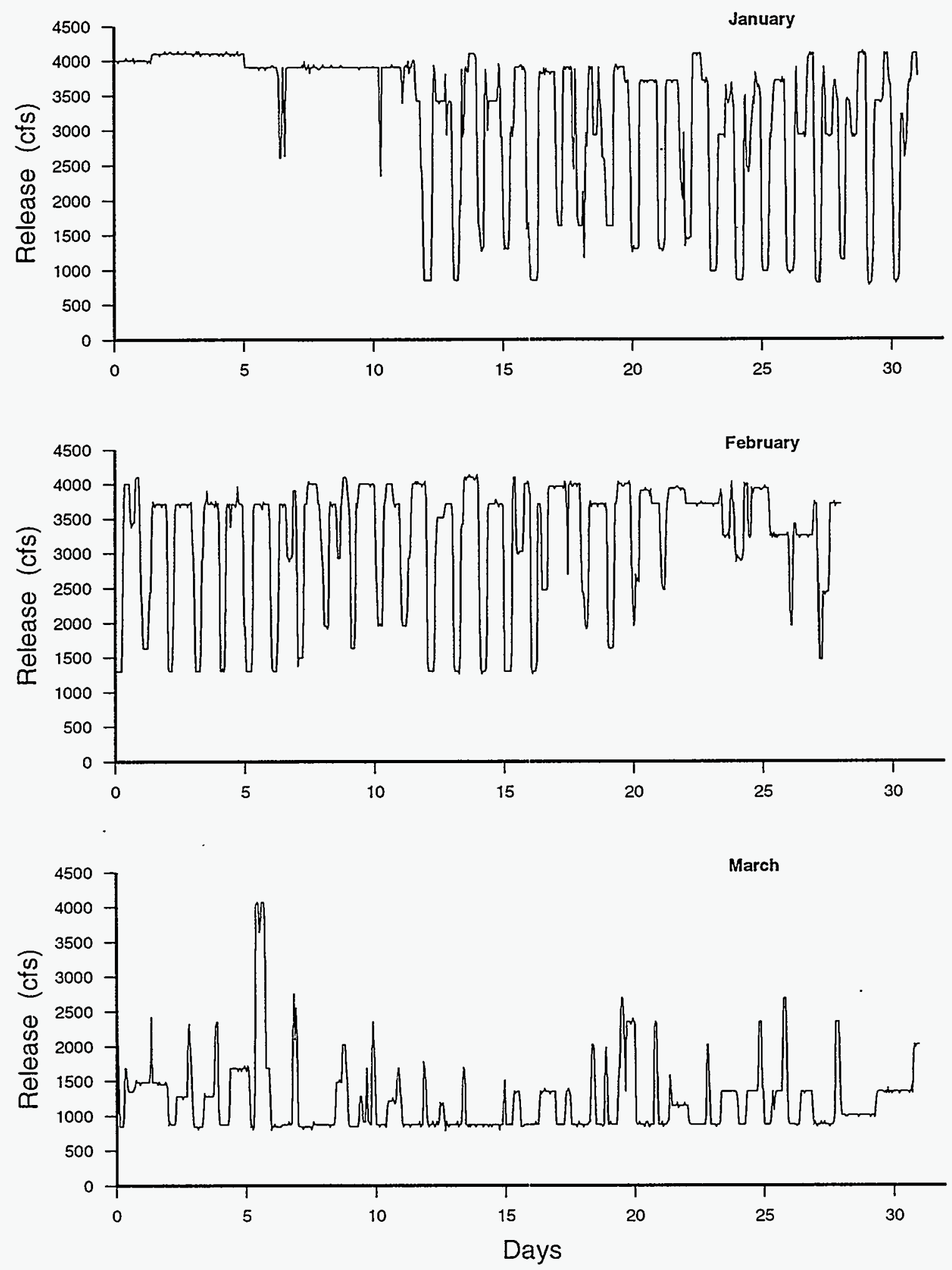

FIGURE A.4 Hourly Flows for the First Quarter of Water Year 1987 

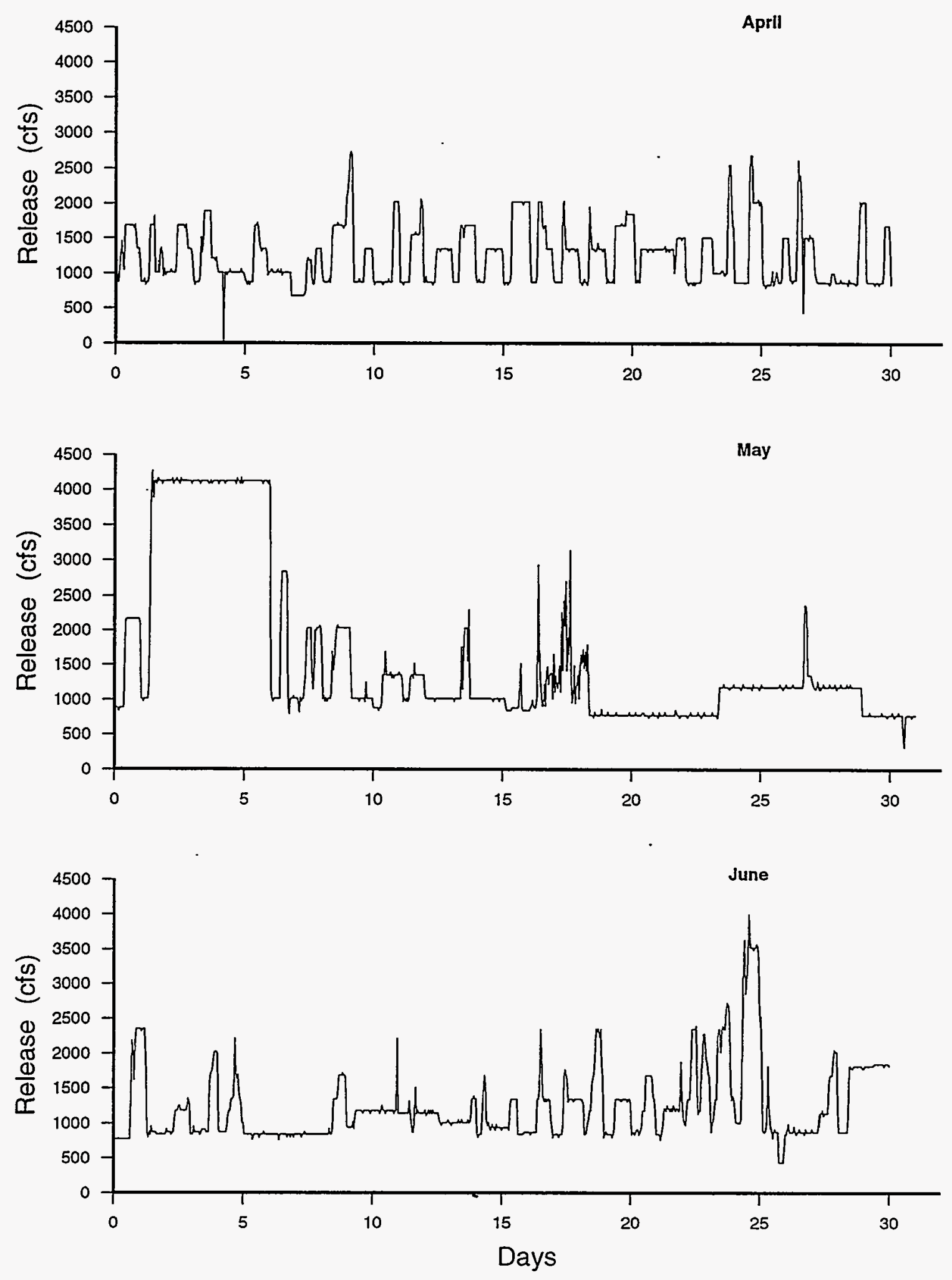

FIGURE A.5 Hourly Flows for the Second Quarter of Water Year 1987 

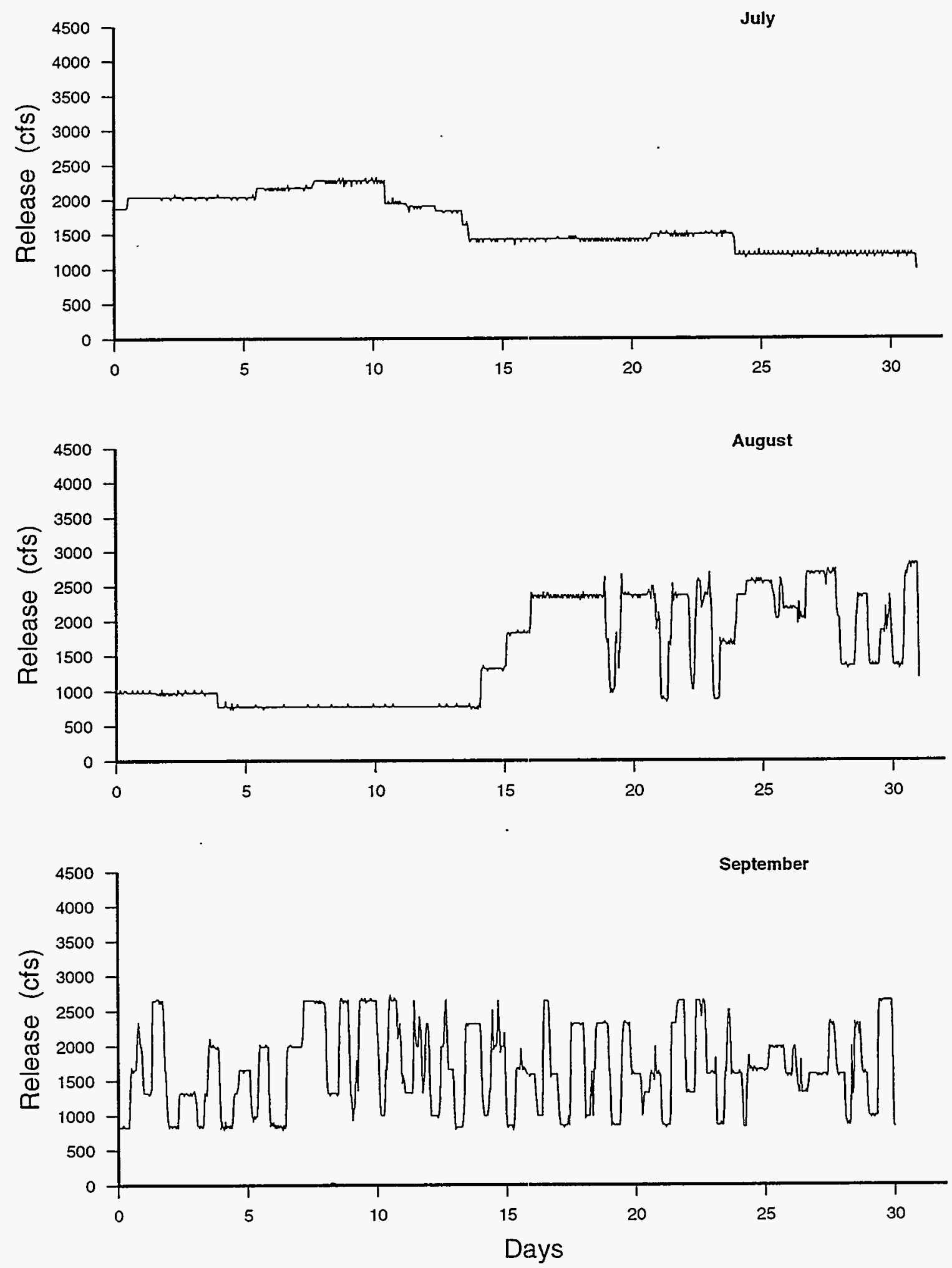

FIGURE A.6 Hourly Flows for the Third Quarter of Water Year 1987 

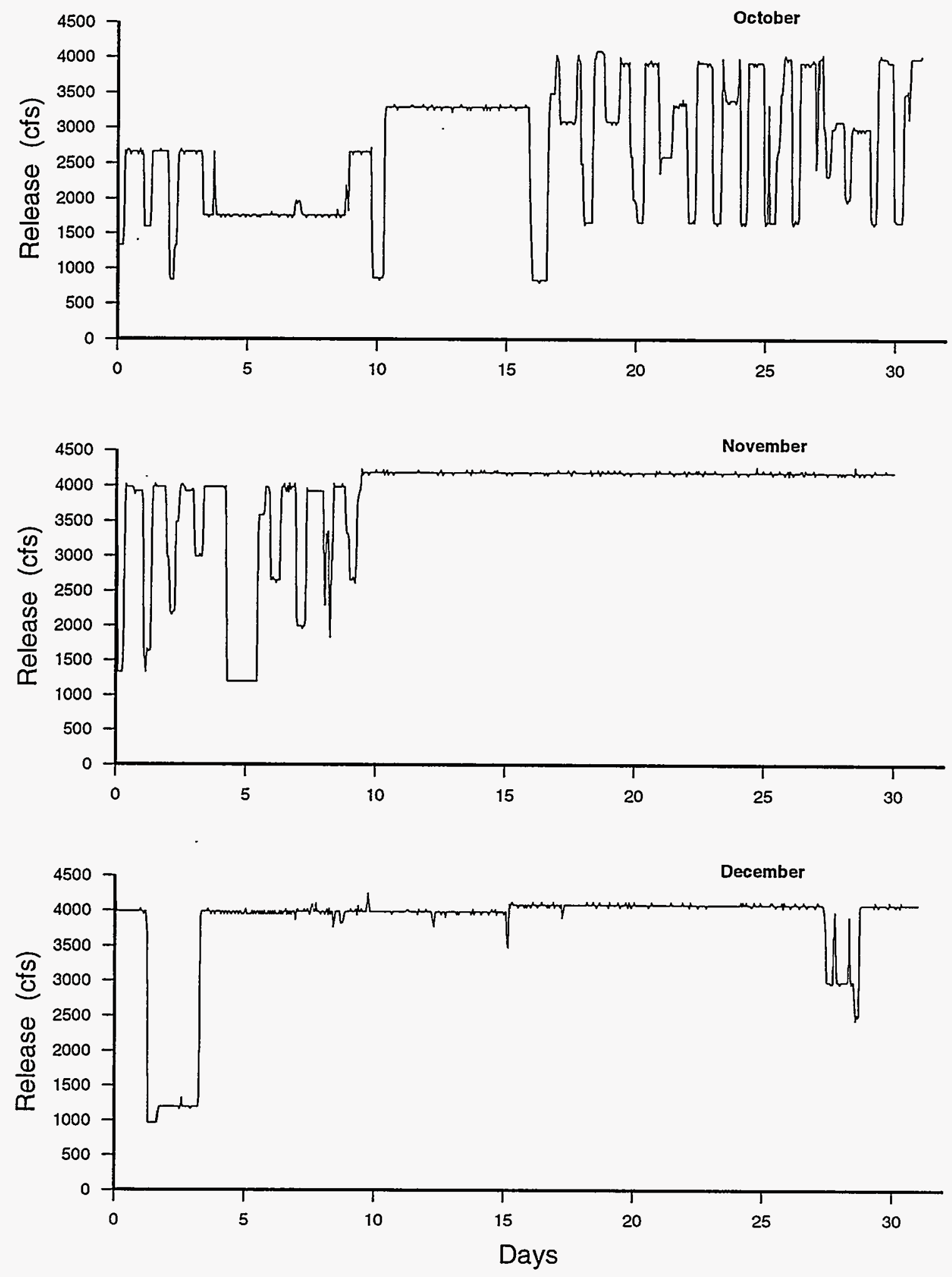

FIGURE A.7 Hourly Flows for the Fourth Quarter of Water Year 1987 


\section{APPENDIX B: \\ HYDROPOWER OPERATIONAL SCENARIOS}

Figures B.1 through B.42 show the various hydropower operational scenarios under consideration. Each figure presents one year of data. The typical day for each month is plotted showing the minimum flow and its duration and the maximum flow and its duration. For all the scenarios, the ramp up and ramp down time from the minimum to the maximum (or maximum to the minimum) flow is one hour. For conservative results, sediment transport during ramping is assumed to occur at the maximum flow for the one-hour interval. 

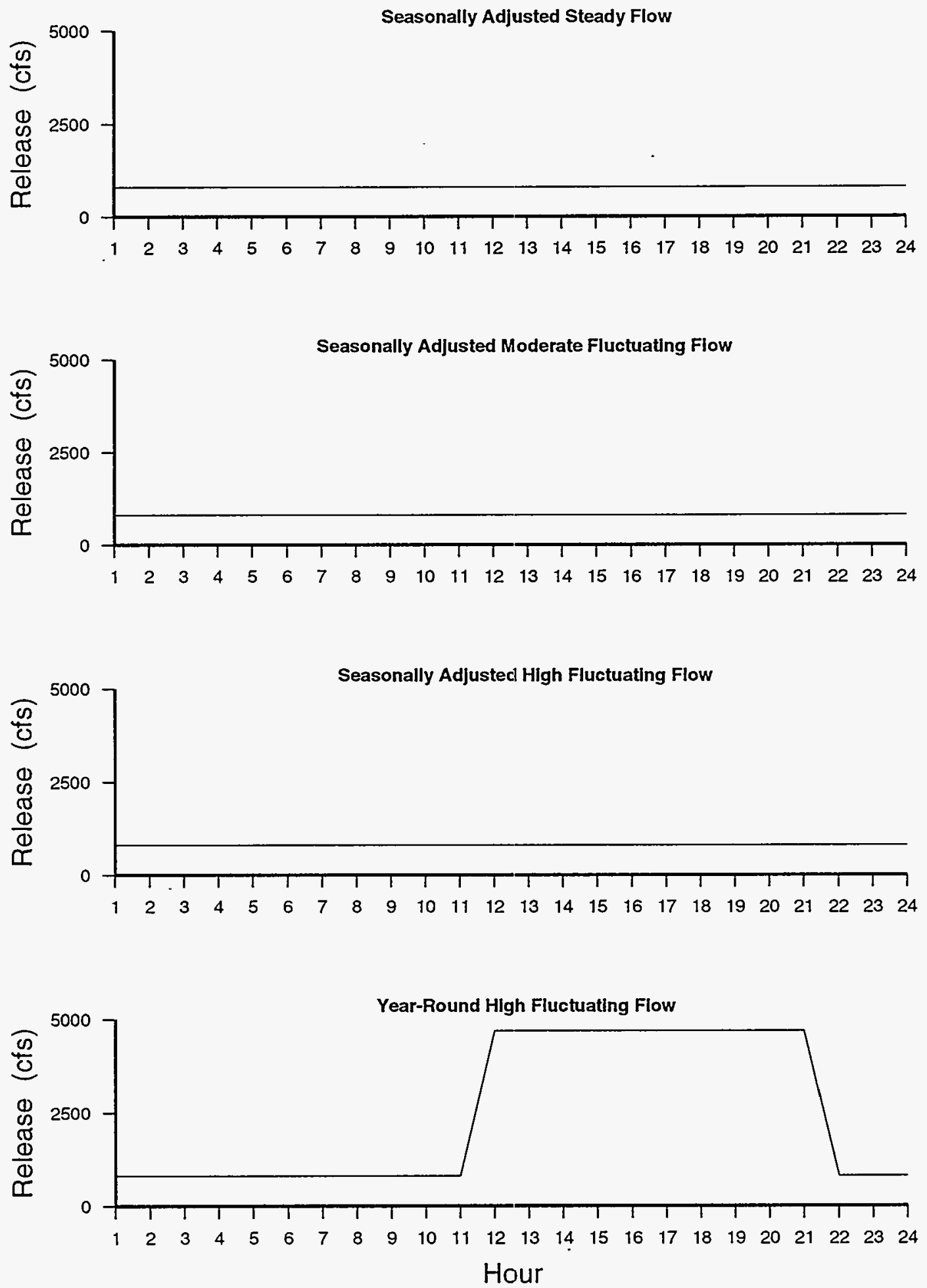

FIGURE B.1 Hourly Release Patterns under the Four Hydropower Operational Scenarios for October, Moderate Water Year 

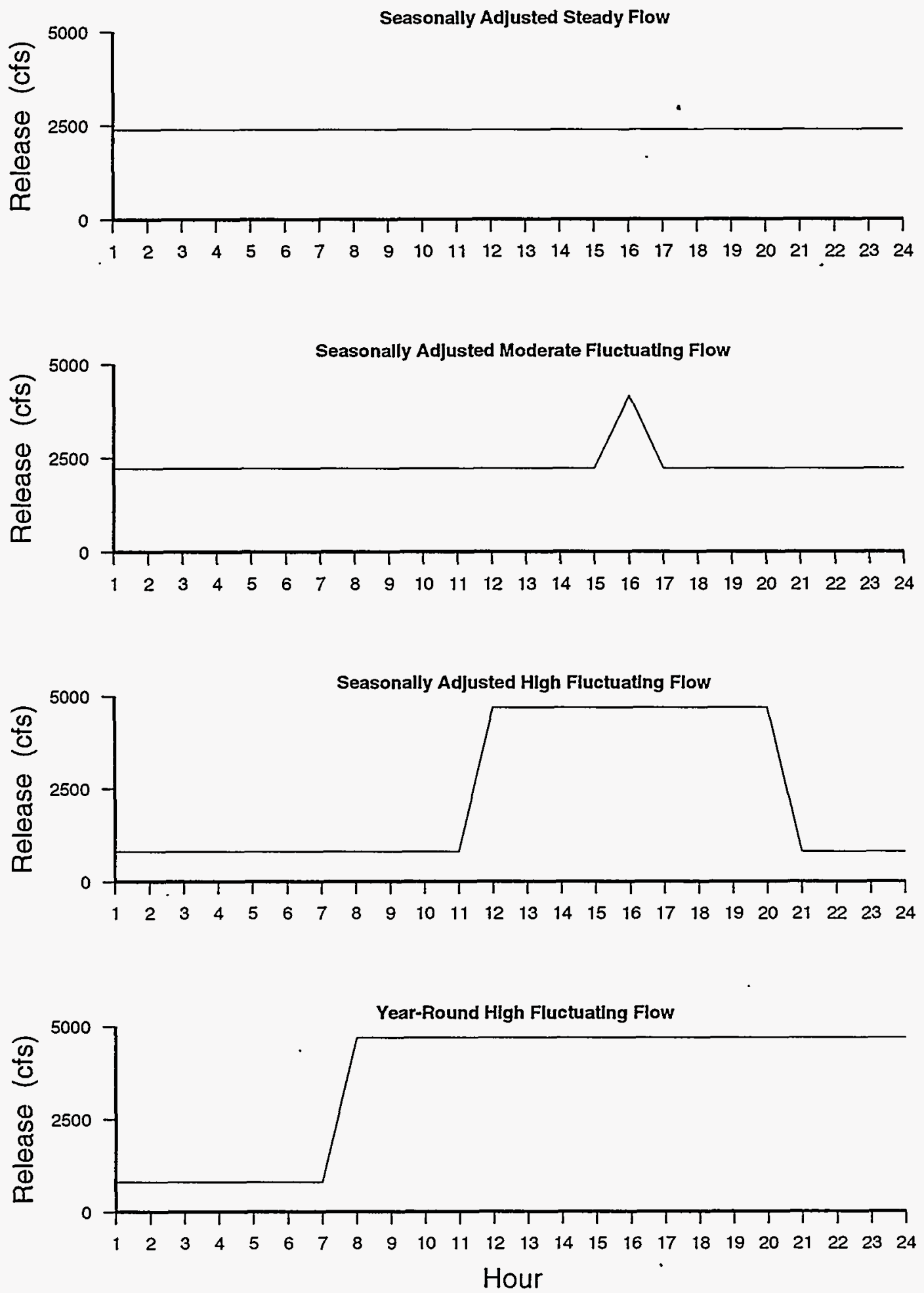

FIGURE B.2 Hourly Release Patterns under the Four Hydropower Operational Scenarios for November, Moderate Water Year 

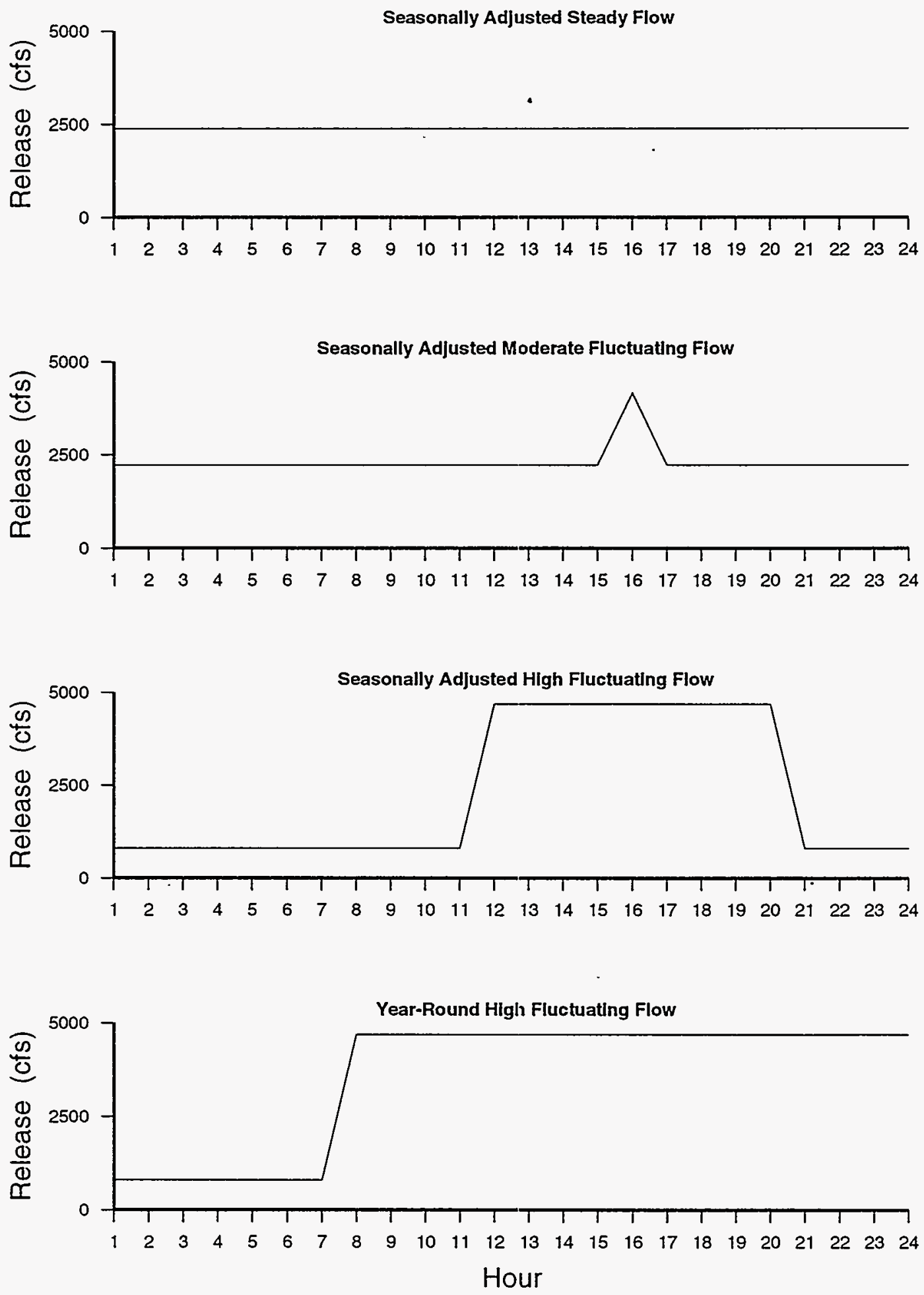

FIGURE B.3 Hourly Release Patterns under the Four Hydropower Operational Scenarios for December, Moderate Water Year 

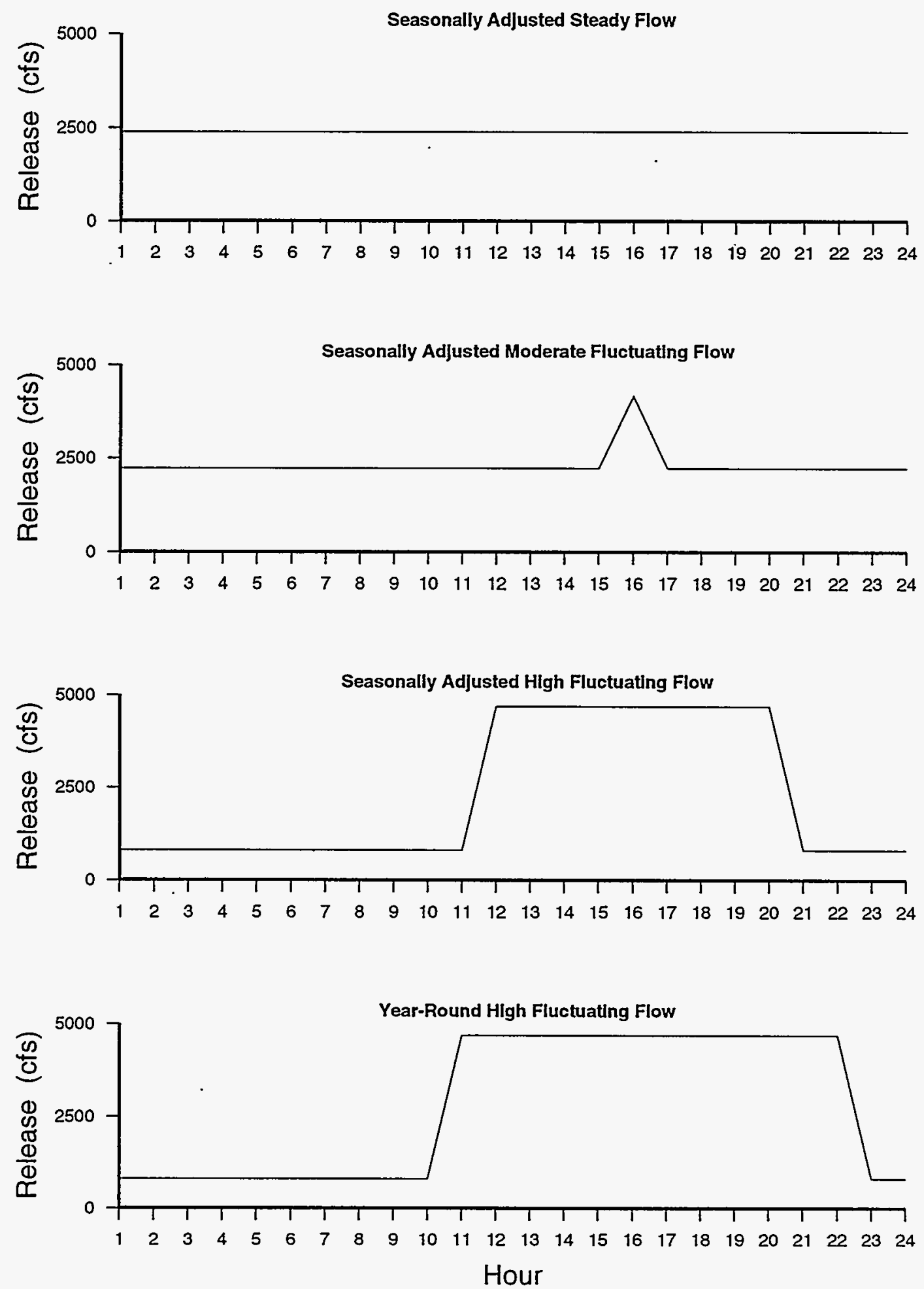

FIGURE B.4 Hourly Release Patterns under the Four Hydropower Operational Scenarios for January, Moderate Water Year 

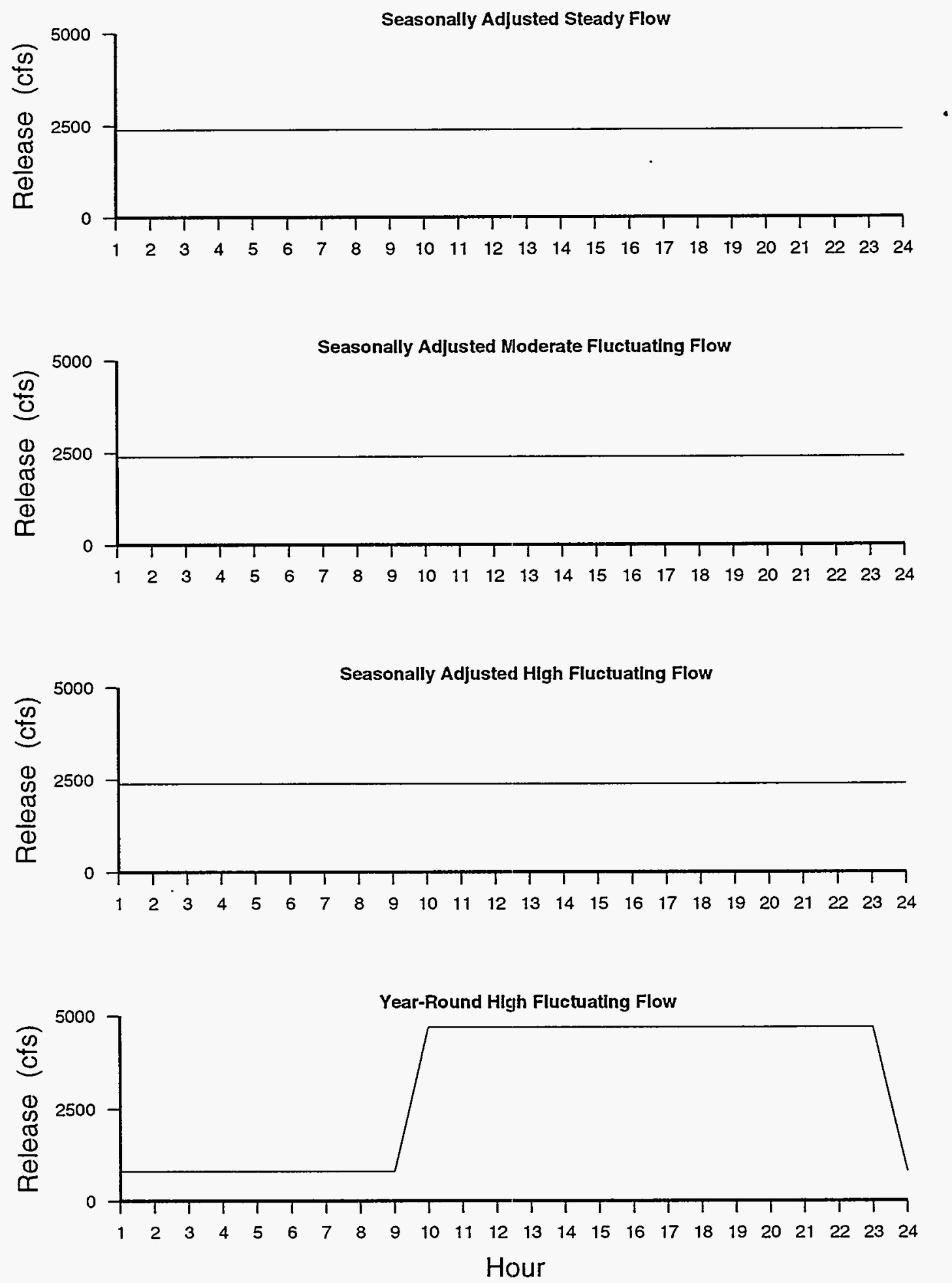

FTGURE B.5 Hourly Release Patterns under the Four Hydropower Operational Scenarios for February, Moderate Water Year 

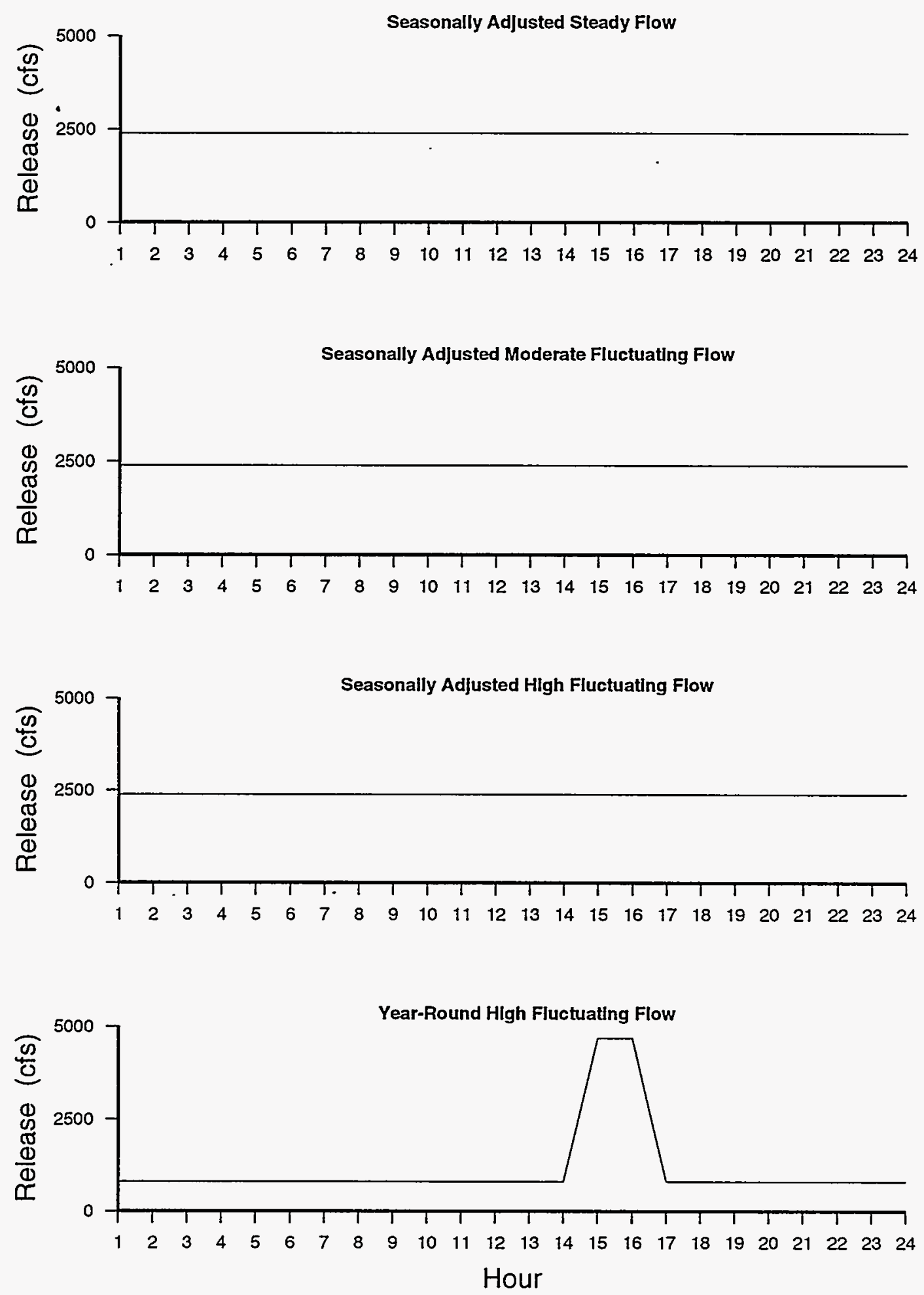

FIGURE B.6 Hourly Release Patterns under the Four Hydropower Operational Scenarios for March, Moderate Water Year 

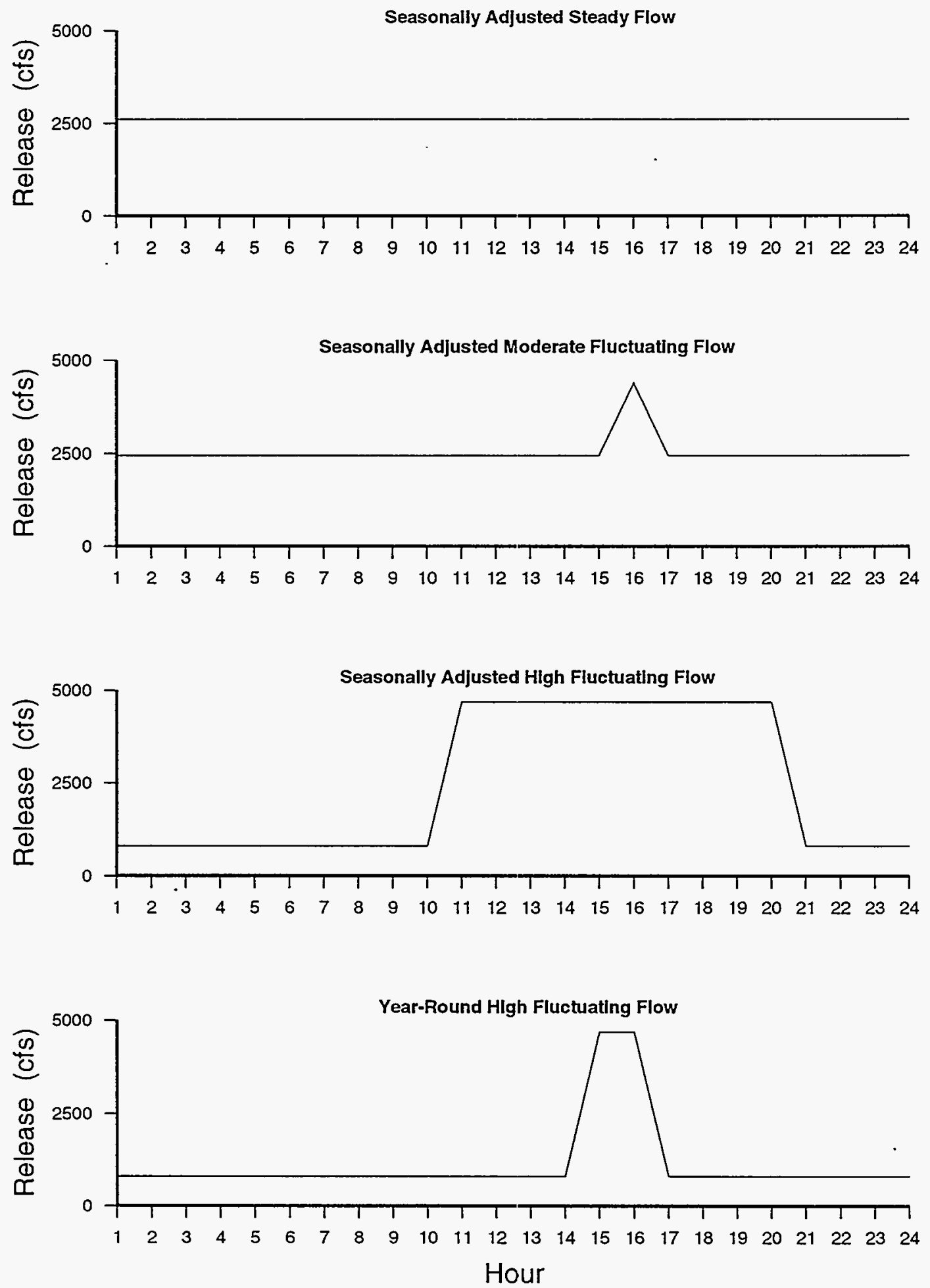

FIGURE B.7 Hourly Release Patterns under the Four Hydropower Operational Scenarios for April, Moderatie Water Year 

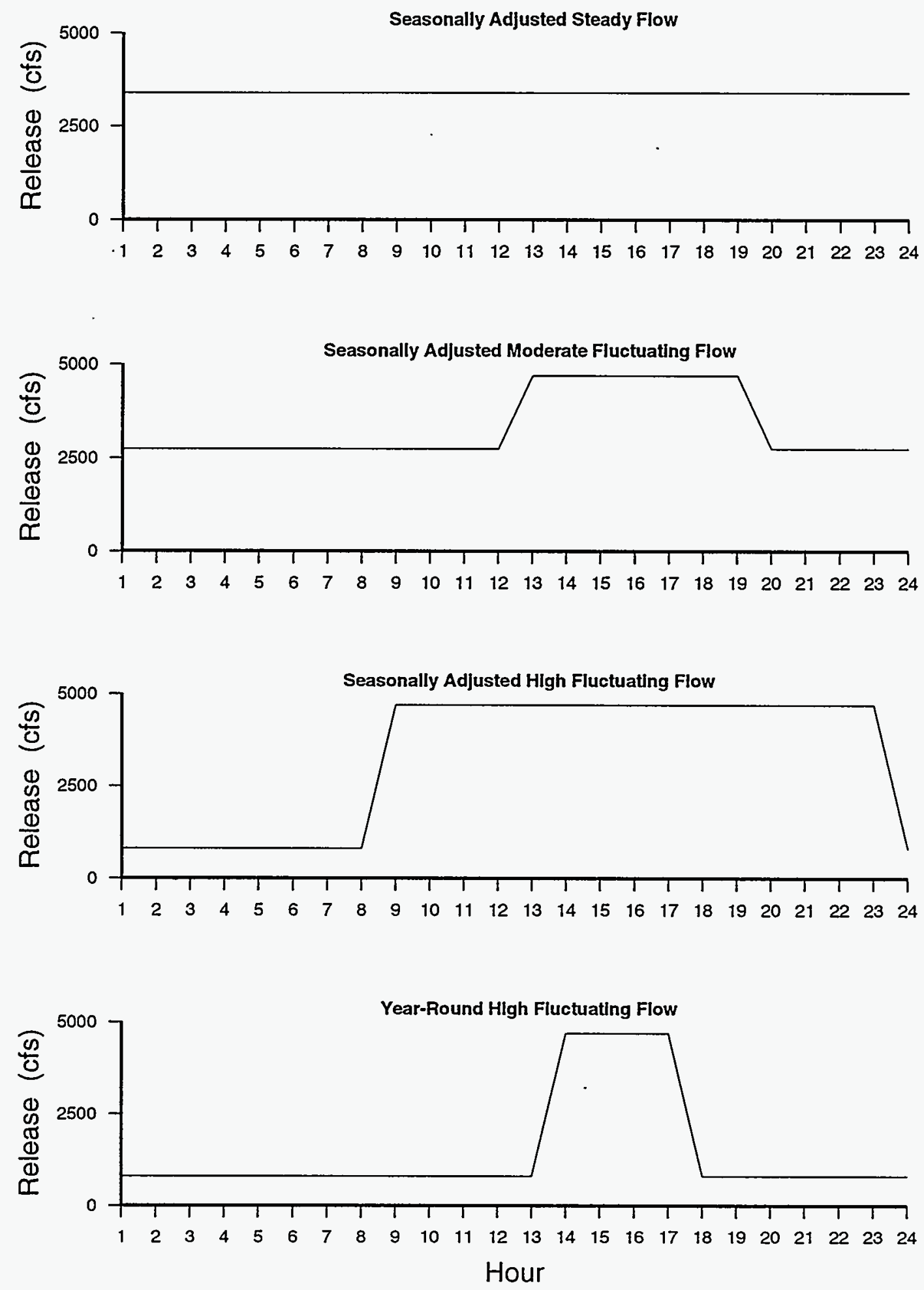

FIGURE B.8 Hourly Release Patterns under the Four Hydropower Operational Scenarios for May, Moderate Water Year 

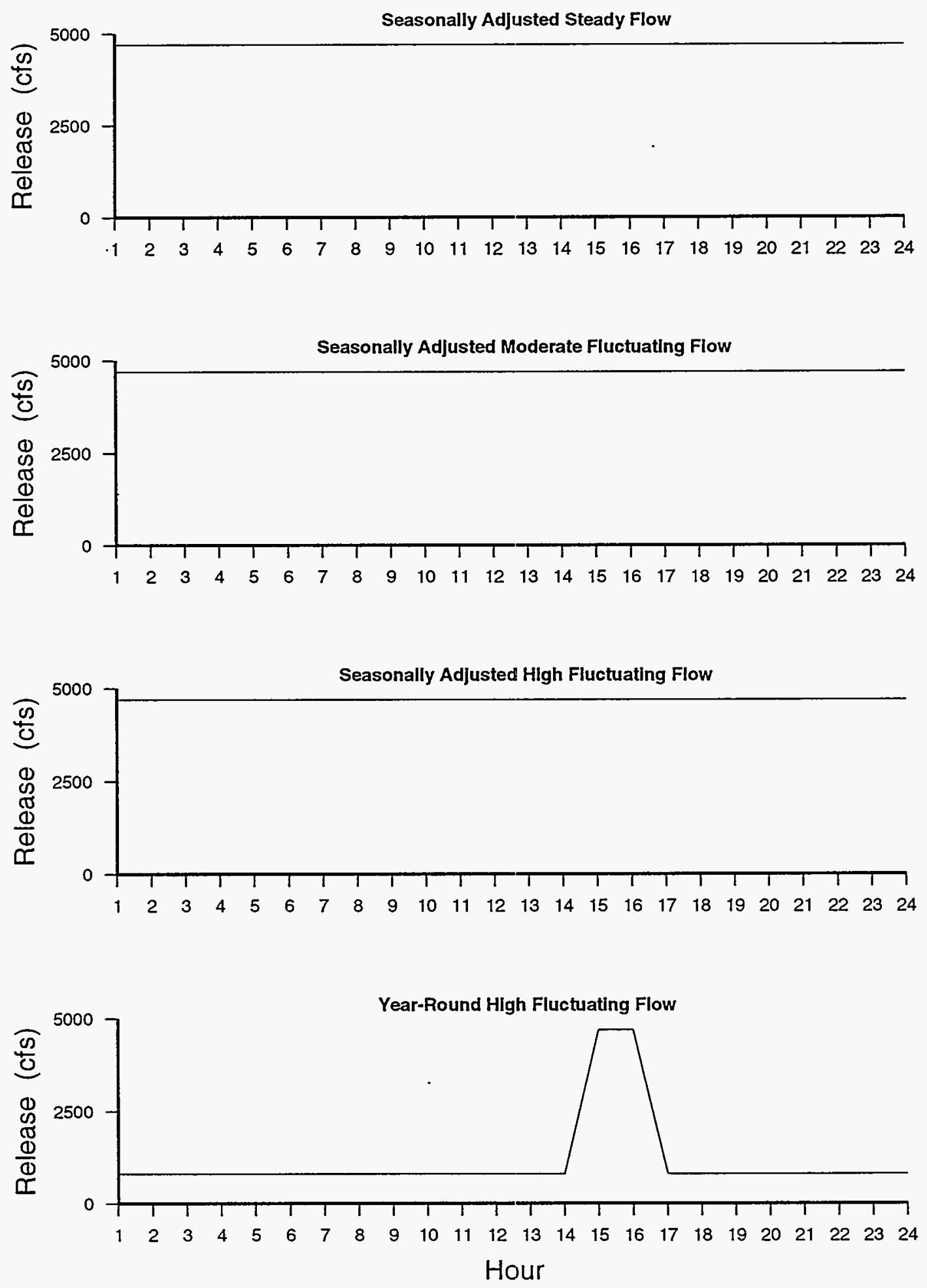

FIGURE B.9 Hourly Release Patterns under the Four Hydropower Operational Scenarios for June 1 - June 21, Moderate Water Year 

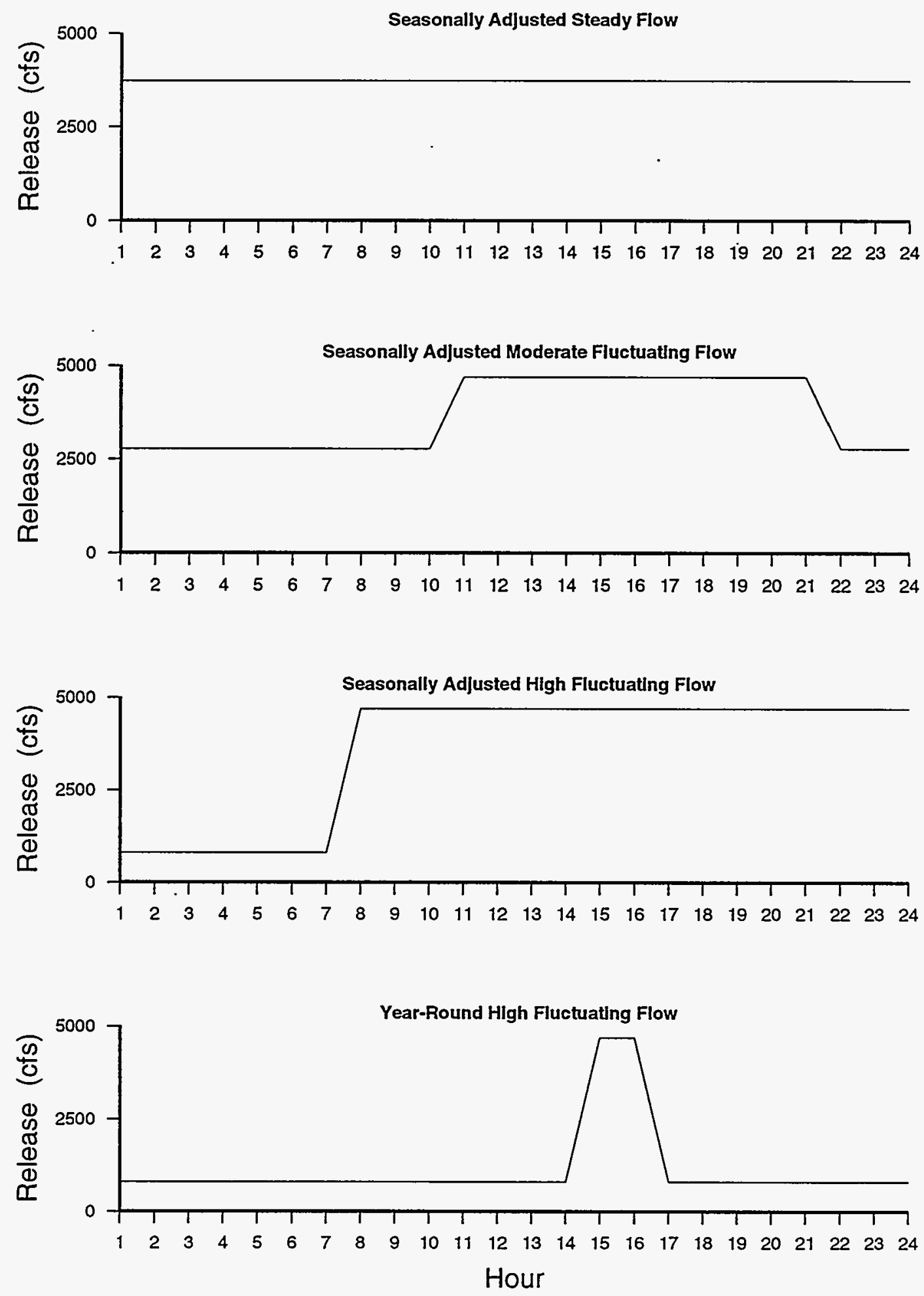

FIGURE B.10 Hourly Release Patterns under the Four Hydropower Operational Scenarios for June 22 - June 30, Moderate Water Year 

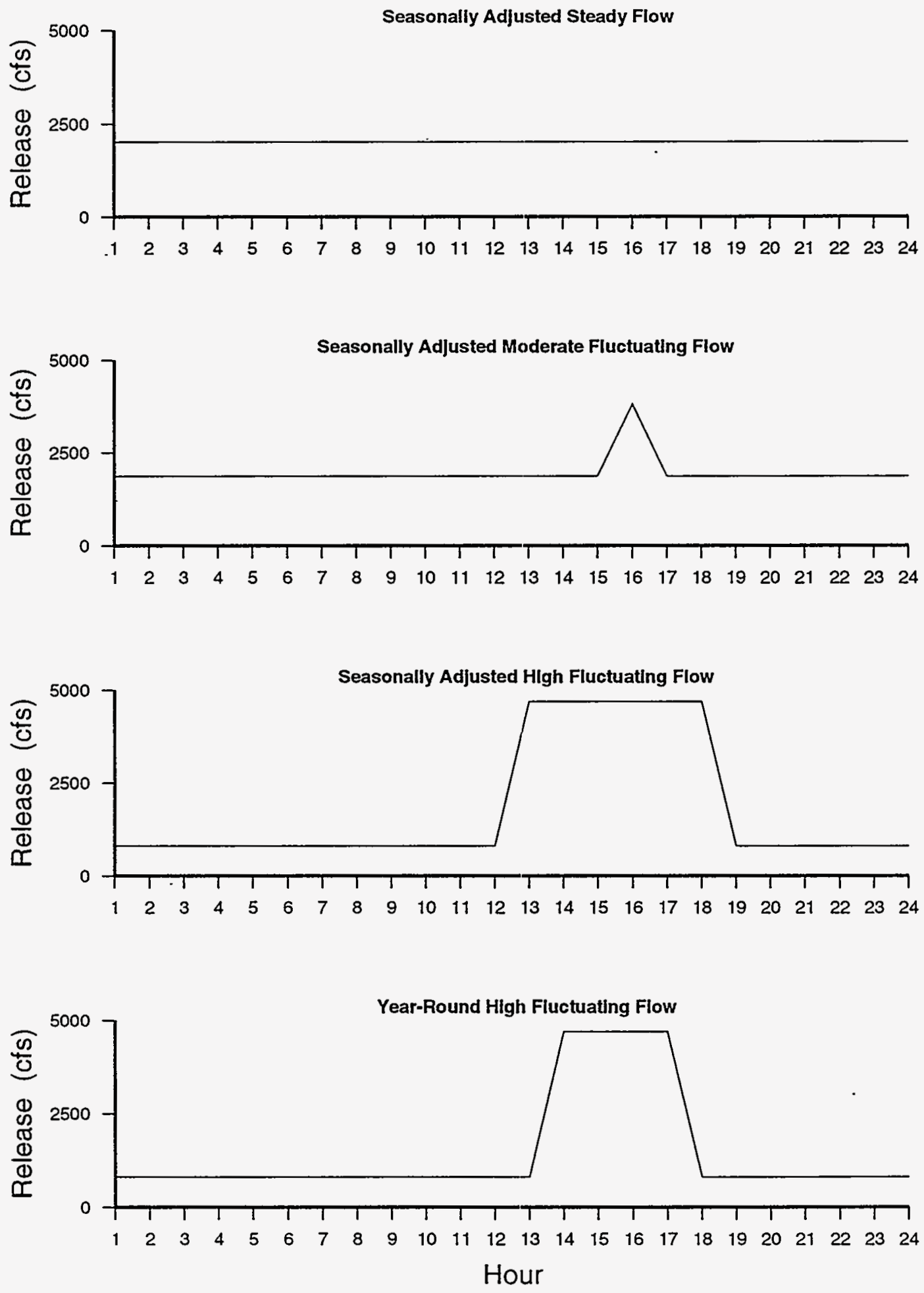

FIGURE B.11 Hourly Release Patterns under the Four Hydropower Operational Scenarios for July 1 - July 9, Moderate Water Year 

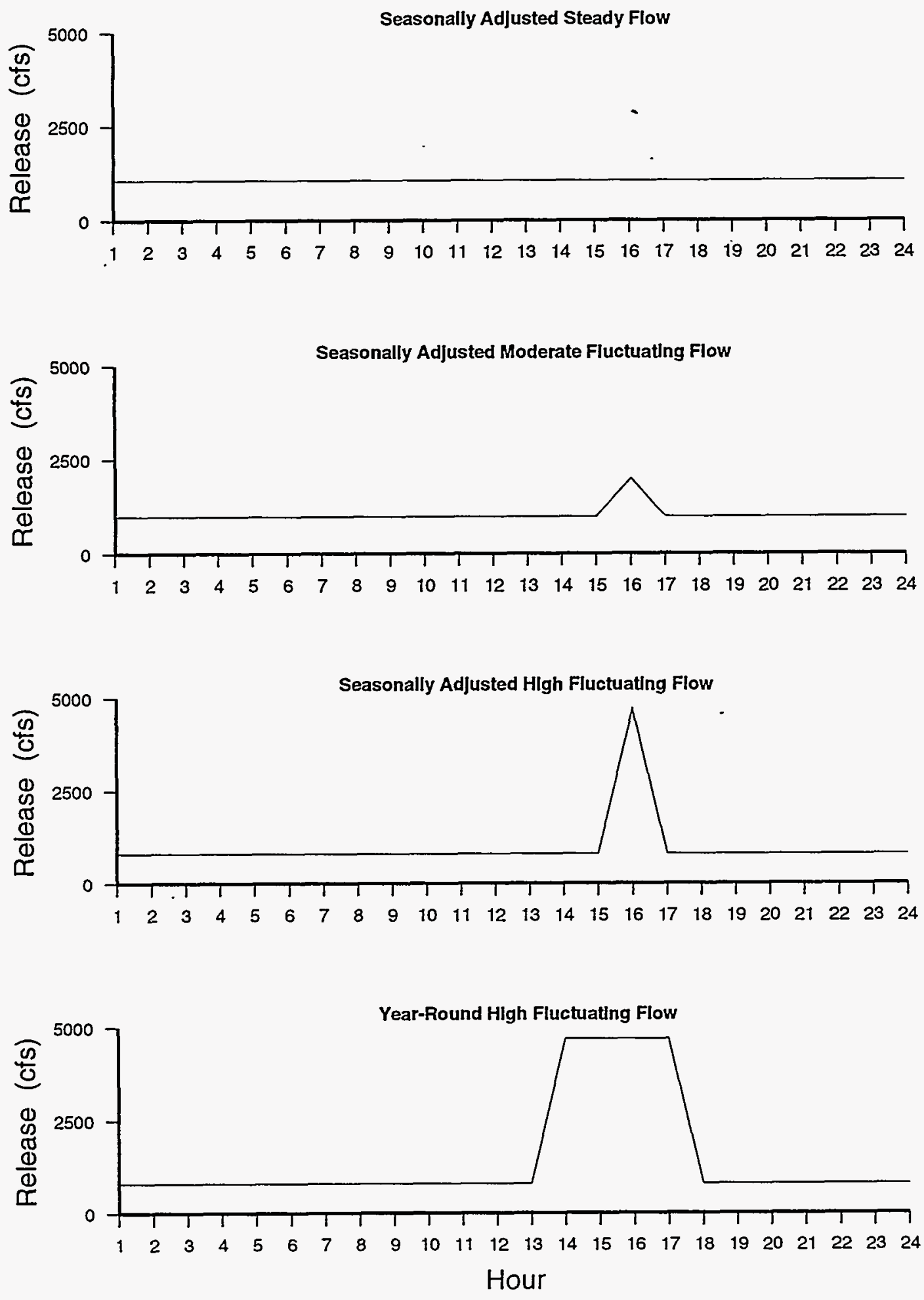

FIGURE B.12 Hourly Release Patterns under the Four Hydropower Operational Scenarios for July 10 - July 31, Moderate Water Year 

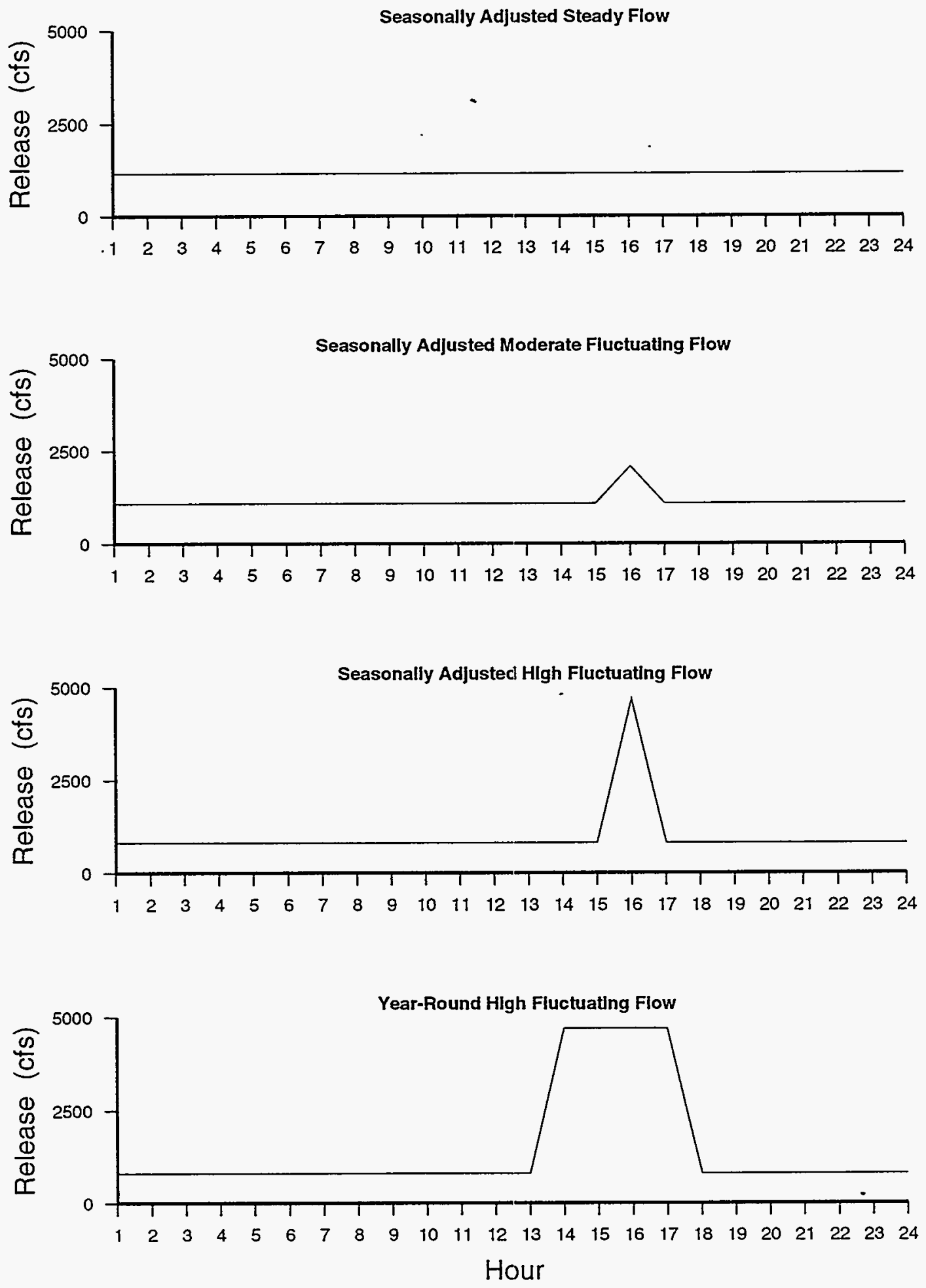

FIGURE B.13 Hourly Release Patterns under the Four Hydropower Operational Scenarios for August, Moderate Water Year 

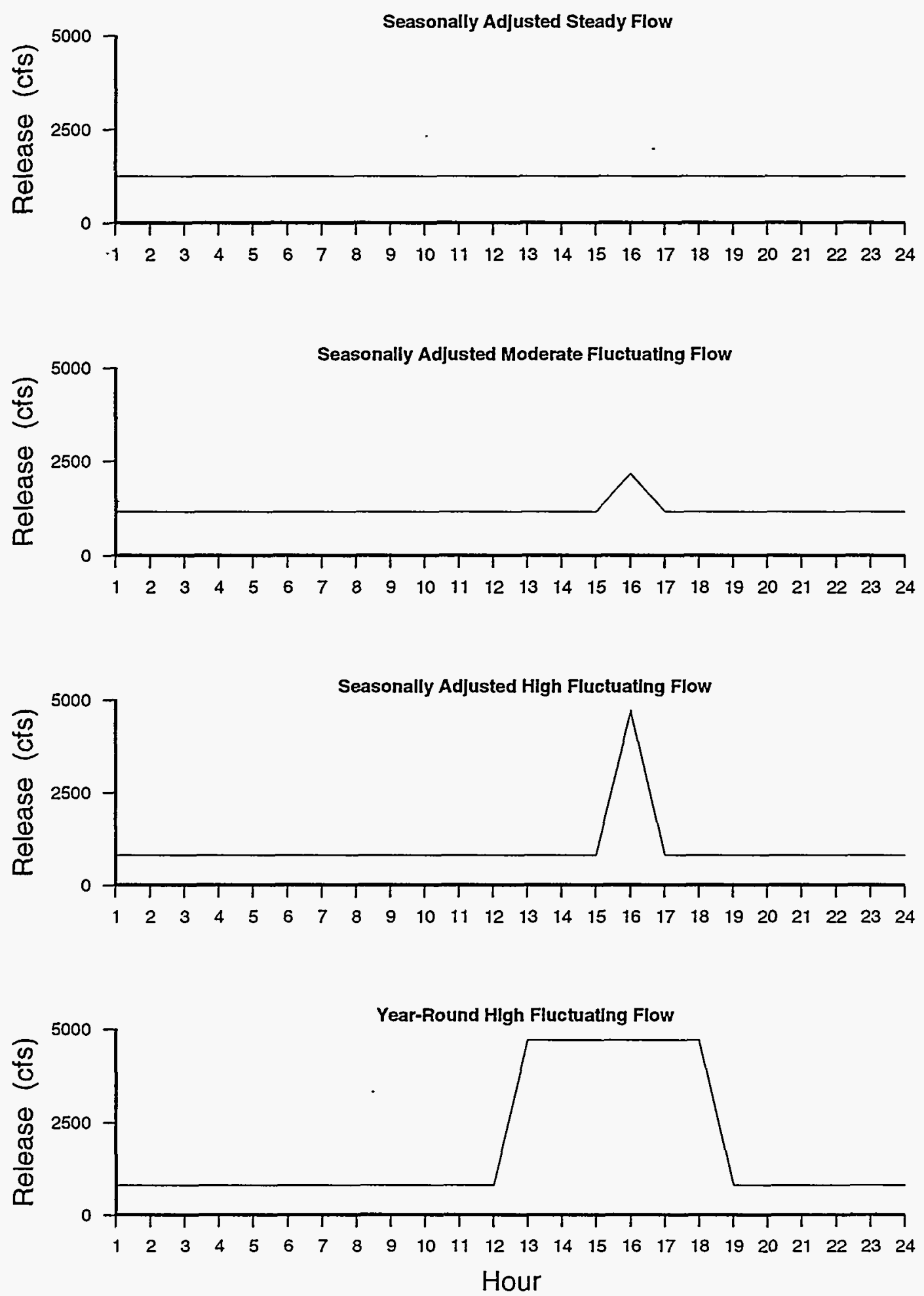

FTGURE B.14 Hourly Release Patterns under the Four Hydropower Operational Scenarios for September, Moderate Water Year 

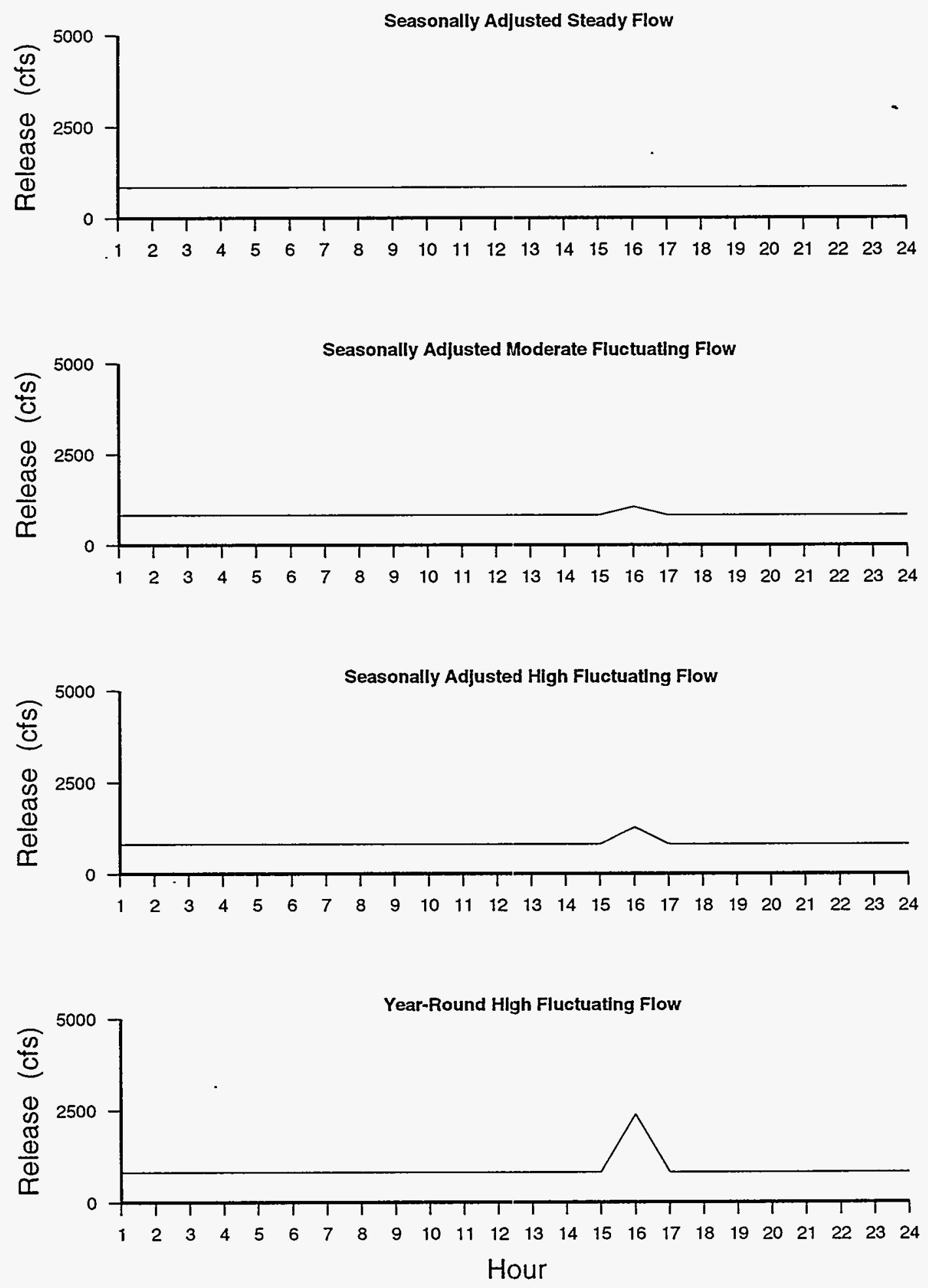

FIGURE B.15 Hourly Release Patterns under the Four Hydropower Operational Scenarios for October, Dry Water Year 

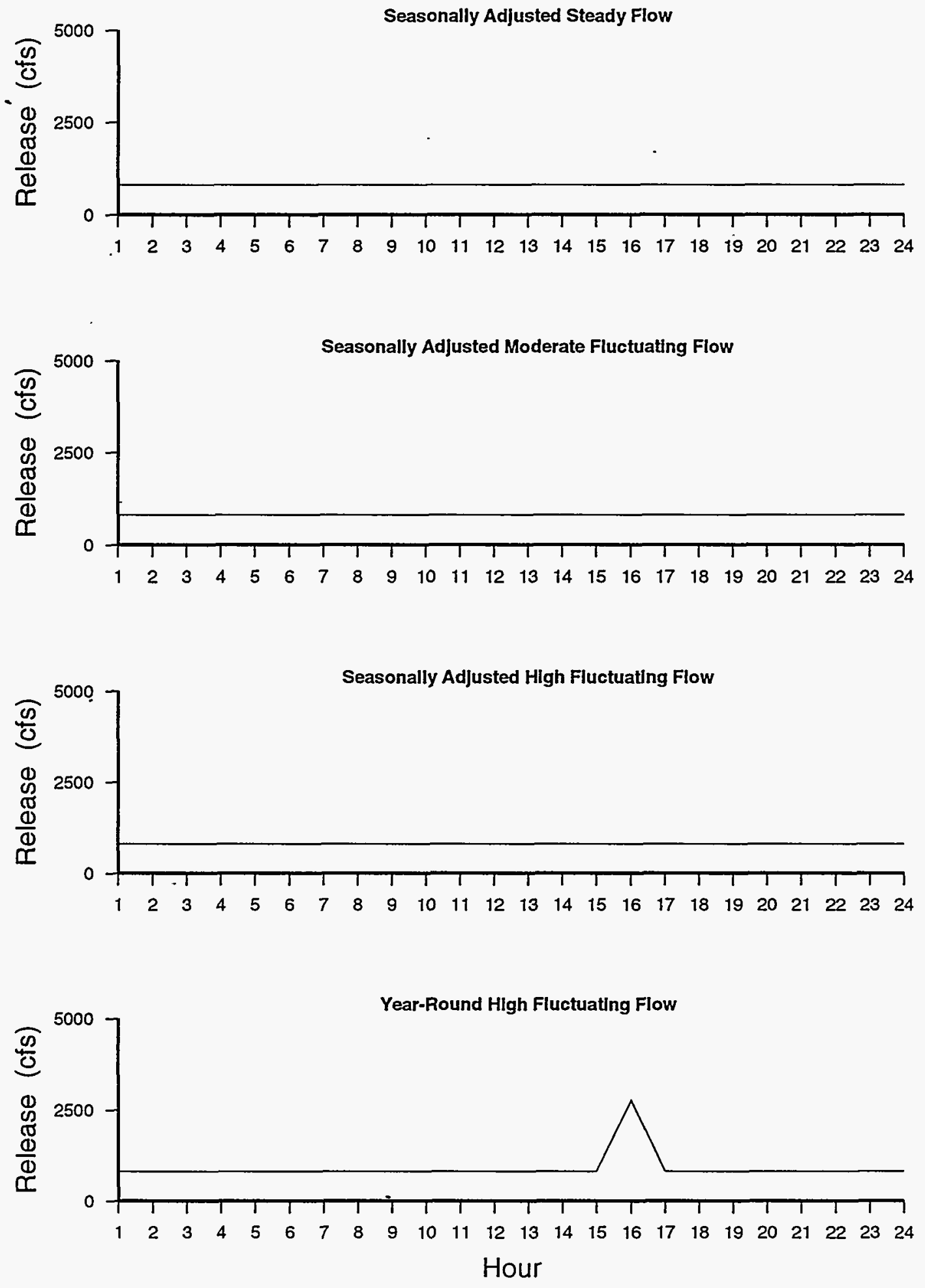

FIGURE B.16 Hourly Release Patterns under the Four Hydropower Operational Scenarios for November, Dry Water Year 

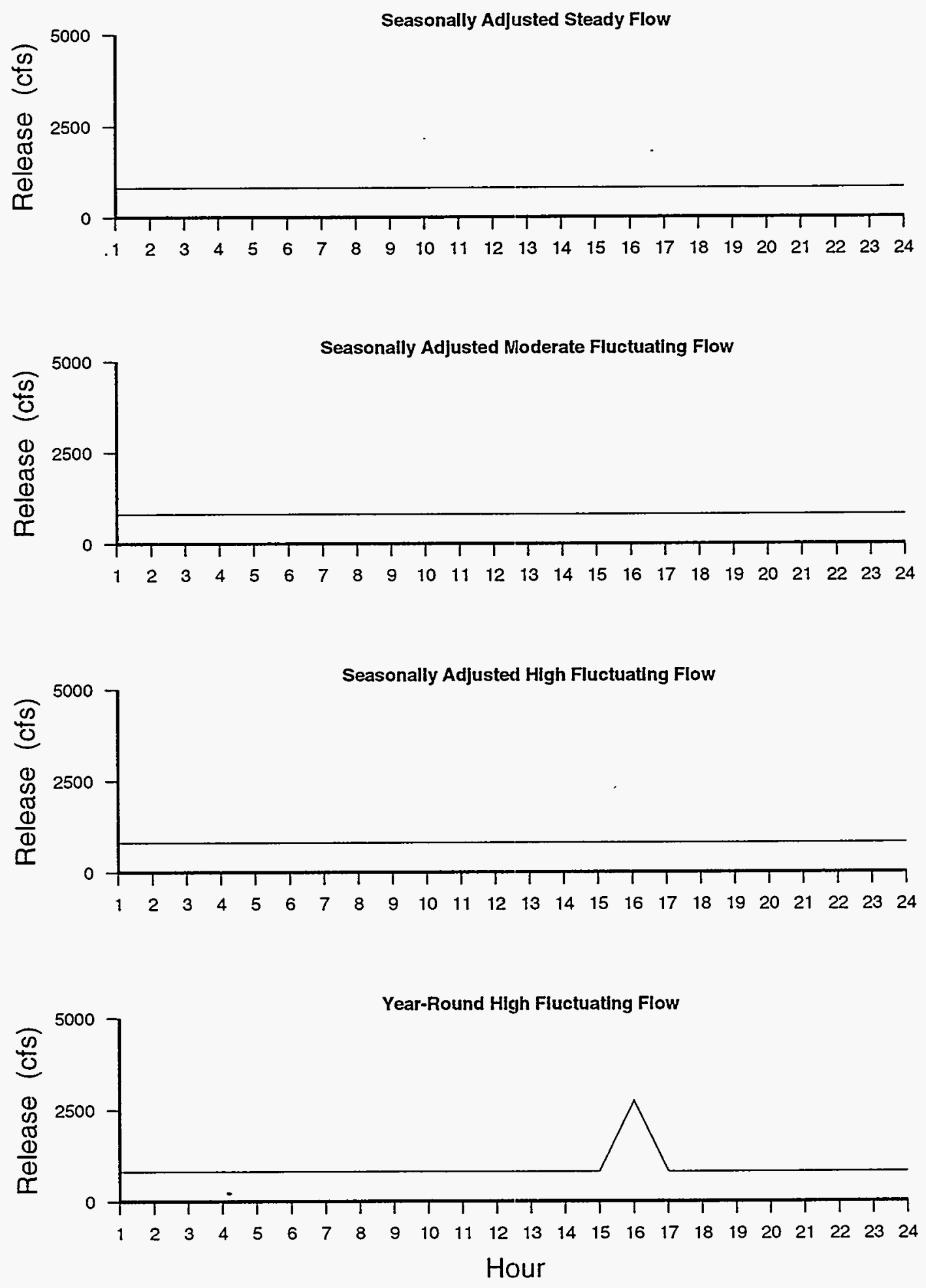

FIGURE B.17 Hourly Release Patterns under the Four Hydropower Operational Scenarios for December, Dry Water Year 

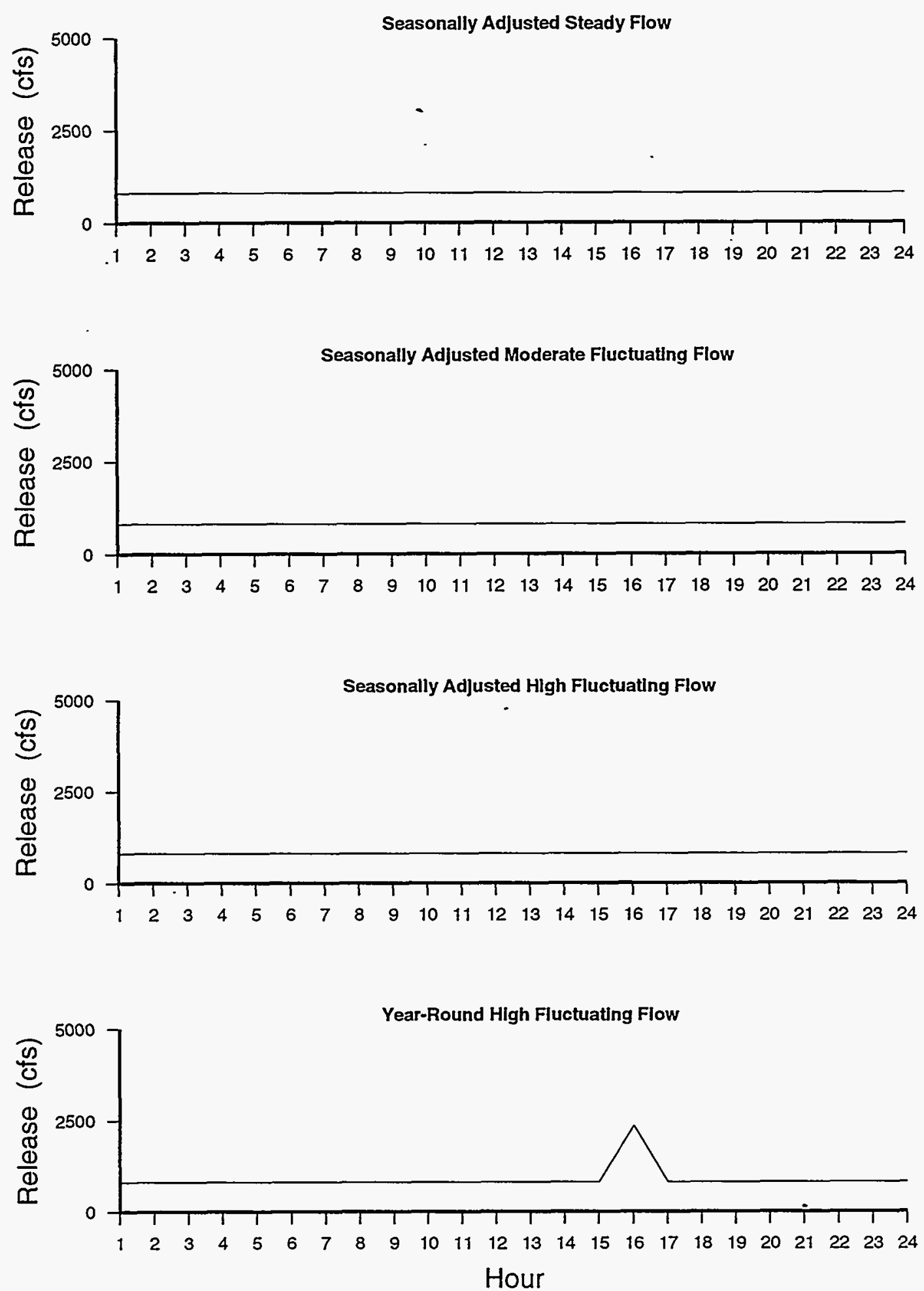

FIGURE B.18 Hourly Release Patterns under the Four Hydropower Operational Scenarios for January, Dry Water Year 

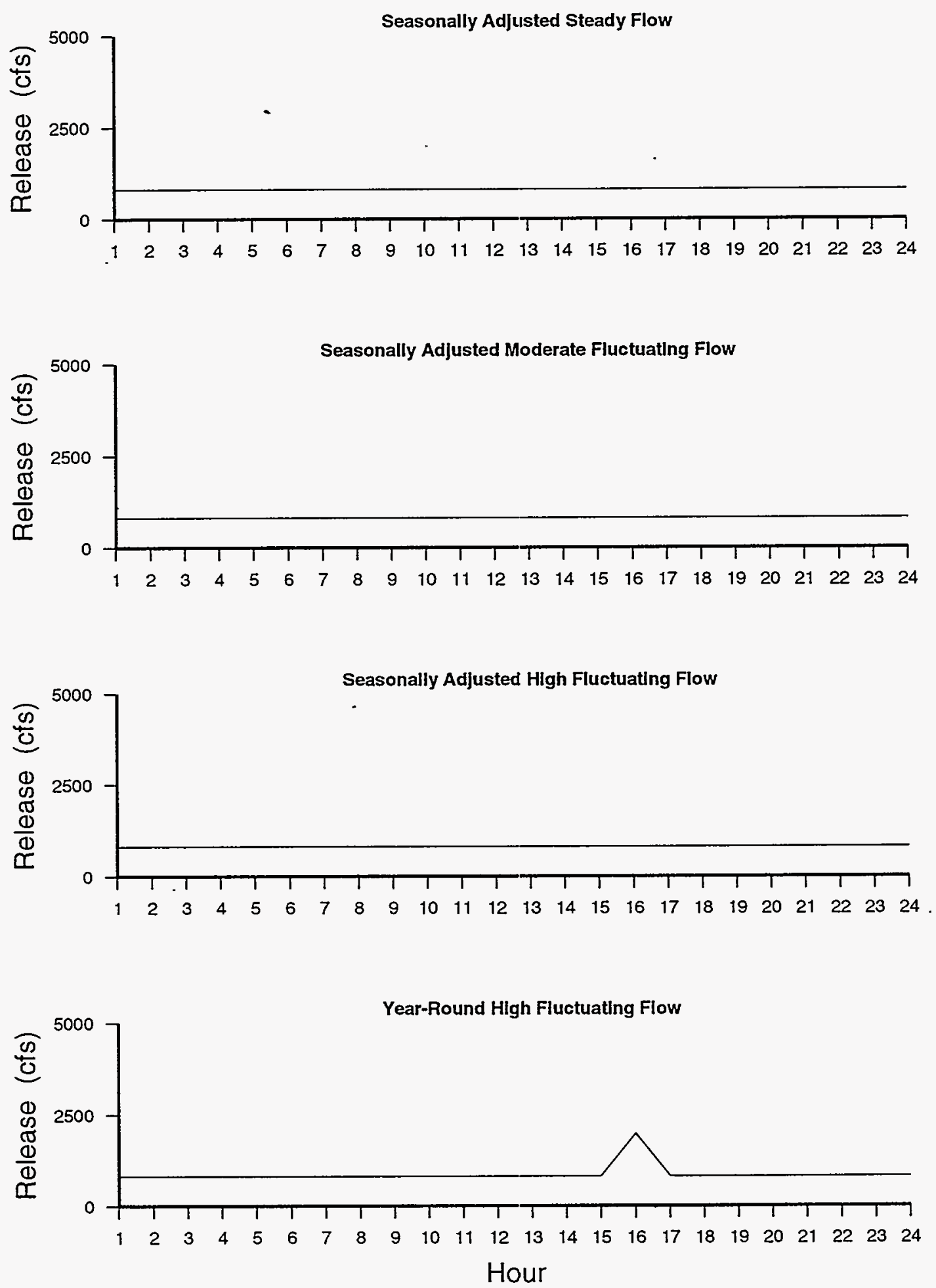

FIGURE B.19 Hourly Release Patterns under the Four Hydropower Operational Scenarios for February, Dry Water Year 

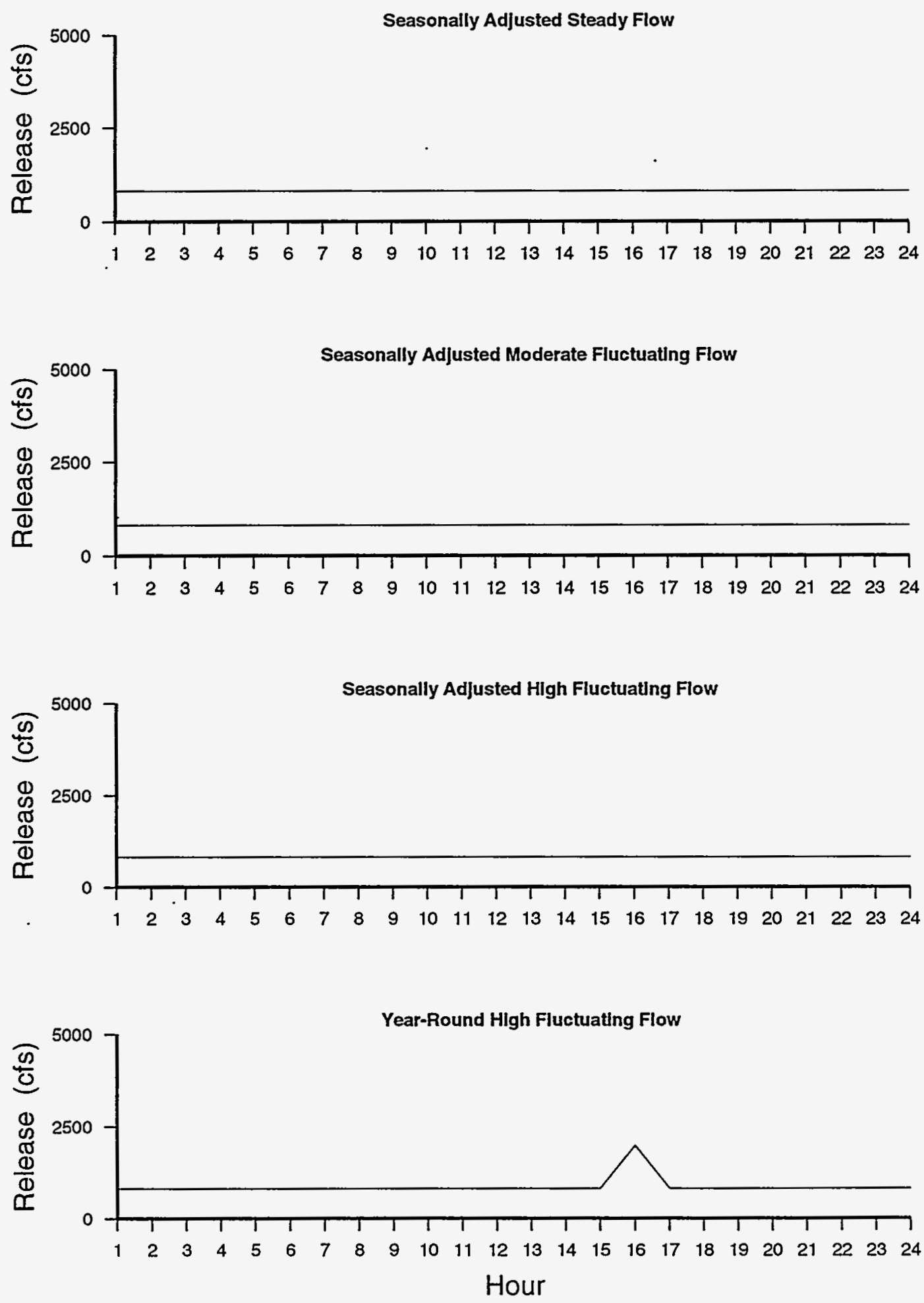

FIGURE B.20 Hourly Release Patterns under the Four Hydropower Operational Scenarios for March, Dry Water Year 

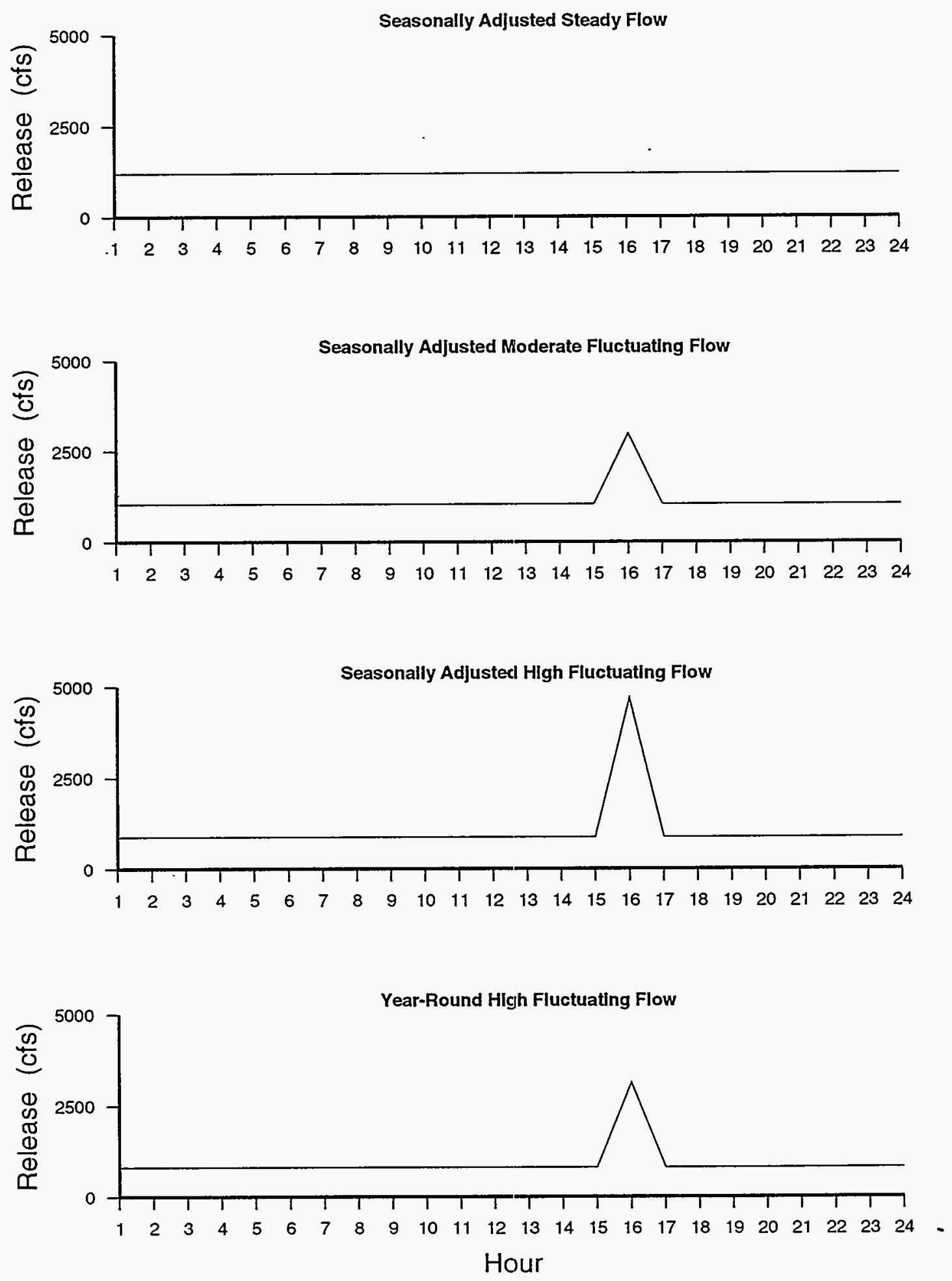

FIGURE B.21 Hourly Release Patterns under the Four Hydropower Operational Scenarios for April, Dry Water Year 

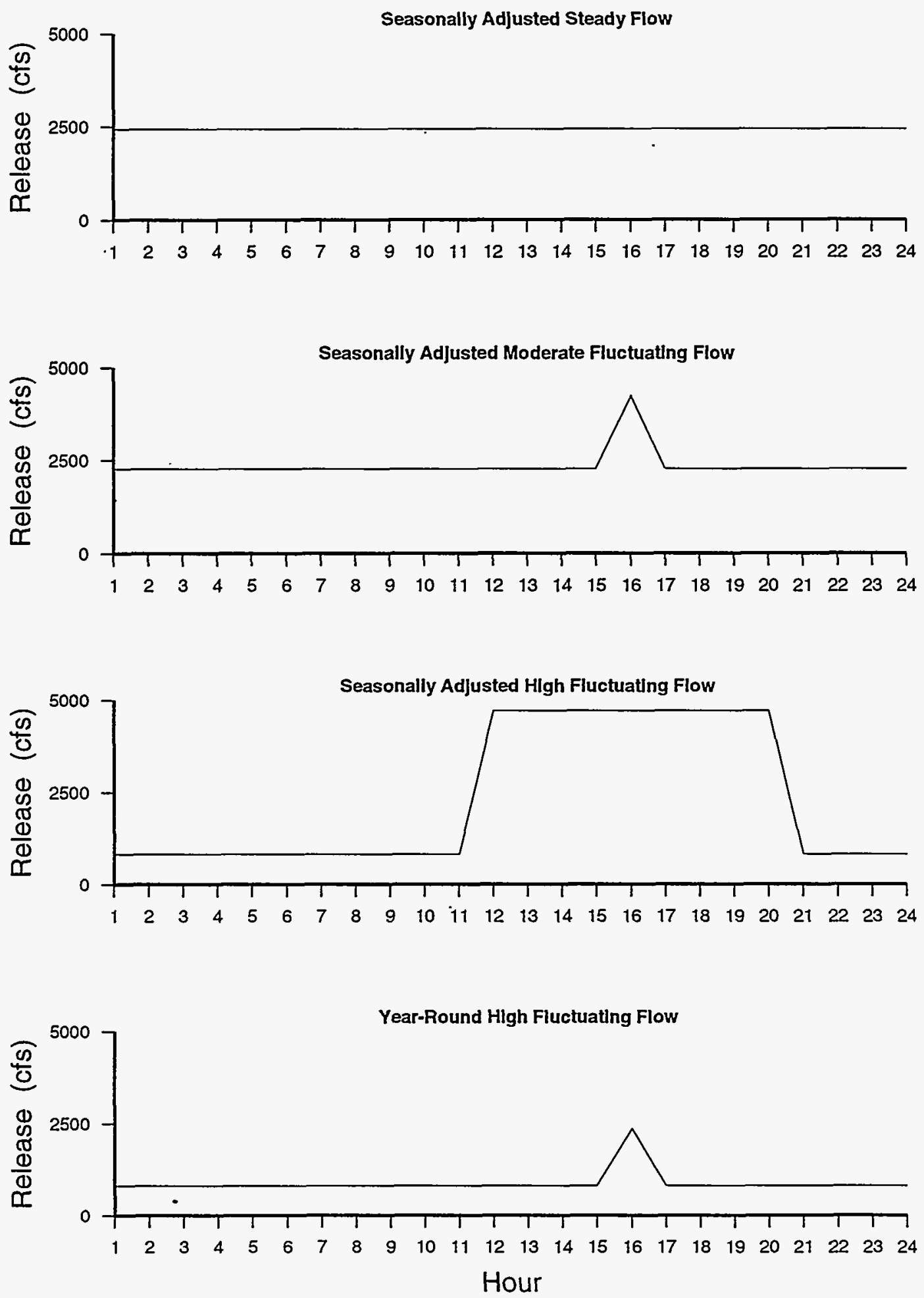

FIGURE B.22 Hourly Release Patterns under the Four Hydropower Operational Scenarios for May, Dry Water Year 

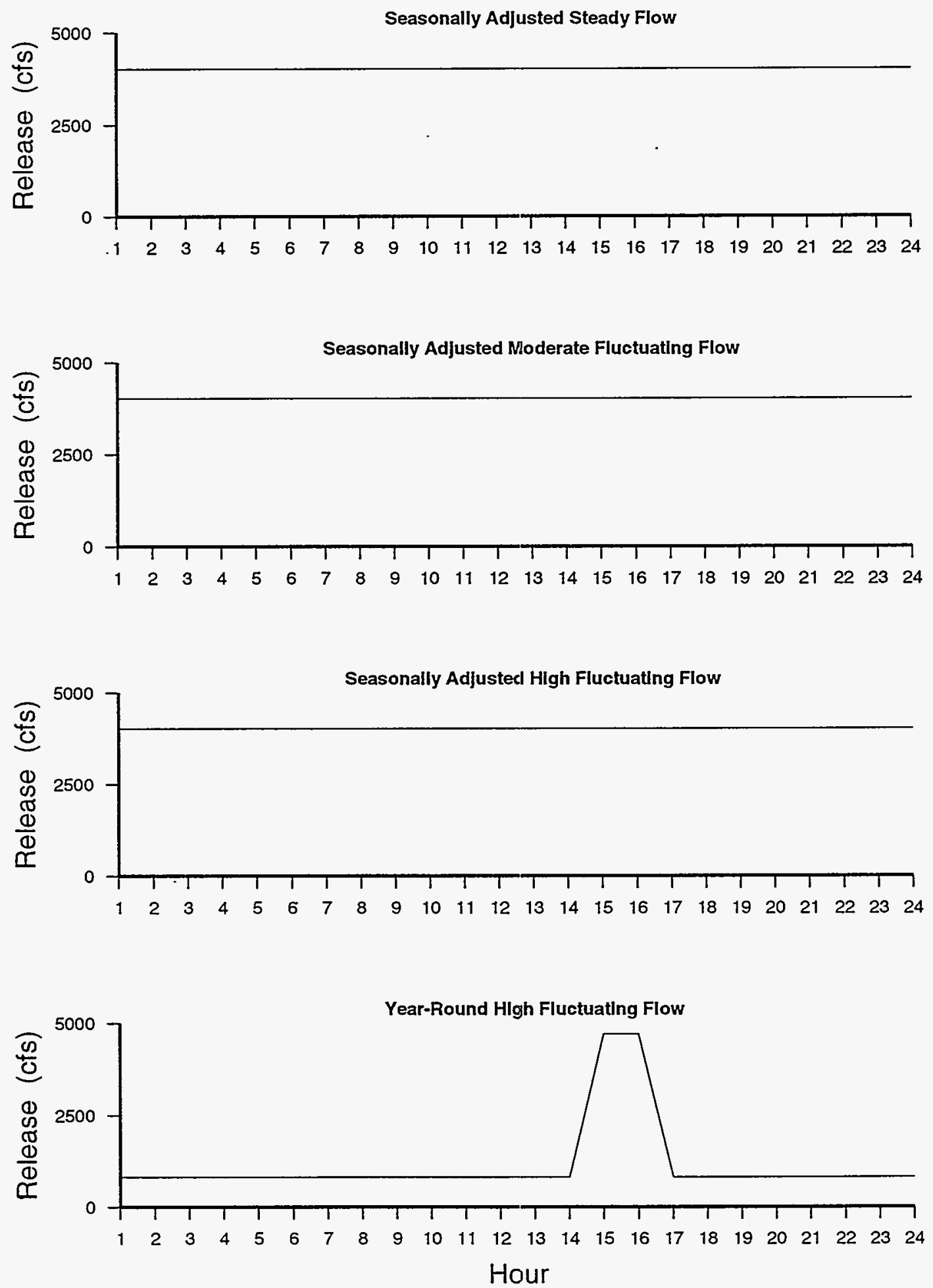

FIGURE B.23 Hourly Release Patterns under the Four Hydropower Operational Scenarios for June 1 - June 21, Dry Water Year 

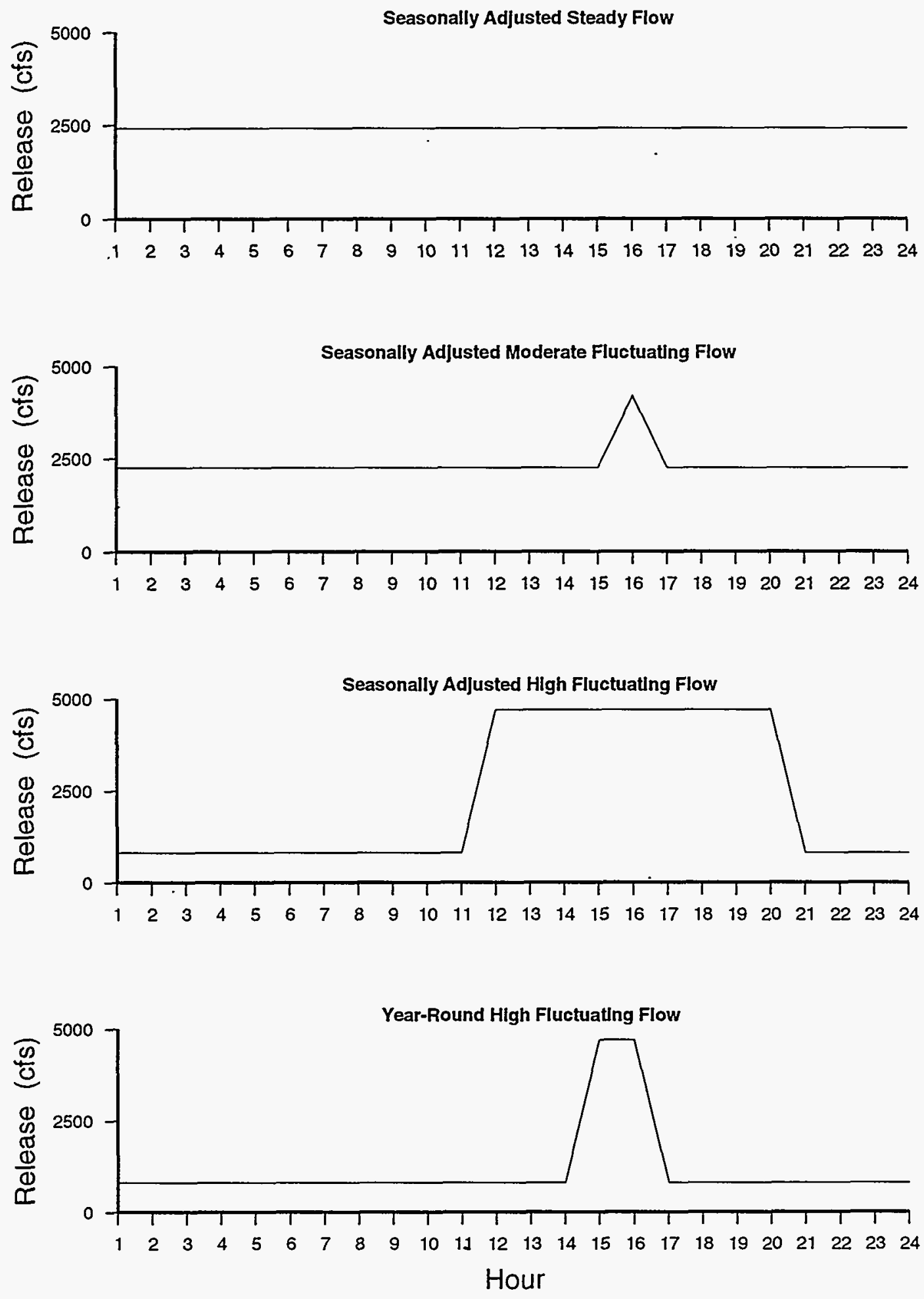

FIGURE B.24 Hourly Release Patterns under the Four Hydropower Operational Scenarios for June 22 - June 30, Dry Water Year 

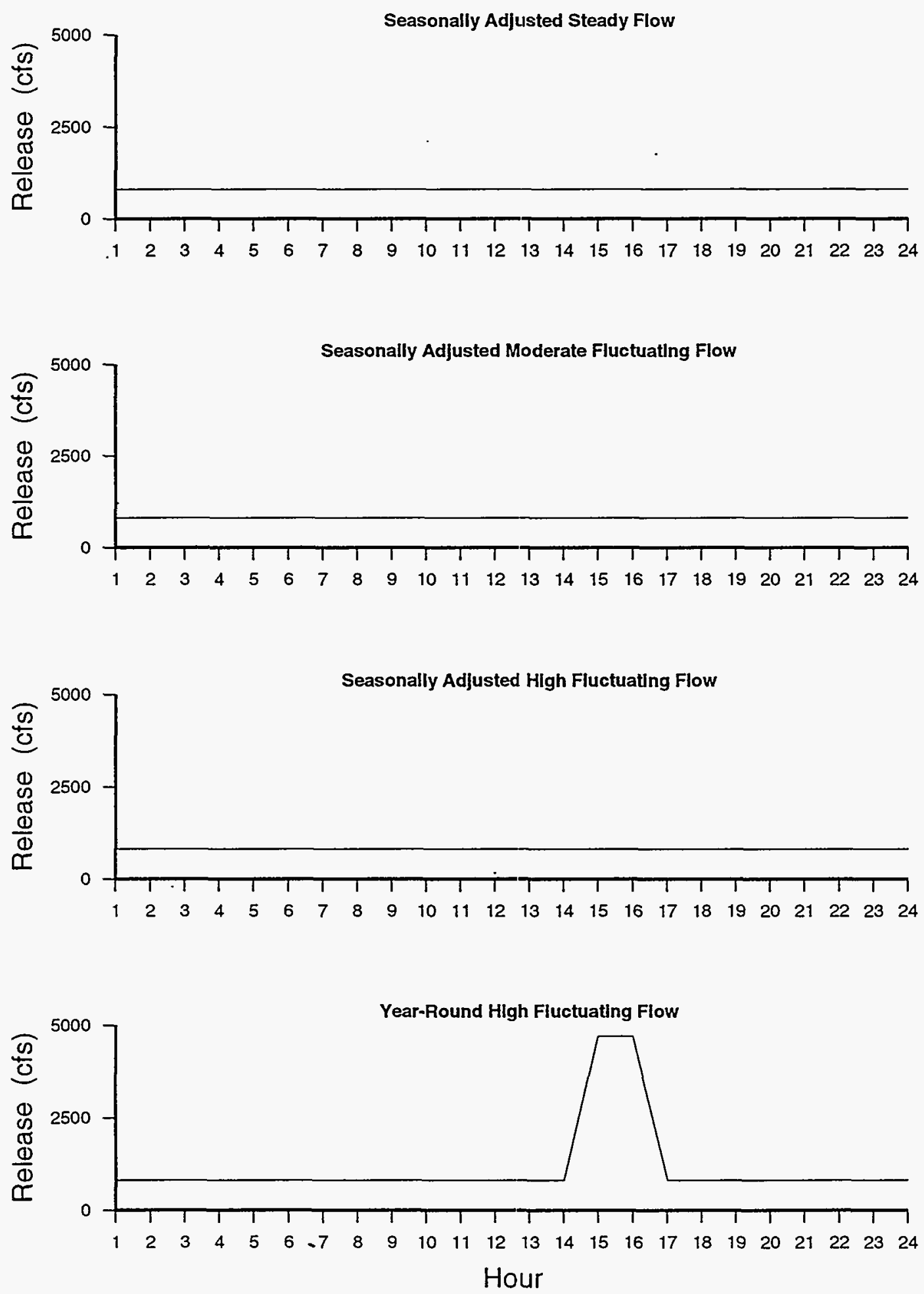

FIGURE B.25 Hourly Release Patterns under the Four Hydropower Operational Scenarios for July 1 - July 9, Dry Water Year 

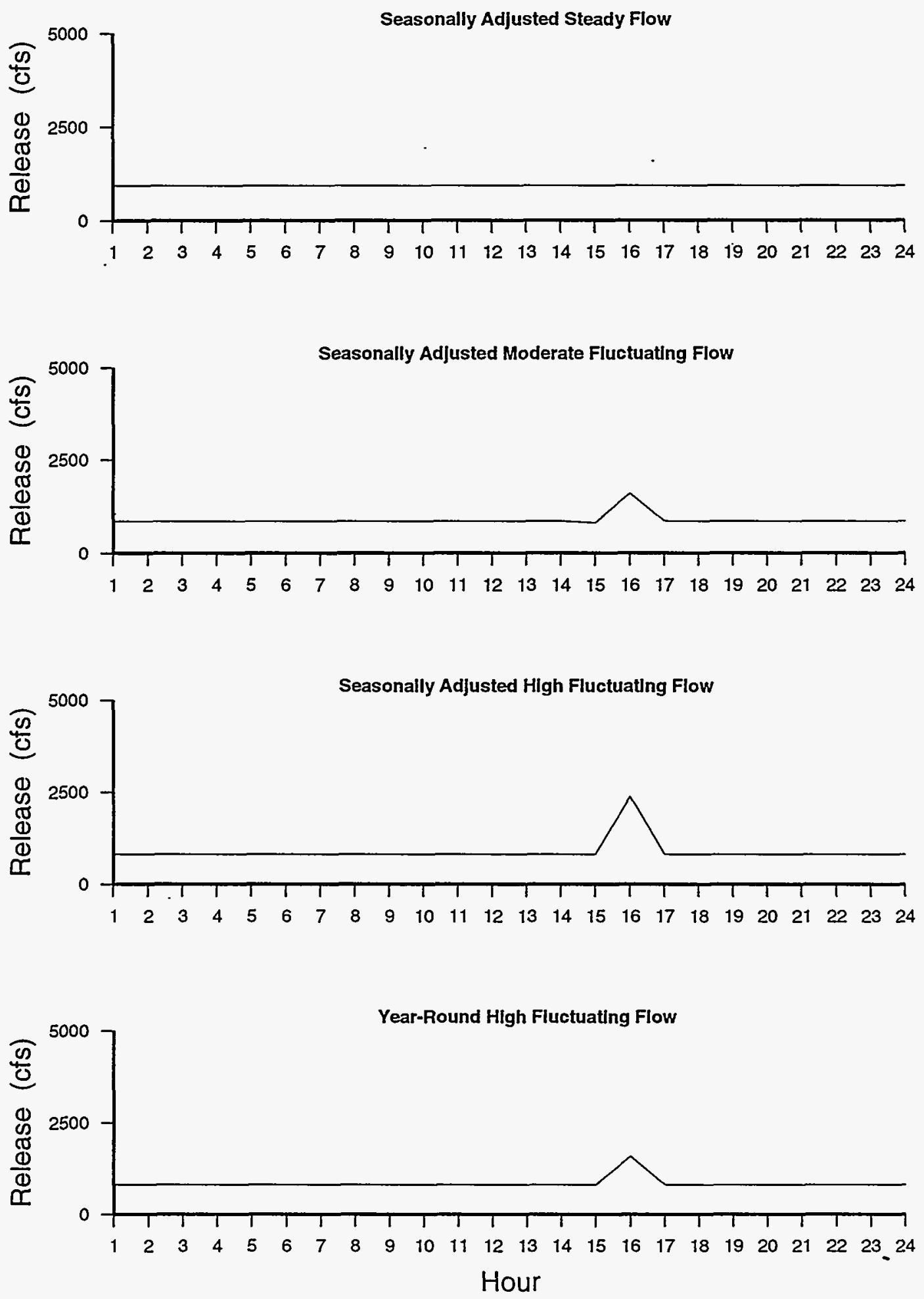

FIGURE B.26 Hourly Release Patterns under the Four Hydropower Operational Scenarios for July 10 - July 31, Dry Water Year 

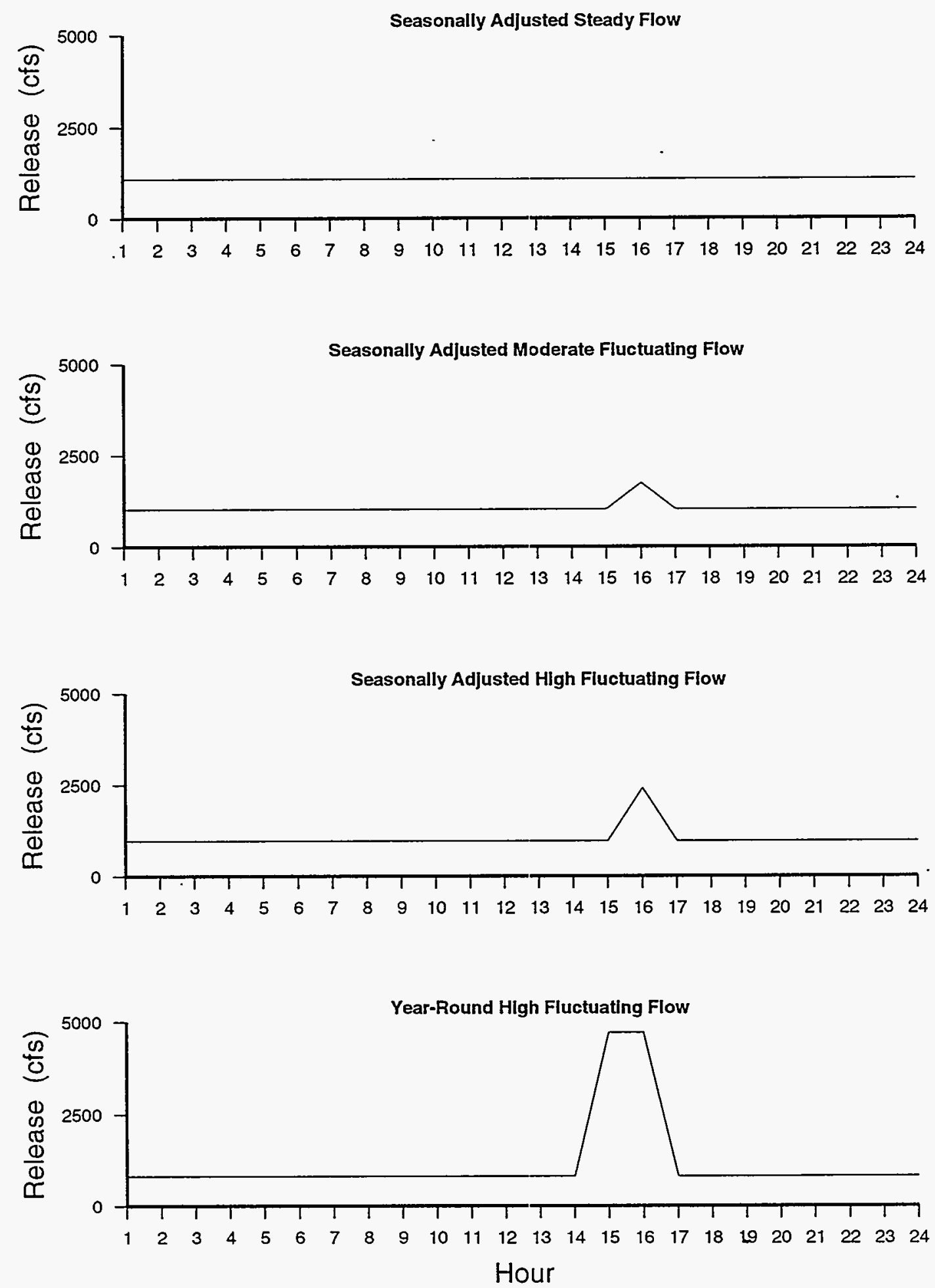

FIGURE B.27 Hourly Release Patterns under the Four Hydropower Operational Scenarios for August, Dry Water Year 

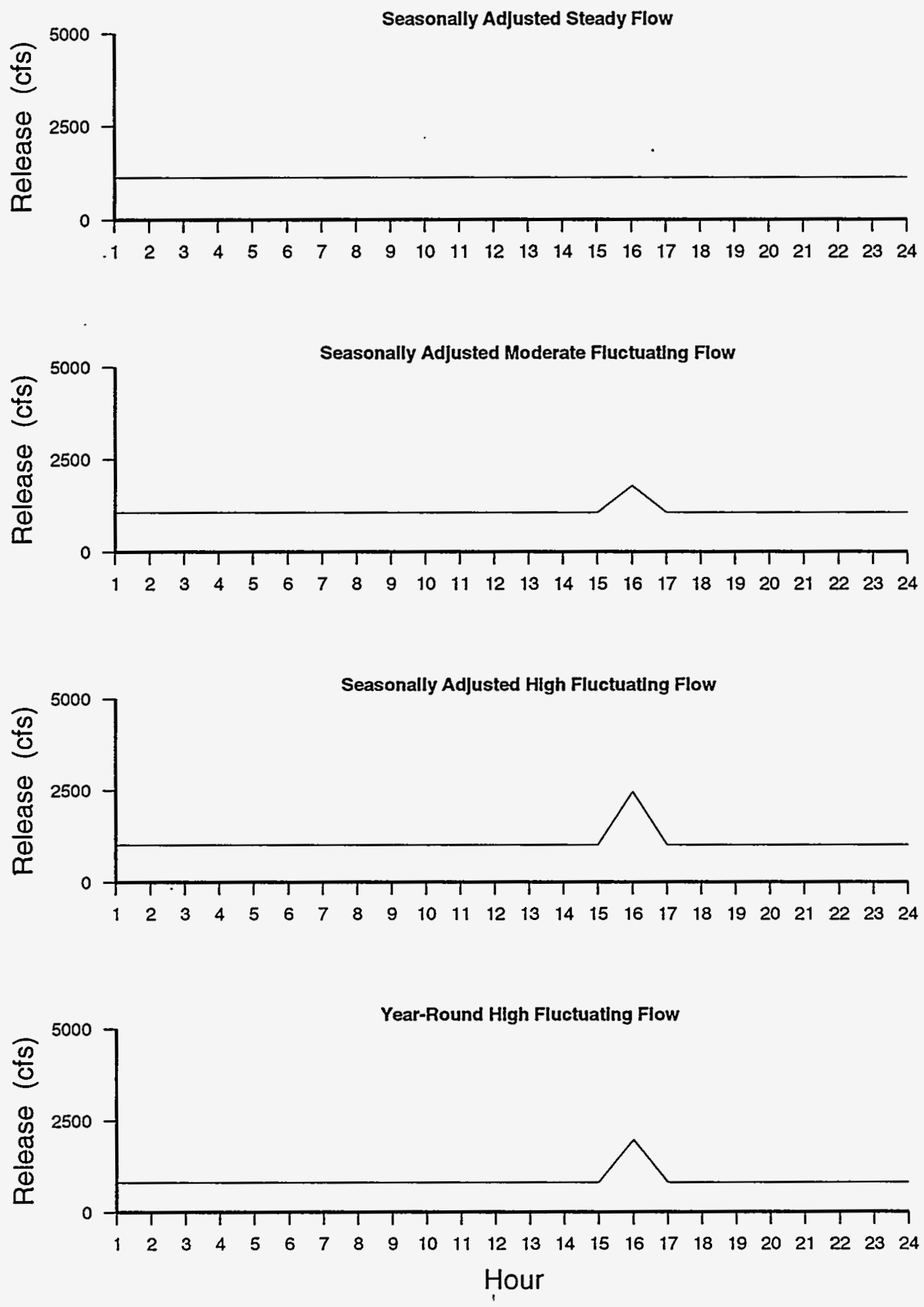

FIGURE B.28 Hourly Release Patterns under the Four Hydropower Operational Scenarios for September, Dry Water Year 

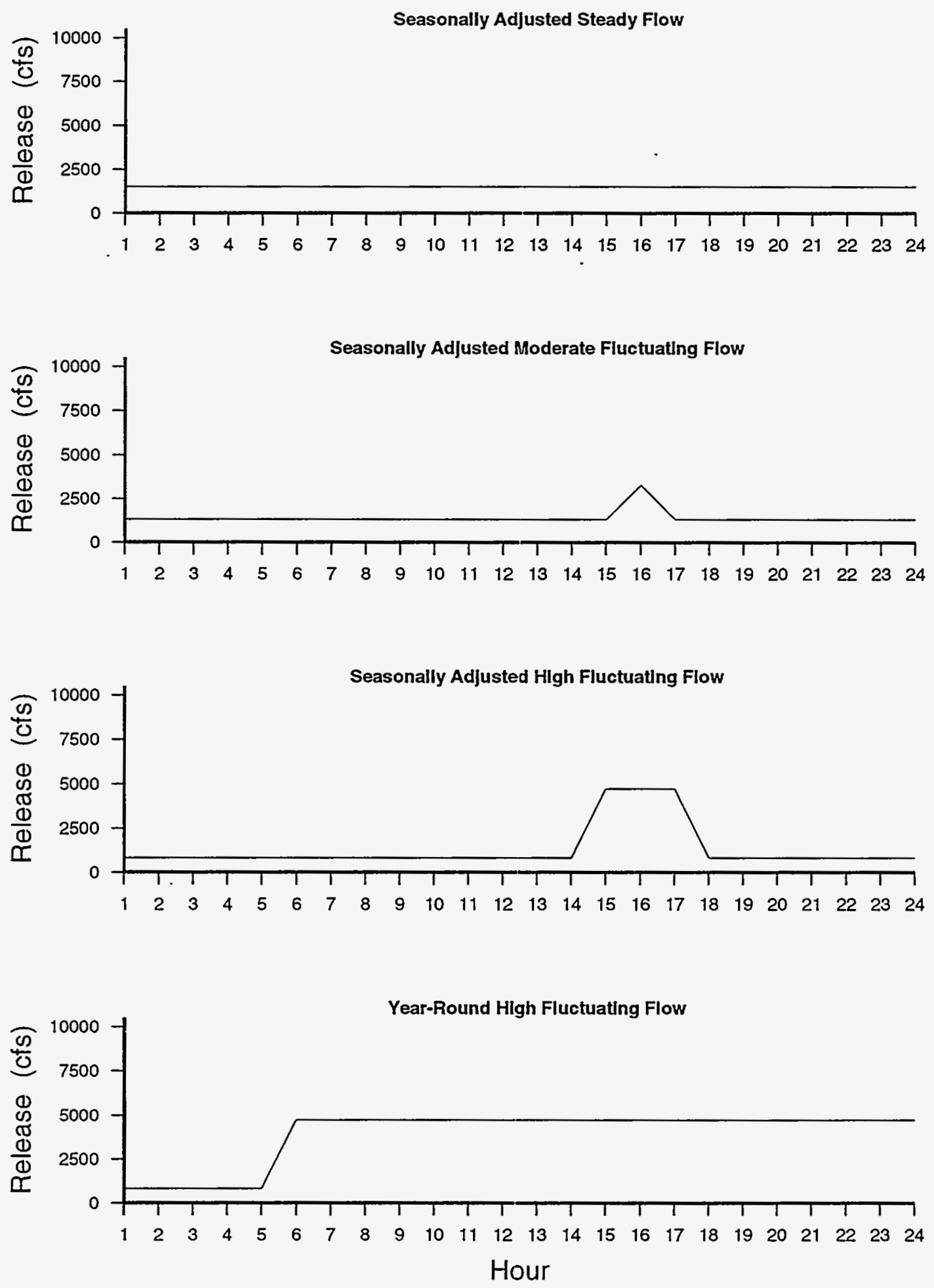

FIGURE B.29 Hourly Release Patterns under the Four Hydropower Operational Scenarios for October, Wet Water Year 

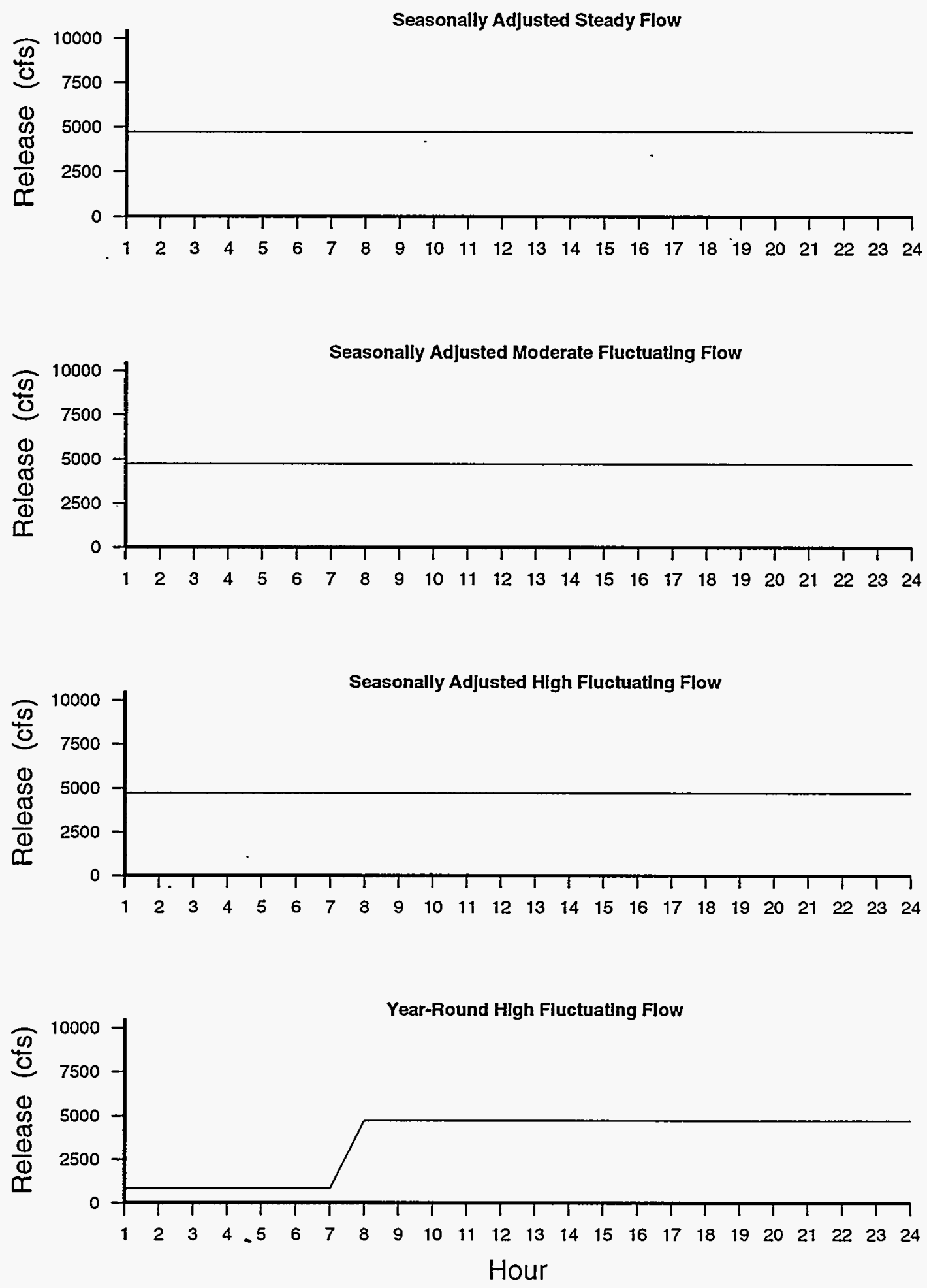

FIGURE B.30 Hourly Release Patterns under the Four Hydropower Operational Scenarios for November, Wet Water Year 

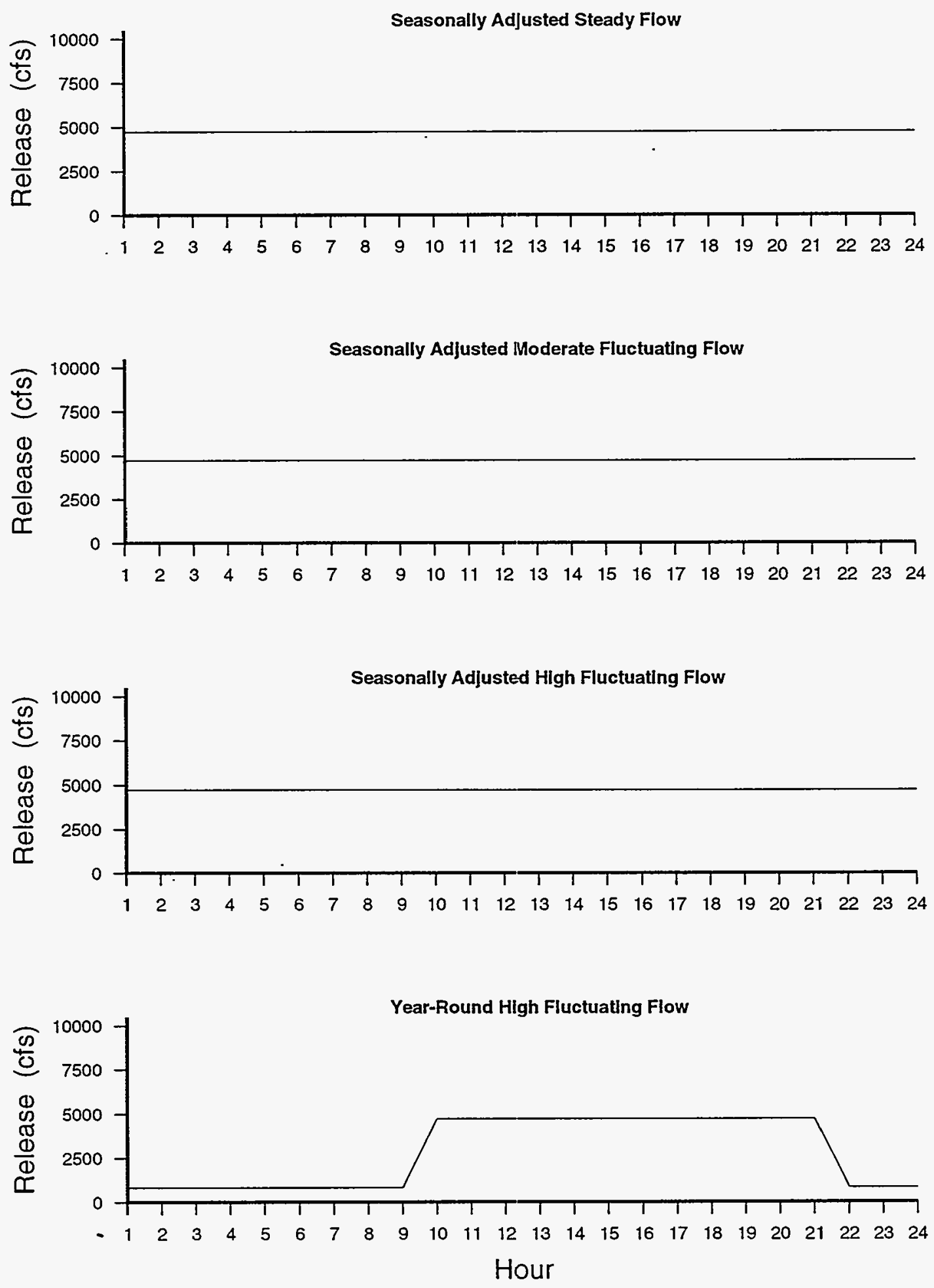

FIGURE B.31 Hourly Release Patterns under the Four Hydropower Operational Scenarios for December, Wet Water Year 

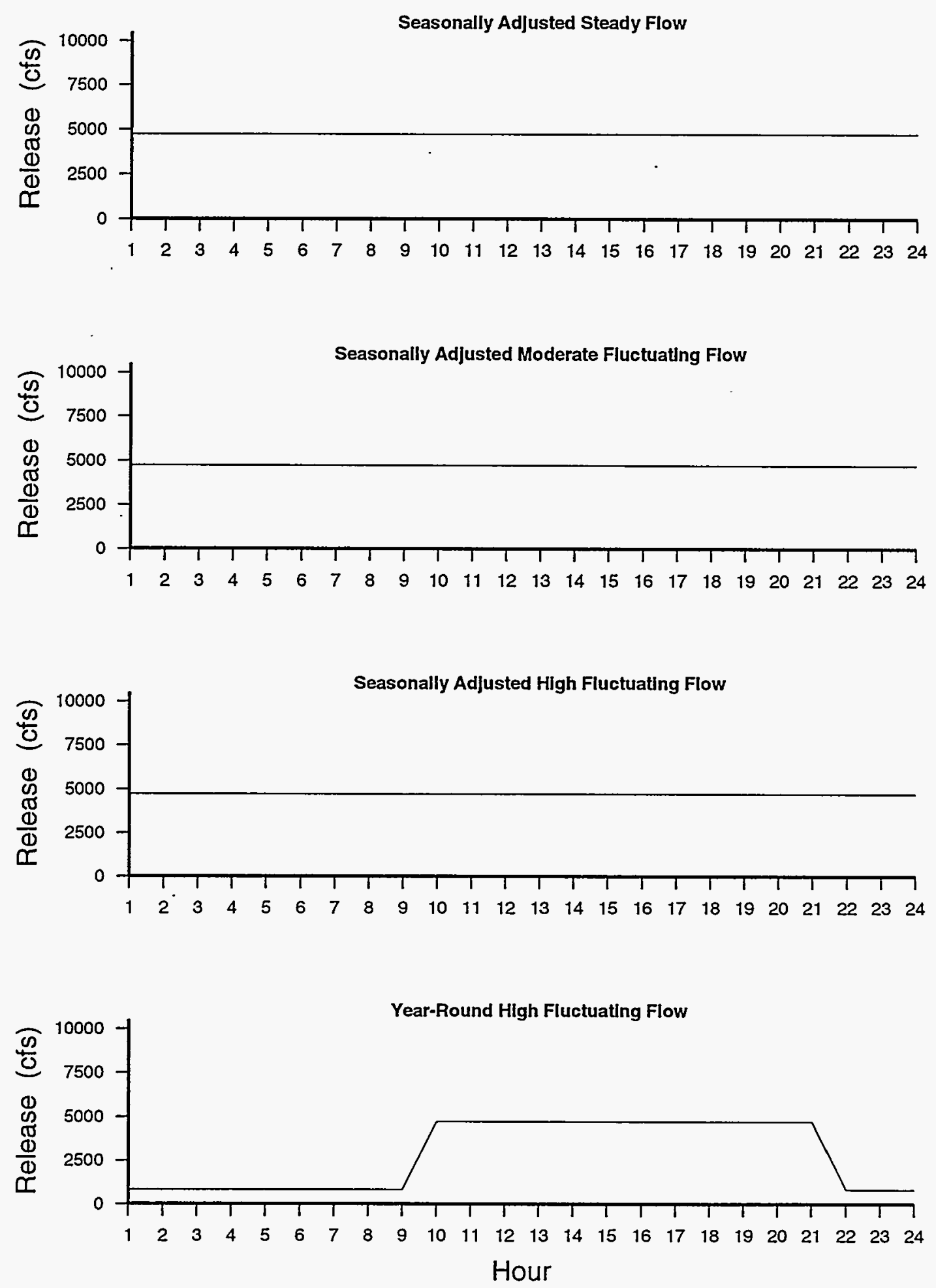

FIGURE B.32 Hourly Release Patterns under the Four Hydropower Operational Scenarios for January, Wet Water Year 

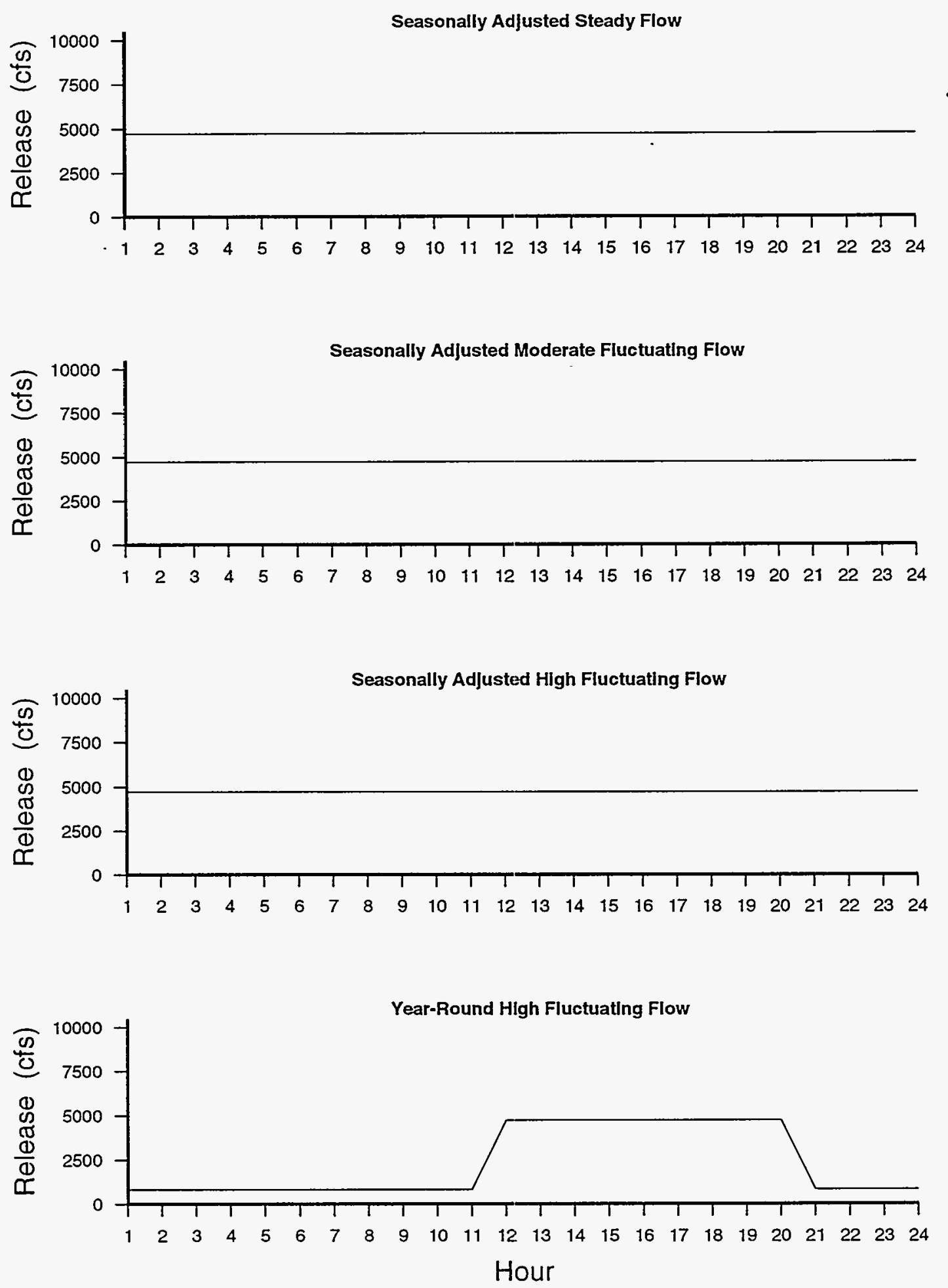

FIGURE B.33 Hourly Release Patterns under the Four Hydropower Operational Scenarios for February, Wet Water Year 

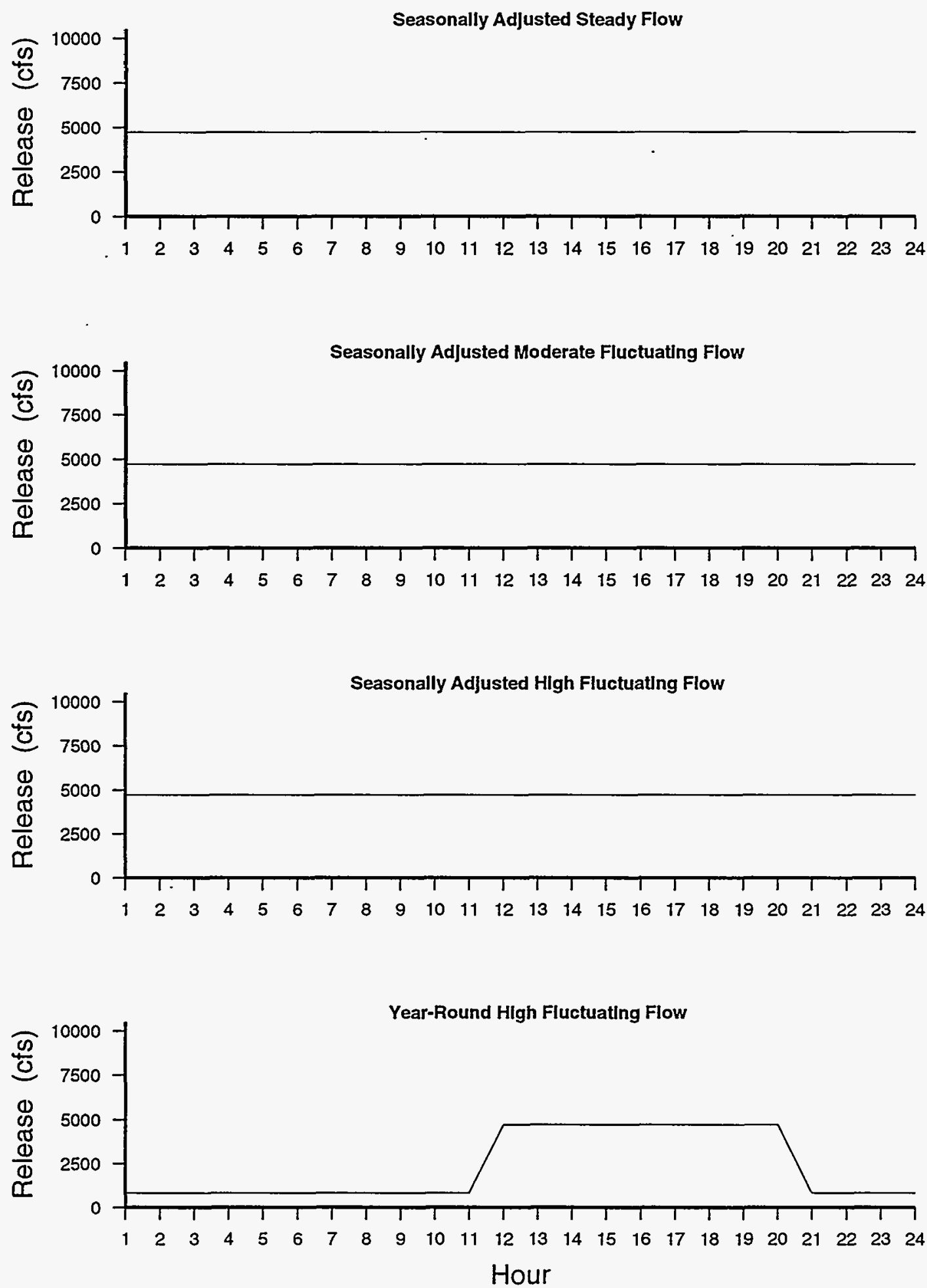

FIGURE B.34 Hourly Release Patterns under the Four Hydropower Operational Scenarios for March, Wet Water Year 

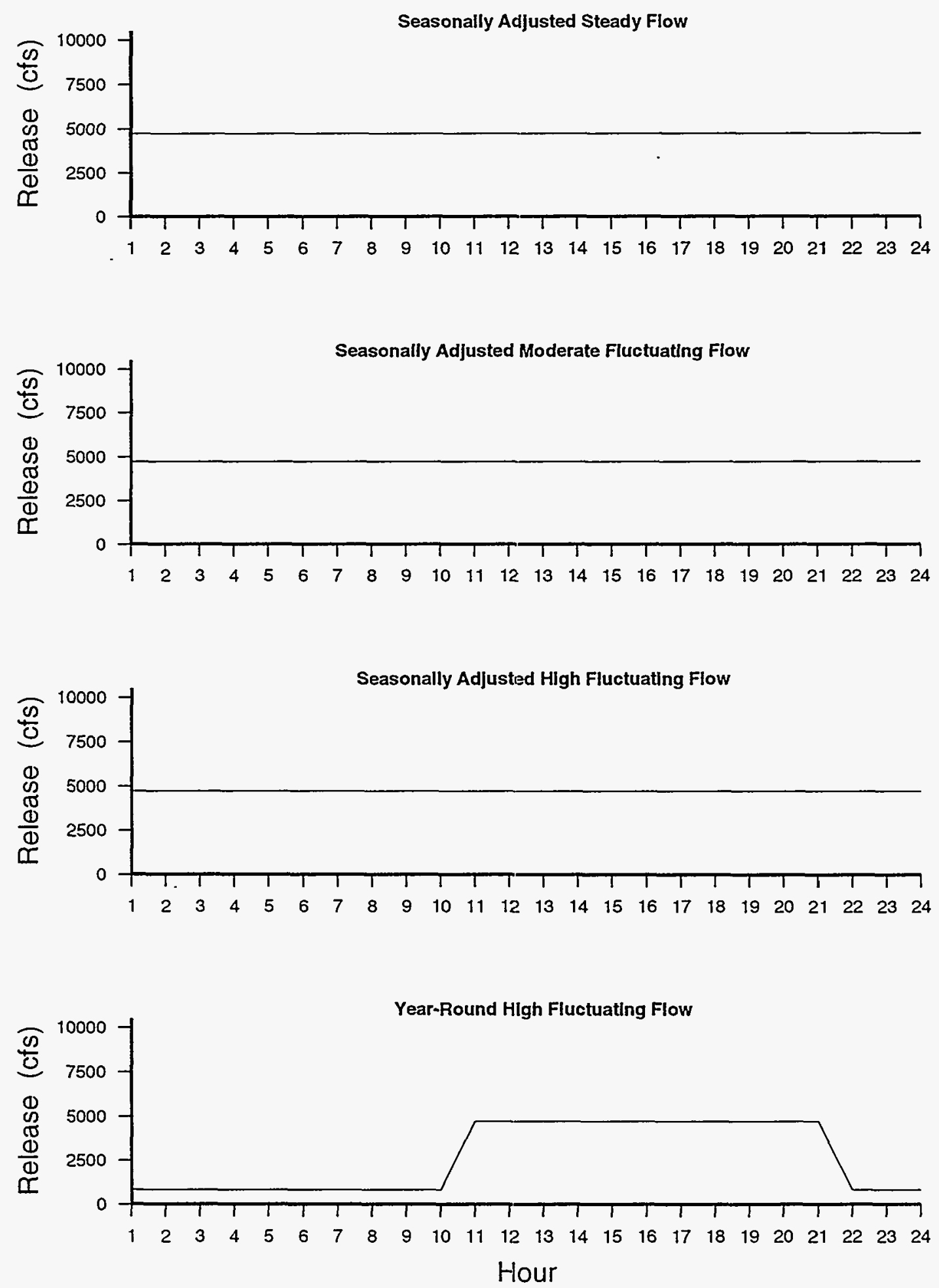

FIGURE B.35 Hourly Release Patterns under the Four Hydropower Operational Scenarios for April, Wet Water Year 

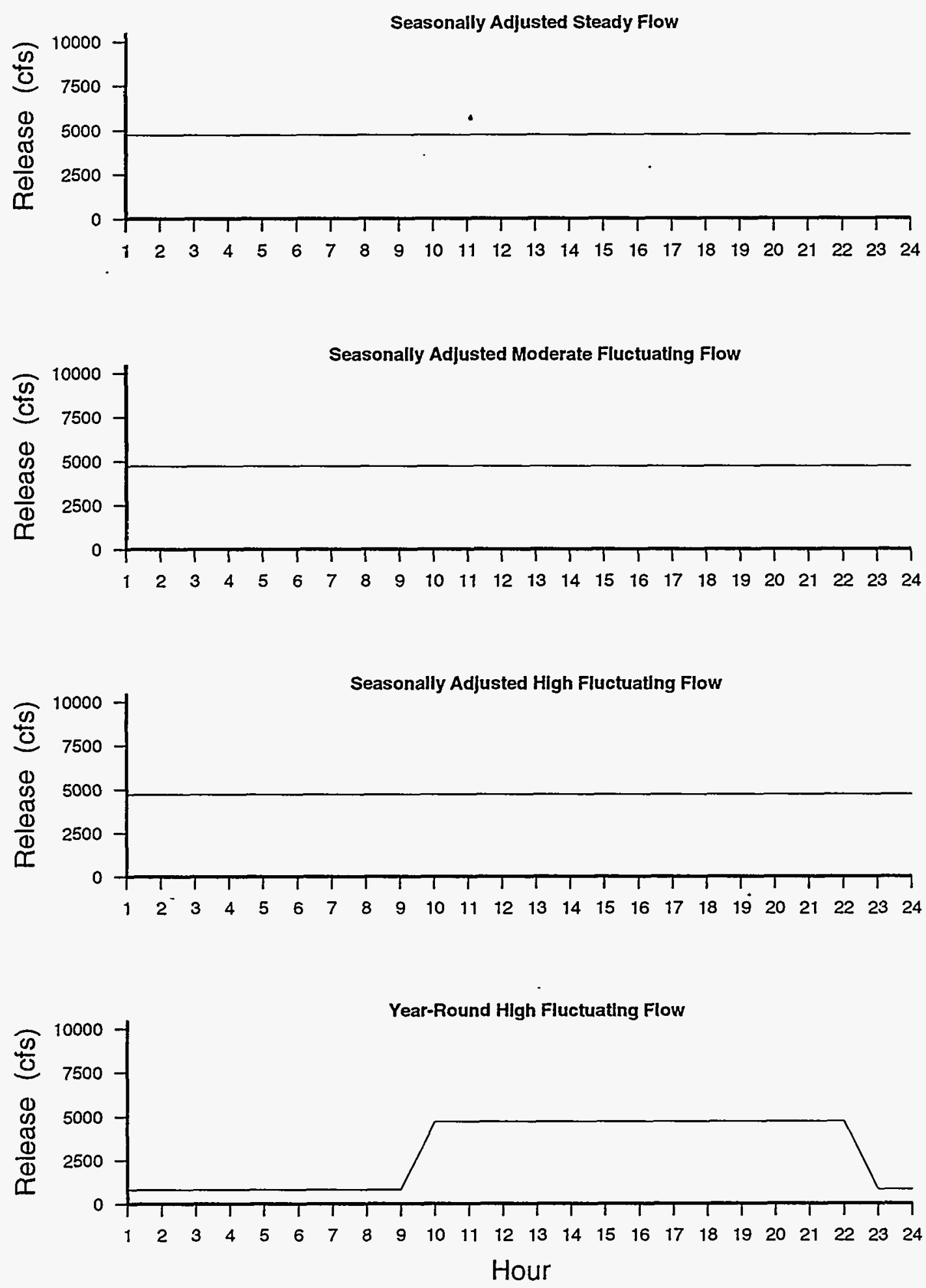

FIGURE B.36 Hourly Release Patterns under the Four Hydropower Operational Scenarios for May, Wet Water Year 

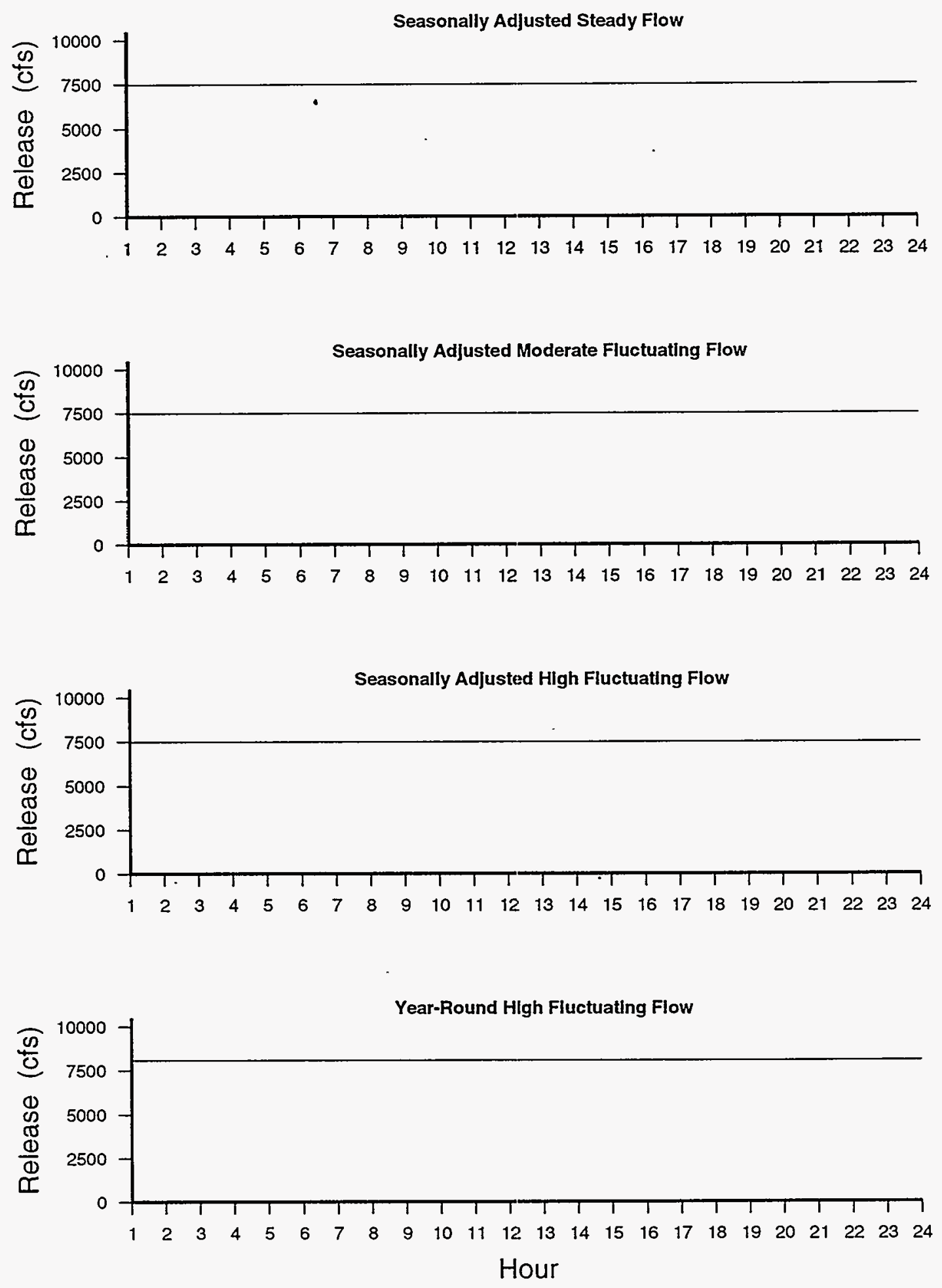

FIGURE B.37 Hourly Release Patterns under the Four Hydropower Operational Scenarios for June 1 - June 21, Wet Water Year 

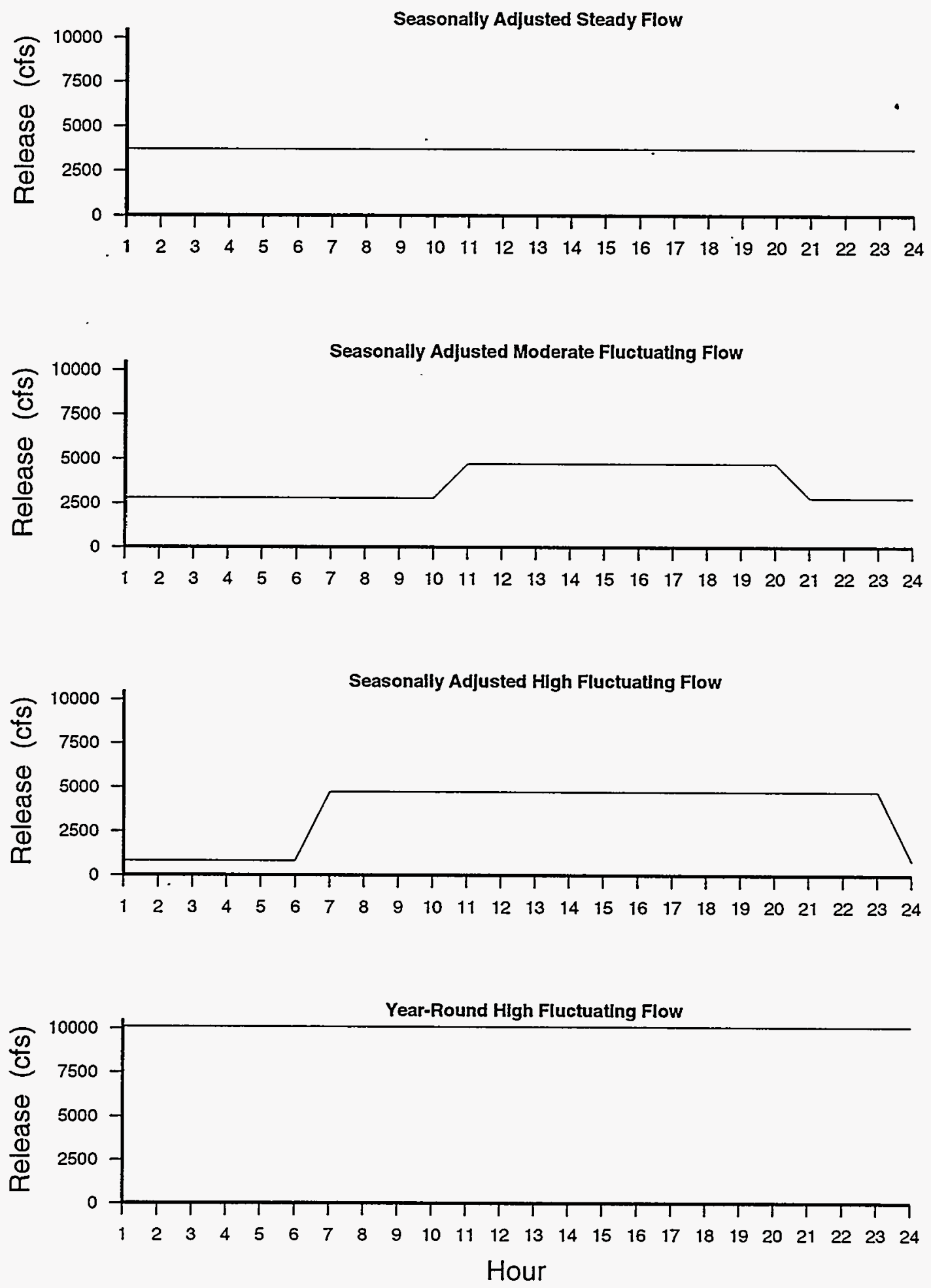

FIGURE B.38 Hourly Release Patterns under the Four Hydropower Operational Scenarios for June 22 - June 30, Wet Water Year 

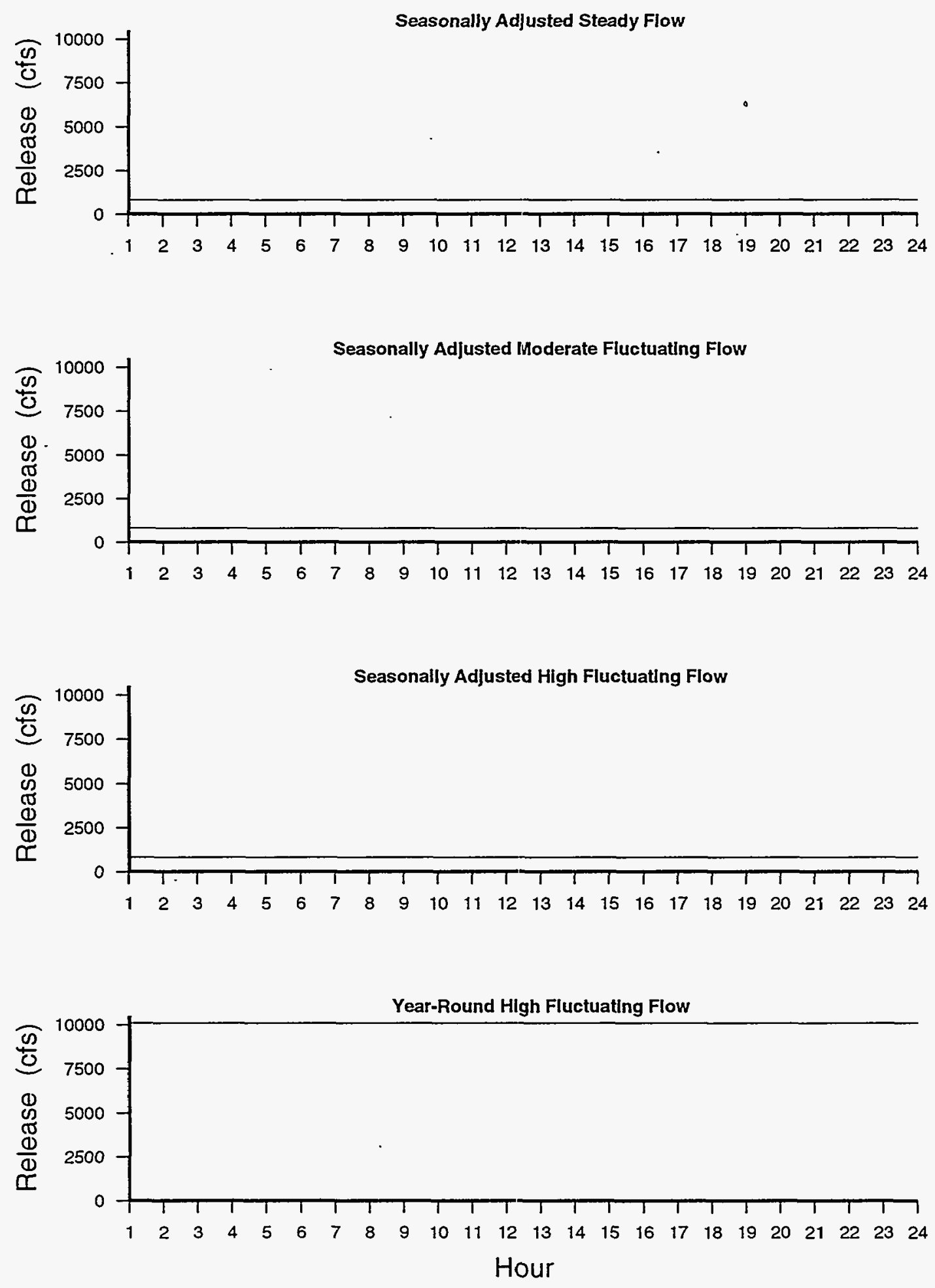

FIGURE B.39 Hourly Release Patterns under the Four Hydropower Operational Scenarios for July 1 - July 9, Wet Water Year 

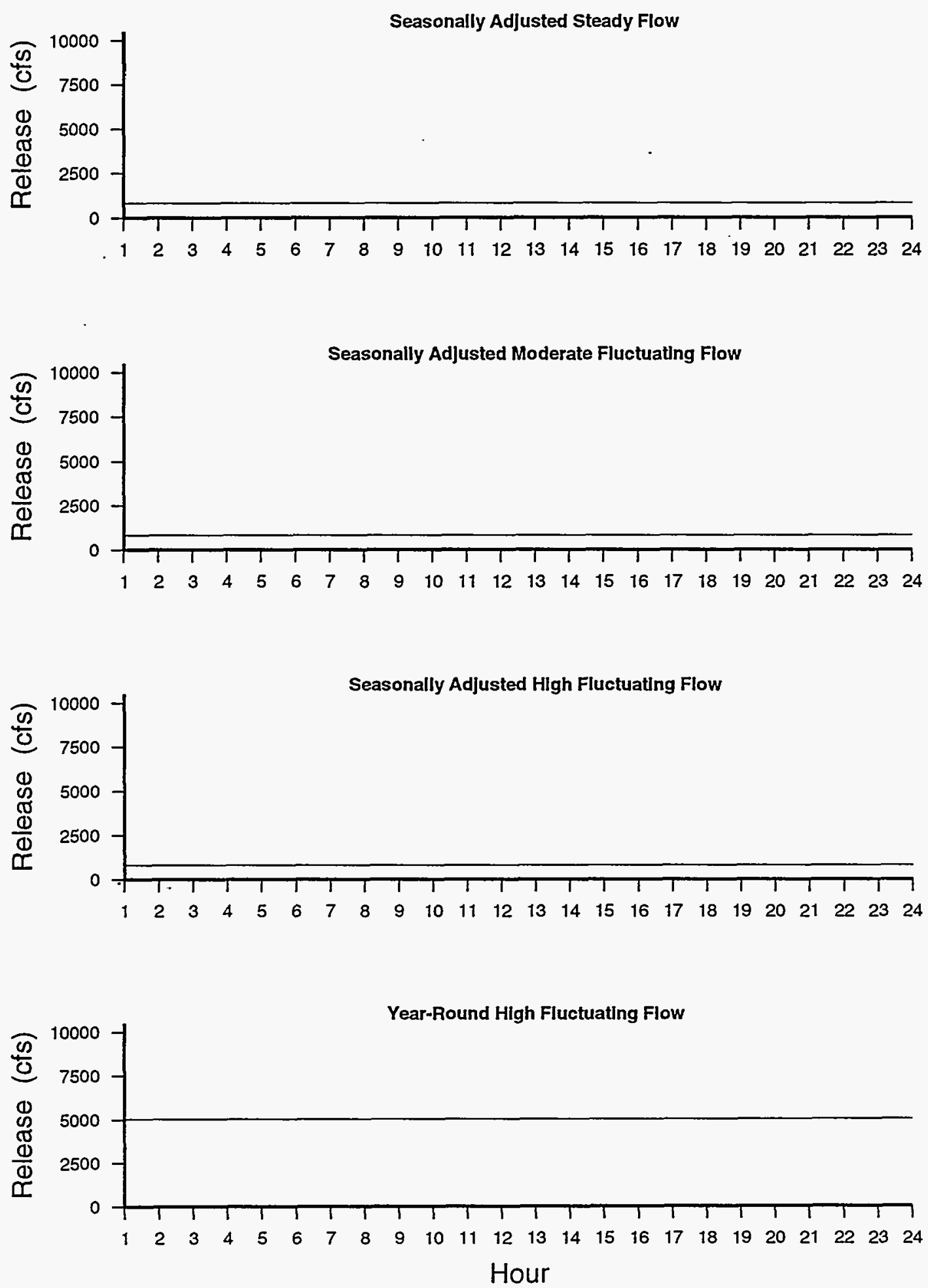

FIGURE B.40 Hourly Release Patterns under the Four Hydropower Operational Scenarios for July 10 - July 31, Wet Water Year 

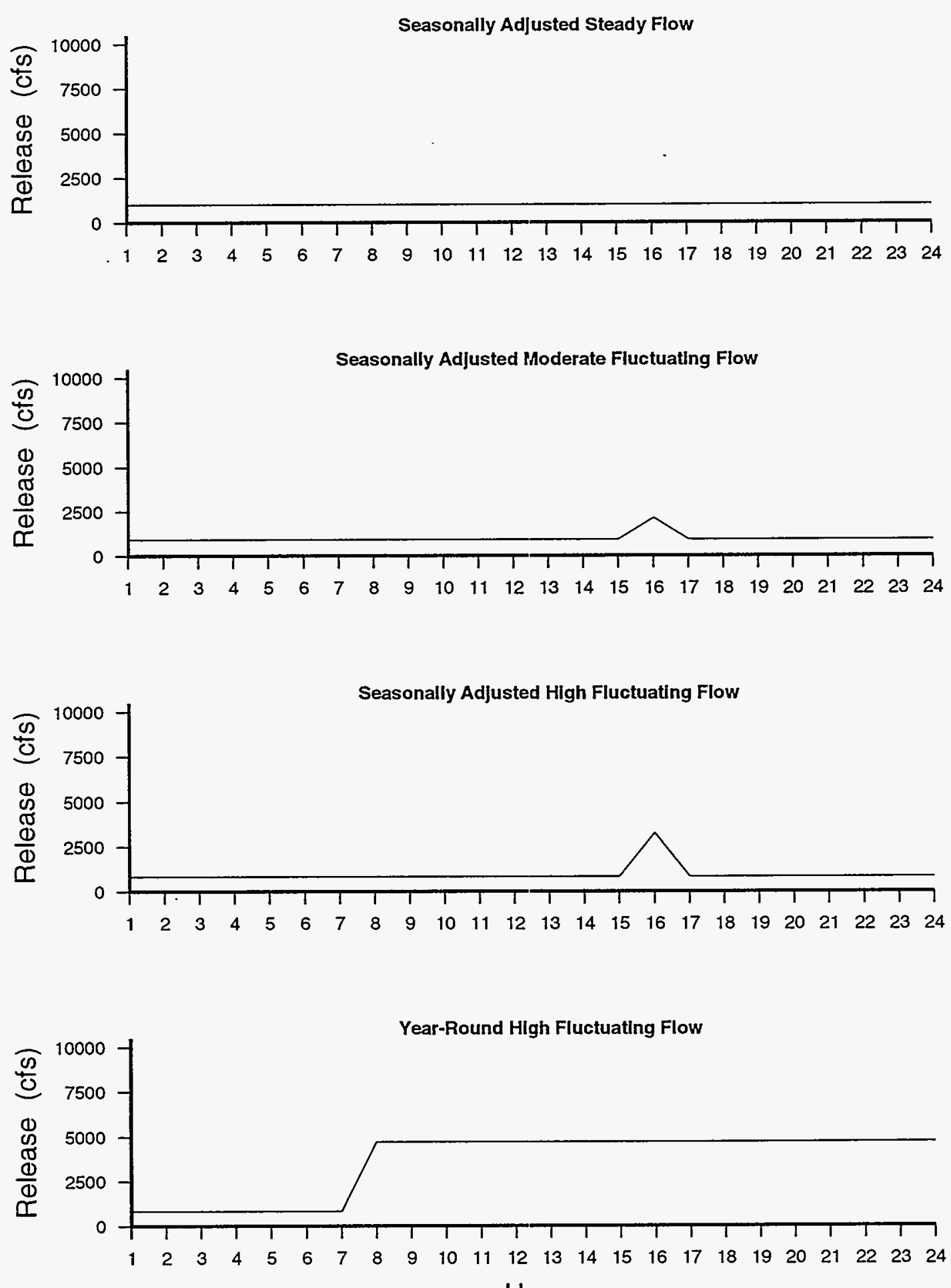

Hour

FIGURE B.41 Hourly Release Patterns under the Four Hydropower Operational Scenarios for August, Wet Water Year 

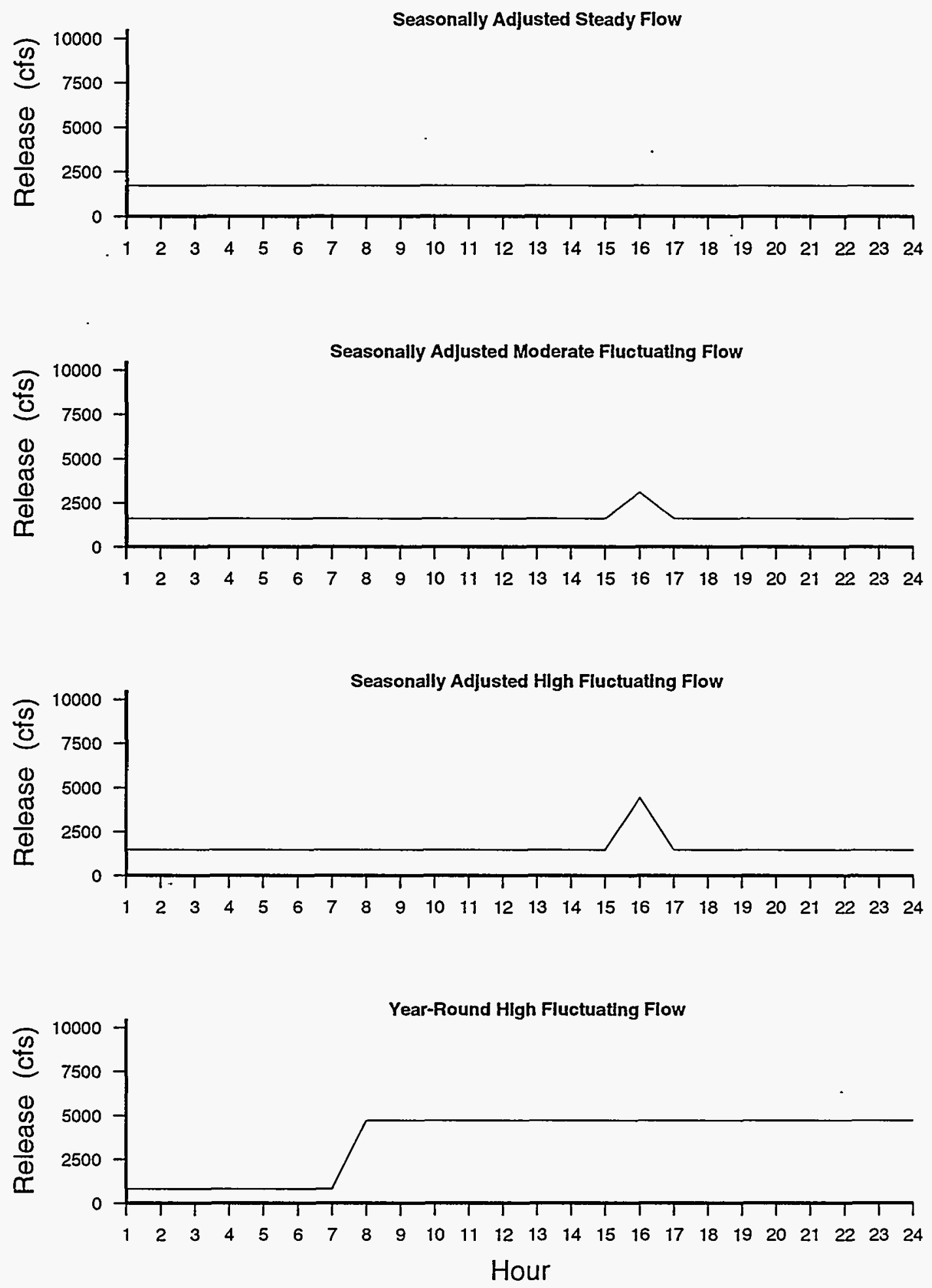

FIGURE B.42 Hourly Release Patterns under the Four Hydropower Operational Scenarios for September, Wet Water Year 